\title{
What can explain momentum? Evidence from decomposition*
}

\author{
Jiaqi Guo ${ }^{\mathrm{a}}$, Peng Li ${ }^{\mathrm{b}}$, Youwei $\mathrm{Li}^{\mathrm{c}}$
}

\begin{abstract}
This study comprehensively evaluates and ranks a large number of competing explanations for the momentum anomaly. As a benchmark for evaluation, firm fundamentals are found to be the most promising among well-known explanations of momentum, followed by prospect theory and mental accounting, and anchoring effect. Collectively, all explanations capture $31 \%$ of momentum, while $69 \%$ of momentum remains unexplained. This study thoroughly examines what fractions of the momentum anomaly emerge from the interaction effects between past returns and various firm characteristics. It is further found that strategies based on firm characteristics and residual momentum can significantly alleviate the severity of momentum crashes. Finally, robustness analysis is provided for choosing different formation and holding periods, excluding January observations, and analyze at the level of portfolio rather than individual stock.
\end{abstract}

JEL Classification: G12, G14

Keywords: Momentum, Momentum Candidate Variables, Momentum Decomposition, Momentum Crashes

\footnotetext{
${ }^{a}$ Dr Jiaqi Guo, Birmingham Business School, University of Birmingham, Birmingham B15 2TT, United Kingdom. Email: j.guo.3@bham.ac.uk

${ }^{\mathrm{b}}$ Dr Peng Li, Accounting \& Finance Division, Leeds University Business School, University of Leeds, Leeds, LS2 9JT, UK. Email: p.li@leeds.ac.uk.

${ }^{\mathrm{c}}$ Corresponding Author: Professor Youwei Li, Hull University Business School, University of Hull, HU6 7RX, UK. Tel: +44 (0) 1482 462119. Email: youwei.li@hull.ac.uk.

*Acknowledgements: We would like to thank the Editor (David Simchi-Levi), Associate Editor and two anonymous referees, Xing Han, Kai Li, Min Zheng, and conference and seminar participants at the 2020 International Symposium of Quantitative Economic at Jilin University, China Institute of Actuarial Science of Central University of Finance and Economics in Beijing, Hull University Business School, and University of Reading for helpful comments and suggestions. Youwei Li acknowledges financial support from the National Natural Science Foundation of China (NSFC) Grant (71571197). The usual caveats apply.
} 
"Of all the potential and embarrassments to market efficiency, momentum is the primary one"

—Eugene Fama (Fama and Litterman, 2012, p4)

\section{Introduction}

Momentum refers to the propensity for relative winning stocks to continue to win and losing stocks to continue to lose. Jegadeesh and Titman $(1993)^{1}$ document that buying stocks with recent high returns and selling stocks with recent low returns resulted in a profitable trading strategy. Momentum has been intriguing because it continues to perform well over two decades since 1993 (Jegadeesh and Titman, 2001, 2011) and across different asset classes (Asness et al., 2013). The existence of momentum is a well-established empirical fact and a serious investment strategy (Asness et al., 2014) ${ }^{2}$. There is a vast literature on momentum and its explanations, most readers are left with the impression that momentum has been well studied and explained, although the explanation and extent remain obscure. In fact, there is little consensus on the determinants of momentum. Different studies propose diverse explanations based on their specific samples, proxies, and variables. It is thus difficult to directly assess the contribution of each explanation and to evaluate the performances of the competing explanations. A comprehensive evaluation and quantification of the contribution of competing explanations for momentum is important. It helps in fundamental and theoretical understanding of momentum. Policy makers can improve market stability and efficiency by better understanding the relationship of momentum with underreaction, overreaction, and information diffusion. Investors can build models that better capture momentum and enhance performance through conditioning on the sources of momentum.

This study comprehensively evaluates the explanations and provides a benchmark for quantifying and ranking the contribution of each explanation of momentum. Momentum profit is intricately driven by various forces. By linear projection, the decomposition method of Hou and Loh (2016) provides a simple and unified framework to evaluate explanations of momentum. The simplicity and empirical tractability of the decomposition method facilitates direct evaluation and comparison of these explanations in a unified framework.

A thorough theoretical understanding of momentum is still lacking although numerous arguments have been put forward to explain the momentum, from both rational and behavioral perspectives. Jegadeesh and Titman (1993, 2001, and 2011) argue that a strong and persistent momentum premium cannot be easily reconciled by standard risk factors. The source of momentum from a risk-based

\footnotetext{
1 The study of Jegadeesh and Titman (1993) has been cited more than 12,000 times as of October 2020, according to the Google citation.

2 Asness et al. (2014) refute the most common myths around momentum including momentum is too "small and sporadic" a factor, works mostly on the short side, works well only among small stocks and doesn't survive trading costs, momentum is best used as a "screen" but not as a regular factor in an investment process.
} 
perspective, including macroeconomic conditions (e.g., Chordia and Shivakumar, 2002) and macroeconomic risk factors (e.g., Asness et al., 2013; Sadka, 2006), is still debated. In terms of behavioral explanations, examples include overreaction (e.g., Cooper et al., 2004; Daniel et al., 1998), underreaction (e.g., Antoniou et al., 2013; George and Hwang, 2004; Grinblatt and Han, 2005; Hong and Stein, 1999; Zhang, 2006), and limits to arbitrage (e.g., Arena et al., 2008; McLean, 2010). Momentum has also been examined from the perspectives of past intermediate returns (Novy-Marx, 2012), 52-week high (George and Hwang, 2004), earnings momentum (Chan, 1996; Chordia and Shivakumar, 2006), revenue momentum (Chen et al., 2014), skewness (Barrosos and Santa-Clara, 2015), prospect theory and mental accounting (Grinblatt and Han, 2005), and industry effects (Moskowitz and Grinblatt, 1999). Moreover, momentum effect is significant during periods of high sentiment (Antoniou et al., 2013), lagged up market states (Cooper et al., 2004), low volatility (Wang and $\mathrm{Xu}, 2015$ ), low economic uncertainty (Stivers and Sun, 2010), and among stocks with high idiosyncratic risk (Arena et al., 2008), low market capitalization (Hong et al., 2000), low analyst coverage (Zhang, 2006), and high dispersion in analyst forecasts (Verardo, 2009).

For prominent explanations of momentum, this study assesses the contribution of each explanation and evaluates competing explanations using a decomposition method proposed by Hou and Loh (2016). Specifically, we decompose the momentum beta, which is the coefficient of past 6-month stock return, by regressing future 1-month return on the past 6-month return, into a number of candidate components and a residual term. The ratio of a candidate component to the momentum beta represents the fraction of momentum anomaly explained by the candidate component and the ratio of the residual term represents the fraction of the anomaly left unexplained by the candidate component.

To examine the candidate explanations, we follow the momentum literature and group the candidate variables into five categories. Only cross-sectional candidate variables are included. ${ }^{3}$ The first category of explanations relates to anchoring effect, which consists of a 52-week high. The second category of explanations attributes the momentum to fundamental components, including earnings surprises, returns around earnings announcements, and revenue surprises. The third category includes capital gains overhang, which is related to the prospect theory and mental accounting (PT/MA). The fourth category relates to firm characteristics, including return volatility, dispersion in analyst forecasts, turnover, analyst coverage, revenue growth volatility, costs of goods sold, and idiosyncratic volatility. The remaining variables (i.e., industry momentum, past intermediate-term return and skewness) are included in the other group.

\footnotetext{
3 Time-series variables are not included because of the decomposition method by Hou and Loh (2016), which require the variables at the stock level (cross-sectional variables).
} 
The baseline results show that some candidate variables alone can explain a significant portion of the momentum anomaly. The fundamentals, anchoring effect and PT/MA, are the most promising in capturing the anomaly, consistent with previous studies that they are important drivers of momentum (e.g., George and Hwang, 2004; Grinblatt and Han, 2005; Chordia and Shivakumar, 2006). In assessing each explanation, the largest contributor to momentum is earnings surprises at $59 \%$, followed by a $52-$ week high at $40 \%$, three-day returns around earnings announcement at $31 \%$, PT/MA at $20 \%$, and revenue surprises at $20 \%$. However, no variable can fully explain momentum. Conversely, most of firm characteristics and candidate variables in others group contribute little to momentum. For example, the explained fraction is $11.9 \%$ for dispersion in analyst forecasts, $2.35 \%$ for analyst coverage, $-3.53 \%$ for total return volatility , $-10.71 \%$ for turnover, $-1.96 \%$ for revenue growth volatility, $0 \%$ for cost of goods sold , and $-1.19 \%$ for idiosyncratic volatility. Their insignificant contribution suggests that although these variables are highly correlated with past stock return, they do not explain a significant fraction of the anomaly. Studies have shown that momentum is stronger among stocks with certain firm characteristics (e.g., Lee and Swaminathan, 2000; Zhang, 2006) as those characteristics proxy for the speed of information diffusion, information uncertainty and limits to arbitrage. Slow diffusion of news or high cost to arbitrage resulting in stronger momentum effect. While firm characteristics fail to explain the anomaly, we find that the explanatory power of those variables improves after interacting with past stock return.

To investigate the marginal contribution of each variable, we conduct the decomposition analysis by including all candidate variables simultaneously. This helps make direct comparisons of the contribution of each candidate variable and quantify the fraction of the momentum that is collectively captured by these variables. This study focuses on the portion of the anomaly that can be explained by each group of candidate variables, allowing us to see which explanation has more potential for capturing momentum. After controlling for competing variables, the fundamental factors are ranked the highest among all candidate variables in capturing momentum at $20 \%$, followed by PT/MA at $12 \%$ and anchoring effect at 5\%. This is consistent with the conclusion of Novy-Marx (2015) that momentum is fundamental (earnings) momentum. However, most firm characteristics and other variables have limited explanatory power to the anomaly. Novy-Marx (2012) shows that portfolios sorted on intermediate prior returns better predict average future returns than portfolios sorted on recent prior returns and argued that momentum is driven by intermediate prior returns. This does not necessarily mean that intermediate prior returns better explain momentum based on recent prior returns. Under our decomposition framework, we find that the intermediate prior returns fail to explain momentum after controlling for other prominent candidate variables simultaneously. Overall, the examined variables explain $31 \%$ of the anomaly and $69 \%$ is left unexplained.

This study further examines the contribution of the candidate variables under different market 
conditions. Studies have shown that the momentum effect is significantly different across different market conditions (e.g., Antoniou et al., 2013; Stivers and Sun, 2010; Wang and Xu, 2015). We explore the explanatory power of candidate variables under strong and weak market conditions as proxied by investor sentiment, economic uncertainty, and market volatility. ${ }^{4}$ Consistent with literature, the momentum effect is stronger under strong than weak market conditions. The total explained fraction is higher under strong market conditions, in which candidate variables collectively explain $37 \%(10 \%)$ of the anomaly under market conditions associated with a strong (weak) momentum effect. The anchoring effect variable offers the most explanatory power under strong market conditions, but its contribution entirely reverses under weak market conditions. Similarly, PT/MA variable captures much of the anomaly under strong market conditions, but its explanatory power diminishes under weak market conditions. In contrast, the explanatory power of fundamental variables is relatively stable across the market conditions. Moreover, the variables related to firm characteristics and other explanations that contribute negatively to momentum under strong market conditions capture most of the anomaly under weak market conditions. Overall, the findings suggest that while the anchoring effect, PT/MA, and fundamental variables are important drivers of momentum under strong market conditions, the anchoring effect variable dampens the momentum under weak market conditions. However, firm characteristics and other variables become relatively dominant in explaining the anomaly under weak market conditions.

By decomposing the momentum beta, our results shed light on the momentum crash documented by Daniel and Moskowitz (2016). They highlight that when the market rebounds following bear markets, the negative beta of the momentum portfolio results in infrequent and persistent losses. However, the source of momentum crashes during market rebounds remains unclear. We thus investigate whether momentum crashes can be attributed to specific group of candidate variables since the contribution of candidate components to momentum varies significantly across market conditions. We develop component momentum strategies according to the fitted value of different groups of candidate variables instead of the past 6-month return. ${ }^{5}$ We find that the momentum strategies based on the anchoring effect, PT/MA, and fundamental components yield significantly negative market betas during market rebounds, with the anchoring effect of component momentum having the lowest beta. The component momentum

\footnotetext{
4 The strong (weak) momentum refers to the periods with high (low) investor sentiment, low (high) economic uncertainty, and low (high) volatility.

5 We refer to the component momentum strategy as the momentum strategy developed using the fitted return explained by the candidate variables in that component. We run regression of past 6-month return on all candidate variables in each month, which is the Stage 3 of the decomposition. The fitted value of the past 6-month return, therefore, can be classified into different components. Then, momentum portfolios based on each component of the past 6-month return (using fitted value of each component) instead of the total past 6-month return are formed. For example, the fundamental momentum strategy is developed using the sum of the past 6-month returns explained by earnings surprises, returns around earnings announcement, and revenue surprises.
} 
earns $-4.43 \%,-2.51 \%$, and $-1.50 \%$ per month for the anchoring effect, PT/MA, and fundamentals during market rebounds, respectively, suggesting that drivers of momentum also significantly contribute to momentum crashes. In contrast, the momentum strategy related to firm characteristics and other components experience no crash and even earn significantly positive returns at $3.37 \%$ and $1.04 \%$ per month when market rebounds, respectively. This is not surprising because those variables fail to capture the momentum. Overall, our results suggest that candidate components that capture momentum profits also drive momentum crashes, which is consistent with Ehsani and Linnainmaa (2020). They argue that momentum is not a distinct factor but related to all other factors, while the component momentum strategy built on components with limited explanatory power survives the crash.

Interestingly, the crash of residual momentum, which hedges out all candidate variables, ${ }^{6}$ considerably reduces during market rebound periods, earning $-0.94 \%$ returns per month compared with $-2.60 \%$ per month of the total momentum strategy. Such a strategy considerably alleviates the severity of momentum crashes. The results suggest that all candidate momentum strategies, except for firm characteristics, other explanations, and residual momentum strategies, exhibit significant losses during market rebounds. ${ }^{7}$ Blitz et al. (2011) show that the residual momentum strategy, which is developed by hedging out the Fama-French (1993) three factors, is more profitable than traditional momentum in the United States. Chang et al. (2018) find that such a strategy is significantly profitable in Japan and attributes it to investor underreaction. This study offers an alternative approach of the residual momentum developed by hedging out all momentum candidate variables that alleviate momentum crashes, such as Fan et al. (2021).

A series of robustness tests are conducted to examine the validity of our empirical findings. The results are robust in different sample periods, excluding January (that has been shown by studies on non-momentum effect in January) and momentum with alternative formation and holding periods. Moreover, to alleviate the measurement errors at an individual stock level, we analyze at the portfolio level by sorting individual stocks into portfolios based on their past returns. Our findings largely hold, with an exception being the anchoring effect in the portfolio multivariate analysis. The fundamental and PT/MA variables are the largest contributors to momentum, while firm characteristics and others have limited explanatory power to momentum. Collectively, candidate variables on average account for $36 \%$ of the anomaly and a sizable portion of momentum remains unexplained.

This study contributes significantly to the literature in several aspects. First, it quantifies the

\footnotetext{
${ }^{6}$ The residual momentum is developed using the residual from Stage 3 of the decomposition instead of the total past 6-month return.

7 The reason why the residual momentum is profitable during market rebounds is beyond the scope of this study and remains an open question for future research.
} 
contribution of prominent explanations of momentum while controlling for other competing explanations under a unified decomposition framework. Quantification allows ranking and directly comparing existing explanations simultaneously. Second, to the best of our knowledge, this study is the first to provide the most comprehensive evaluation of existing explanations to the momentum anomaly. Third, by analyzing the market exposure of component momentum portfolios, this study sheds further light on momentum crashes during market rebounds. We find that momentum crashes are primarily driven by the anchoring effect component. Fourth, by studying the performance of each component momentum strategy, we show that the residual momentum alleviates momentum crashes, and momentum components related to firm characteristics and other explanations perform well during market rebounds, whereas momentum strategies based on the anchoring effect and PT/MA experience significant losses.

The study is presented as follows: Section 2 describes the methodology and data and outlines the candidate explanations of momentum. Section 3 evaluates the contribution of each candidate variable alone and compares competing candidate variables in a multivariate setting. Section 4 investigates the contribution of each candidate variable under different market conditions and sources of momentum crash via decomposition. Section 5 checks the robustness of the main results and Section 6 concludes.

\section{Methodology and data}

This section introduces the momentum decomposition methodology used to quantify the candidate variables for the anomaly. This section also discusses various candidate variables for momentum anomaly and provides data description and summary statistics.

\subsection{Decomposition methodology}

Following Hou and Loh's (2016) decomposition methodology, we evaluate a range of candidate variables for the momentum anomaly. For each month $t$, we use the Fama-Macbeth (1973) procedure to regress the cross section of individual stock return in month $t$ on their past return over $t-2$ to $t-7$ as follows:

$r_{i, t}=\alpha_{t}+\beta_{t} r 6,1_{i, t-1}+\varepsilon_{i, t}$

where $\mathrm{r}_{\mathrm{i}, \mathrm{t}}$ is the characteristics-adjusted return of stock $i$ in month $t$, adjusted by firm size and bookto-market ratio following Daniel et al. (1997) (DGTW). ${ }^{8}$ This is to ensure that the momentum effect examined is not driven by size and book-to-market factors. Appendix A presents a detailed construction of characteristics-adjusted returns. $\mathrm{r} 6,1_{\mathrm{i}, \mathrm{t}-1}$ is stock $i$ 's past 6-month return skipping the month $t-1$,

\footnotetext{
${ }^{8}$ The decomposition results are similar to those using unadjusted returns.
} 
that is, cumulative return of stock $i$ over $t-7$ to $t-2$. We focus on the 6-month formation period momentum, which is commonly examined in momentum studies. ${ }^{9} \beta_{\mathrm{t}}$ is the momentum beta, which measures the relation between $r 6,1_{i, t-1}$ and $r_{i, t}$. For our baseline analysis, the coefficient $\beta_{t}$ is $0.84 \%$, which is statistically significant at the $1 \%$ level, confirming the existence of the momentum anomaly.

In Stage 2, we add a candidate explanatory variable to Eq. (1) as follows:

$r_{i, t}=\widetilde{\alpha}_{t}+\widetilde{\beta_{t}^{R}} r 6,1_{i, t-1}+\widetilde{\beta_{t}^{C}}$ candidate ${ }_{i, t-1}+\widetilde{\varepsilon}_{i, t}$

The regression helps assess whether the candidate variable significantly subsumes the explanatory power of $r 6,1_{i, t-1}$ in explaining $r_{i, t}$. If the candidate variable fully captures the role of $r 6,1_{i, t-1}$, the coefficient $\left(\widetilde{\beta_{t}^{R}}\right)$ should become insignificant. If $\widetilde{\beta_{t}^{R}}$ remains significantly positive and its magnitude is largely unchanged than that of $\beta_{\mathrm{t}}$ in Eq. (1), one typically concludes that the candidate variable has no explanatory power to the momentum anomaly regardless of its own return predictability (the relation between candidate variable and future return). ${ }^{10}$

In Stage 3, we regress past return $\left(\mathrm{r} 6,1_{\mathrm{i}, \mathrm{t}-1}\right)$ on a candidate explanatory variable (Candidate $\mathrm{C}_{\mathrm{i}, \mathrm{t}-1}$ ) as follows:

$\mathrm{r} 6,1_{\mathrm{i}, \mathrm{t}-1}=\mu_{\mathrm{t}-1}+\delta_{\mathrm{t}-1}$ Candidate $_{\mathrm{i}, \mathrm{t}-1}+\varphi_{\mathrm{i}, \mathrm{t}-1}$

Equation (3) helps examine the relation between past return and the candidate variable as any candidate variable that can be served as a potential driver of momentum must be correlated with past return, r6, $1_{\mathrm{i}, \mathrm{t}-1}$. Therefore, past return can be decomposed into two orthogonal components: a related candidate component $\left(\delta_{\mathrm{t}-1}\right.$ Candidate $\left._{\mathrm{i}, \mathrm{t}-1}\right)$ and an unrelated residual component $\left(\mu_{\mathrm{t}-1}+\varphi_{\mathrm{i}, \mathrm{t}-1}\right)$.

In Stage 4, the linearity of covariance is used to decompose the momentum beta $\left(\beta_{t}\right)$ from Eq. (1) into two components: a related candidate momentum beta $\left(\beta_{\mathrm{t}}^{\mathrm{C}}\right)$, which is related to the candidate variable and an unrelated residual momentum beta $\left(\beta_{\mathrm{t}}^{\mathrm{R}}\right)$ (from Eq. (3)). Specifically,

\footnotetext{
${ }^{9}$ Alternative formation and holding periods are used to examine the sensitivity of the results (see Section 4.3). Another popular measure of momentum is the past 12-month returns (Asness et al., 2013, 2014), because of the possible effect of a carryover of short-term reversals from month -2 and stronger momentum performance using the past 12-month return compared with others (Goyal and Wahal, 2015), our choice of the past 6-month returns is thus a conservative one.

${ }^{10}$ In addition, if $\widetilde{\beta_{t}^{R}}$ reduces, researchers always use the difference between $\widetilde{\beta_{t}^{R}}$ and $\beta_{t}$ in Eq. (1) to estimate the fraction of the anomaly that is captured by the candidate variable. According to Hou and Loh (2016), such a method is inappropriate because the two coefficients $\left(\widetilde{\beta_{t}^{R}}\right.$ and $\left.\beta_{t}\right)$ are not directly comparable. This is because $\beta_{t}$ is estimated based on the variation in $r 6,1_{\mathrm{i}, \mathrm{t}-1}$ alone, but $\widetilde{\beta_{\mathrm{t}}^{\mathrm{R}}}$ is estimated on the basis of the variation in $\mathrm{r} 6,1_{\mathrm{i}, \mathrm{t}-1}$, which is independent of the candidate variable (Candidate $\mathrm{it}_{\mathrm{t}-1}$ ). In the following steps, we overcome this challenge and estimate the fraction of anomaly explained by the candidate variable.
} 


$$
\begin{aligned}
\beta_{\mathrm{t}}= & \frac{\operatorname{Cov}\left[\mathrm{r}_{\mathrm{i}, \mathrm{t}}, \mathrm{r} 6,1_{\mathrm{i}, \mathrm{t}-1}\right]}{\operatorname{Var}\left[\mathrm{r} 6,1_{\mathrm{i}, \mathrm{t}-1}\right]} \\
= & \frac{\operatorname{Cov}\left[\mathrm{r}_{\mathrm{i}, \mathrm{t}}\left(\mu_{\mathrm{t}-1}+\delta_{\mathrm{t}-1} \operatorname{Candidate~}_{\mathrm{i}, \mathrm{t}-1}+\varphi_{\mathrm{i}, \mathrm{t}-1}\right)\right]}{\operatorname{Var}\left[\mathrm{r} 6,1_{\mathrm{i}, \mathrm{t}-1}\right]} \\
= & \frac{\operatorname{Cov}\left[\mathrm{r}_{\mathrm{i}, \mathrm{t}}, \delta_{\mathrm{t}-1} \operatorname{Candidate}_{\mathrm{i}, \mathrm{t}-1}\right]}{\operatorname{Var}\left[\mathrm{r} 6,1_{\mathrm{i}, \mathrm{t}-1}\right]}+\frac{\operatorname{Cov}\left[\mathrm{r}_{\mathrm{i}, \mathrm{t}}\left(\mu_{\mathrm{t}-1}+\varphi_{\mathrm{i}, \mathrm{t}-1}\right)\right]}{\operatorname{Var}\left[\mathrm{r} 6,1_{\mathrm{i}, \mathrm{t}-1}\right]} \\
= & \frac{\delta_{\mathrm{t}-1} \operatorname{Cov}\left[\mathrm{r}_{\mathrm{i}, \mathrm{t}}, \operatorname{Candidate}_{\mathrm{i}, \mathrm{t}-1}\right]}{\operatorname{Var}\left[\mathrm{r} 6,1_{\mathrm{i}, \mathrm{t}-1}\right]}+\frac{\operatorname{Cov}\left[\mathrm{r}_{\mathrm{i}, \mathrm{t}}\left(\mu_{\mathrm{t}-1}+\varphi_{\mathrm{i}, \mathrm{t}-1}\right)\right]}{\operatorname{Var}\left[\mathrm{r} 6,1_{\mathrm{i}, \mathrm{t}-1}\right]} \\
= & \beta_{\mathrm{t}}^{\mathrm{C}}+\beta_{\mathrm{t}}^{\mathrm{R}}
\end{aligned}
$$

$\beta_{\mathrm{t}}^{\mathrm{C}} / \beta_{\mathrm{t}}$ represents the portion of the momentum explained by the candidate variable in month $t$, and $\beta_{\mathrm{t}}^{\mathrm{R}} / \beta_{\mathrm{t}}$ represents the portion of the anomaly that remains unexplained by the candidate variable in month $t$. The time-series average of $\beta_{\mathrm{t}}^{\mathrm{C}}$ divided by the time-series average $\beta_{\mathrm{t}}$ measures the fraction of the anomaly explained by the candidate variable. Similarly, the time-series average of $\beta_{t}^{R}$ divided by the time-series average $\beta_{\mathrm{t}}$ measures the fraction of the anomaly left unexplained by the candidate variable (i.e., residual fraction). ${ }^{11}$

According to Eq. (4), a candidate variable's $\left(\beta_{\mathrm{t}}^{\mathrm{C}}\right)$ contribution depends on two elements: the correlation between the candidate variable and past return $\left(\delta_{t-1}\right)$ and the return predictability of the candidate variable $\left(\operatorname{Cov}\left[\mathrm{r}_{\mathrm{i}, \mathrm{t}}\right.\right.$, Candidate $\left.\left._{\mathrm{i}, \mathrm{t}-1}\right]\right)$, which measures the correlation between the candidate variable and future return. Thus, to explain momentum, the correlation between past return and candidate variable and candidate's return predictability should have the same sign as the momentum beta $\left(\beta_{\mathrm{t}}\right)$ is always positive. Despite the high correlation between the candidate variable and past return, the candidate variable may insignificantly or even negatively contribute to the anomaly if the return predictability of the candidate is either zero or has an opposite sign to its correlation with past return. ${ }^{12}$

Overall, the explanatory power of a candidate variable depends on both its correlation with past return and its future return predictability. In turn, a candidate that is highly correlated with past return may not contribute to the momentum. The decomposition methodology, therefore, attributes a high

11 The means of the ratios $\left(\beta_{\mathrm{t}}^{\mathrm{C}} / \beta_{\mathrm{t}}\right.$ and $\left.\beta_{\mathrm{t}}^{\mathrm{R}} / \beta_{\mathrm{t}}\right)$ are approximately equal to the ratios of means, according to Hou and Loh (2016).

${ }^{12}$ For example, if a candidate variable is positively correlated with past return (i.e., $\delta_{\mathrm{t}-1}>0$ ) but its return predictability is negative (i.e., $\operatorname{Cov}\left[\mathrm{r}_{\mathrm{i}, \mathrm{t}}\right.$ Candidate $\left._{\mathrm{i}, \mathrm{t}-1}\right]<0$ ), the candidate variable negatively contribute to momentum (i.e., $\beta_{\mathrm{t}}^{\mathrm{C}}<0$ ). Section 3 shows that some candidate variables have zero or negative contribution to momentum. 
explanatory power to a candidate for explaining most of the positive relation between past and future returns, i.e., momentum. ${ }^{13}$

\subsection{Stock market data}

The study sample includes monthly data for all common stocks (SHRCD $=10$ or 11) traded on the NYSE, AMEX, and NASDAQ from August 1963 to December 2016. Two selection criteria are applied for inclusion in the analysis. First, to avoid microstructure biases, we skip the most recent month when calculating past 6-month returns. Second, stocks priced below $\$ 5$ are excluded.

\subsection{Candidate variables}

We consider a battery of candidate variables that are responsible for the momentum anomaly. Following the momentum literature, we categorize the candidate variables into five groups: anchoring effect, fundamental factors, PT/MA, firm-specific characteristics, and the other explanations that differ from the other four groups. ${ }^{14}$ Appendix A provides detailed variable definitions and constructions.

\subsubsection{Candidate variables related to the anchoring effect}

The first group of explanations attributes the momentum anomaly to the anchoring effect. George and Hwang (2004) argue that proximity to the 52-week high price level explains much of the momentum profits and show that a 52 -week high $(52 \mathrm{~W})$ has an independent predictive power from past returns (Jegadeesh and Titman, 1993) and industry factors (Moskowitz and Grinblatt, 1999). Investors use the 52-week high as a reference point against which they evaluate the potential impact of news. Such an anchoring bias leads to a delayed reaction (underreaction) to news. When good news pushes stock price near to or exceeds the 52-week high price level, investors are unwilling to buy stocks at prices that are as high as the news implies. Similarly, when bad news arrives and drives the stock prices away from its 52-week high, investors are reluctant to sell stocks, even if guaranteed by the information. The information eventually spreads, leading to stock return continuation. The greatest unwillingness to trade stocks is at the price that is nearest or farthest from the 52-week high. Liu et al. (2011) find consistent evidence in 20 major international stock markets.

13 In the decomposition framework, we interpret the momentum anomaly as the relation between past 6-month return $\left(\mathrm{r} 6,1_{\mathrm{i}, \mathrm{t}-1}\right)$ and future return $\left(r_{i, t}\right)$. One may argue that momentum is not purely attributed to $\mathrm{r} 6,1_{\mathrm{i}, \mathrm{t}-1}$. The momentum (i.e., positive autocorrelation between past and future return) may be purely driven by the relation between any single past-month return during the past 6 or 12 months and future return. If the single past return that is highly correlated with $r_{i, t}$ but is not highly correlated with $\mathrm{r} 6,1_{\mathrm{i}, \mathrm{t}-1}$, it fails to capture much of the relation between $\mathrm{r} 6,1_{\mathrm{i}, \mathrm{t}-1}$ and $r_{i, t}$, that is, momentum. Thus, such a candidate variable would fail to explain momentum. That is, the explanatory power of the candidate variable is sensitive to the definition of the momentum. To alleviate this concern, we define the momentum using various formation and holding periods and repeat the decomposition analysis in Section 5.3. Our conclusions are largely unaltered.

14 We thank the Associated Editor and an anonymous referee for motivating us to consider how to classify candidate variables to have better economic explanations of sources of momentum. 
We use $52 \mathrm{~W}$ to proxy the anchoring effect. The variable is constructed using stock price at the end of month $t-1$ divided by the highest price of the stock during the 12-month period that ends on the end of month $t-1$.

\subsubsection{Candidate variables related to the fundamental factors}

The second group of explanations attributes the momentum to fundamental factors. Chan et al. (1996) argue that momentum profits can be partially due to the underreaction to earnings news and the price momentum is not fully subsumed by earnings momentum. Chordia and Shivakumar (2006) show that the systematic component of earnings momentum drives the price momentum, and earnings surprises subsume the predictive power of past returns to future returns. However, the earnings momentum cannot be explained by the systematic factor of price momentum. Chen et al. (2014) propose revenue momentum, another firm fundamental factor, to explain a significant portion of price momentum profits.

We measure proxies for earnings momentum using earnings surprises (SUE) and cumulative abnormal return around earnings announcement (CAR). SUE is the standardized unexpected earnings surprise. CAR is measured as the cumulative abnormal return during -1 to +1 trading days around the date of earnings announcement. Revenue momentum is considered using revenue surprises (SUR), which is measured as the standardized unexpected revenue surprise. Earnings and revenue data are retrieved from Compustat for the sample period (1974-2016).

\subsubsection{Candidate variables related to prospect theory and mental accounting}

The third group of explanations concerns PT/MA regarding disposition effect. The momentum anomaly can be explained using the prospect theory (Kahneman and Tversky, 1979) and mental accounting (Thaler, 1980). According to the prospect theory, investors are risk-averse in the domain of gains and risk seeking in the domain of losses. The mental accounting theory provides a basis for investors to set different accounts for the domains of gains and losses. Grinblatt and Han (2005) derive an equilibrium model on how prospect theory combined with mental accounting implies that investors hold loser stocks too long and sell winner stocks too early, resulting in winners being undervalued and losers overvalued. The model is consistent with the disposition effect. They argued that capital gains and losses are better than past returns in forecasting future returns, and after controlling for the capital gains and losses, the momentum effect largely disappears. Frazzini (2006) shows that the deposition effect induces underreaction to news, resulting in a return continuation. Specifically, good (bad) news travels slowly in stocks with large capital gains (losses).

We follow Grinblatt and Han (2005) to construct the capital gains overhang (CGO) as a proxy for capital gains and losses to capture the effect of PT/MA. 


\subsubsection{Candidate variables related to firm-specific characteristics}

The fourth group of variables is primarily firm-specific characteristics. Studies have shown that firms with different characteristics exhibit different degrees of momentum. The behavioral models proposed by Barberis et al. (1998), Daniel et al. (1998), and Hong and Stein (1999) suggest that momentum returns are attributed to inefficient stock price to firm-specific information or news. On understanding the behavioral models, the momentum effect is likely related to specific firm characteristics widely used as proxies for the information publicly disclosed, the information uncertainty about the firm, the speed of diffusion of firm-specific news, and the impediments that delay the news incorporated into the prices or arbitrage away momentum profits. Literature shows that all these characteristics affect the diffusion of news incorporated into prices and, hence, the momentum effect.

Hong et al. (2000) find that momentum profits are significantly higher among firms with low analyst coverage (COV). The finding is consistent with Hong and Stein's (1999) model that firmspecific information diffuses gradually among the public. Since stocks with lower COV are always those with less public information, the information diffuses more slowly among the investing public.

Zhang (2006) shows that firms with higher information uncertainty, as proxied by dispersion in analyst forecasts (DISP), return volatility (TVOL) and COV, exhibit stronger momentum effects. He argues that investors strongly underreact to public information when there is uncertainty regarding the information. Consequently, news travels slower among firms with higher information uncertainty, resulting in stronger momentum. Sagi and Seasholes (2007) find consistent empirical results and showed that enhanced momentum strategies that are restricted to stocks with higher revenue volatility (RGVOL) and lower cost of goods sold (COGS) outperform the traditional momentum strategies by approximately 5\% annually. They theoretically show that firms with these characteristics exhibit positive return autocorrelation. Similar to Zhang (2006), Verardo (2009) finds the momentum effect is stronger among firms with higher DISP but interprets it as a measure for investor heterogeneity, which is a prerequisite condition in the framework of gradual information diffusion in Hong and Stein (1999).

Lee and Swaminathan (2000) find that trading volume (TURN) determines momentum profits. They show that momentum returns are significantly higher among stocks with higher TURN and the difference in momentum profits between high and low TURN stocks are primarily due to the underperformance of loser stocks. They argue that stocks with high (low) TURN exhibit glamour (value) characteristics and earn lower (higher) expected returns. Trading strategies that buy past winners with low TURN and sell past losers with high TURN outperform traditional momentum strategies by $2 \%$ to $7 \%$ per annum. 
Arena et al. (2008) examine the relation between momentum profits and idiosyncratic volatility (IVOL) and find that momentum is higher among stocks with higher IVOL. They argue that momentum results from underreaction to firm-specific information and IVOL, which measures the limits to arbitrage (Shleifer and Vishny, 1997) that deters arbitrageurs to exploit momentum profits.

Following this stream of literature, this study considers TVOL, DISP, TURN, COV, RGVOL, COGS, and IVOL as our candidate variables for firm characteristics. ${ }^{15}$

\subsubsection{Candidate variables related to other explanations}

The last group of explanations includes candidate variables that do not naturally belong to the other four groups. Moskowitz and Grinblatt (1999) show that industry effects drive momentum profits at the firm level, suggesting that momentum profits are attributed to industry-specific risk. We measure the industry effect (Industry r6,1) using the past 6-month industry return based on a 2-digit SIC code. Barberis and Huang (2008) show that under the cumulative prospect theory proposed by Tversky and Kahneman (1992), positively skewed stocks become overpriced and subsequently earn negative returns. We examined whether skewness (SK) contributes to the momentum. SK is measured using raw daily returns in each month. Novy-Marx (2012) claim that momentum profits are primarily driven by intermediate-term prior returns (r12,7), instead of recent prior returns. He shows that strategies based on intermediate-term prior returns are more profitable than those based on recent prior returns but does not explain such phenomena. However, Goyal and Wahal (2015) argue that a carryover of short-term reversals from month -2 in the US market drives these phenomena, and there is no such evidence in other 37 countries in the study. Because we use the US data, we control for r12,7 and measure it using stock past 12- to 7-month return.

\subsection{Descriptive statistics}

To mitigate the influence of outliers, we trim all candidate variables at the top and bottom $1 \%$ of their distributions. Table 1 summarizes the five groups of candidate variables in our study. The average characteristics-adjusted monthly return is $-0.1 \%$, with a standard deviation of 0.117 . The average past 6-month return is $11.6 \%$, with a standard deviation of 0.437 . The rest of Panel A presents the summary statistics for the five groups of candidate variables. The anchoring effect variable, $52 \mathrm{~W}$, has an average

15 Avramov et al. (2007) find that momentum is profitable only among firms with low credit rating (RATING). Firms with credit ratings ranging from AAA to BB exhibit insignificant momentum effect, whereas the other firms with noninvestable crediting that account for less than $4 \%$ of the market capitalization exhibited stronger momentum. However, adding RATING into the main analysis significantly reduces the sample size. The monthly average number of stocks is reduced to 963 from 2000 for other candidates. The number of stocks is further decreased to 540 in the multivariate analysis. Further, the study period starts from 1985, which also reduces the time by more than 20 years. Thus, we only discuss our results on credit rating as a robustness check. We thank an anonymous referee for the suggestion. 
value of 0.792. Among fundamental variables, the average SUE and CAR are 0.134 and 0.005, respectively, suggesting that stocks, on average, have positive earnings news. About the PT/MA variable, the average value of CGO is -0.102 , with a standard deviation of 0.53 . Among firm characteristics, TVOL has an average value of $2.5 \%$ per month, suggesting that stock returns are volatile. The average value of $\mathrm{COV}$ is 7.566 , suggesting that, on average, each stock is covered by 7-8 analysts. Among the variables related to other explanations, SK has an average value of 0.433 , suggesting that, on average, stock return is positively skewed. The average $\mathrm{r} 12,7$ and industry $\mathrm{r} 6,1$ are $9.5 \%$ and $10.6 \%$, respectively.

Panel B of Table 1 presents the Pearson correlations. The average correlation between past 6-month return $(\mathrm{r} 6,1)$ and month $t$ stock return $(\mathrm{r})$ is 0.02 , which is consistent with the positive return continuation documented by Jegadeesh and Titman (1993). The second column of Panel B shows that r6,1 is positively correlated with all candidate variables, except for DISP and COV. These correlations are consistent with previous studies that have been shown to explain the momentum anomaly. For example, the positive correlation between $\mathrm{r} 6,1$ and $52 \mathrm{~W}$ is 0.391 , which seems to be consistent with an anchoring effect explanation that $\mathrm{r} 6,1$ forecasts stock future return due to its positive correlation with $52 \mathrm{~W}$. The correlations between r6,1 and fundamental variables (SUE, CAR, and SUR) are 0.150, 0.116, and 0.061, respectively, indicating that good (bad) earnings' diffusions for winner (loser) stocks may be the drivers for momentum. The results are consistent with the findings of Chordia and Shivakumar (2006) and Chen et al. (2014). Regarding the candidate variable of PT/MA, CGO is positively correlated with r6,1, suggesting that stocks with high (low) past returns are associated with capital gains (losses), consistent with the conclusion of Grinblatt and Han (2005). Among the firm-specific characteristics, r6,1 is positively correlated with RGVOL, COGS, TVOL, TURN ${ }^{16}$, and IVOL, suggesting that stocks with high past returns tend to be those with high revenue growth volatility, high cost of goods sold, high trading volume, and high idiosyncratic volatility. The correlations between r6,1 and COV and DISP are -0.04 and -0.06 , respectively, indicating that stocks with high past returns tend to be those with low dispersion in analyst forecasts and low coverage.

[Insert Table 1 about here]

\section{Empirical analysis}

\subsection{The momentum anomaly}

Table 2 reports the results for regressions of 1-month ahead adjusted stock returns on its past 6month return and a candidate variable. The $t$-statistic is estimated based on the heteroskedasticity and

\footnotetext{
16 The correlation between r6,1 and some firm characteristics such as TURN is not consistent with prior studies which show a U-shape pattern among winner and loser portfolios. However, our analysis is at the stock level, the prior studies uses the portfolio-level analysis.
} 
autocorrelation consistent standard errors of Newey-West (1987). The stock return in month $t$ is regressed on r6,1 alone (Model 1 of Table 2). The sample period spans from August 1963 to December 2016 , with an average of 2,726 stocks per month. The coefficient on r6,1 is $0.84 \%$, which is statistically significant at the $1 \%$ level, consistent with the existence of momentum in the literature. We then add each candidate variable to Model 1 . The results for the anchoring effect and fundamental variables appear in Models 2 and 3-5, respectively. Models 6, 7-13, and 14-16 show the results for variables related to PT/MA, firm-specific characteristics, and others, respectively. The sample period and the number of stocks vary across models because of data availability of candidate variables. If the momentum anomaly (i.e., the relation between $\mathrm{r} 6,1_{i, t-1}$ and $r_{t}$ ) is purely driven by any candidate variable, the momentum beta should become insignificant after controlling for such a candidate variable. In all models, the momentum beta, which is the coefficient on r6,1, remains significantly positive after controlling for all candidate variables but SUE, suggesting that most of the candidate variables except for SUE cannot fully capture the anomaly. The coefficient of r6,1 remains statistically significant and its magnitude remains unaltered or even becomes larger after controlling for TVOL, TURN, COV, IVOL, industry r6,1, and SK. The result suggests these candidate variables may not have any explanatory power to the momentum. Moreover, the coefficients of all candidate variables but COV are also significant, suggesting that these candidate variables are strongly associated with stock future return. ${ }^{17}$

[Insert Table 2 about here]

Overall, Table 2 indicates that the momentum effect remains significant after controlling for candidate variables, and it seems that some candidate variables alone have some explanatory power in explaining the anomaly. However, it is unclear how much of the anomaly can be explained by these candidate variables and how much remains unexplained. These candidate variables are proposed by previous studies to explain the momentum anomaly based on different mechanisms and each mechanism seems promising to capture the momentum. Different studies use different methods, variables, and time and do not always control for potential competing variables in their analysis. Some findings are contradictory. Therefore, finding the most suitable mechanism is difficult. We next use the momentum decomposition method to quantify and rank the contribution of each candidate variable.

\subsection{The explanatory power of the candidate variable related to the anchoring effect}

We start with the univariate decomposition analysis. On average, most candidate variables have some explanatory power in explaining the anomaly but none fully captures the momentum effect individually. First, we use the anchoring effect variable, $52 \mathrm{~W}$, as an example to illustrate the

17 The sign and significance of the coefficient of each candidate variable are consistent with literature. 
decomposition method (Column 1 of Table 3). Four stages of analysis are described in Section 2.1. In Stage 1 , adjusted stock return in month $t$ is regressed on the past 6 -month return $(\mathrm{r} 6,1)$ and the average coefficient on $\mathrm{r} 6,1$ is 0.0083 with a $t$-statistic of 5.20.

In Stage 2, 52W is added to the regression of Stage 1. The average coefficient on $52 \mathrm{~W}$ is 0.012 , with a $t$-statistic of 4.56, which is consistent with George and Hwang's (2004) finding that nearness to $52 \mathrm{~W}$ has independent explanatory power to future return. After controlling for $52 \mathrm{~W}$, the average coefficient on r6,1 remains significantly positive, suggesting that $52 \mathrm{~W}$ cannot fully capture the momentum effect.

\section{[Insert Table 3 about here]}

Next, the decomposition method is used to quantify the explanatory power of $52 \mathrm{~W}$ to momentum. In Stage 3, r6,1 is regressed on $52 \mathrm{~W}$ each month and the average coefficient on $52 \mathrm{~W}$ is 0.852 , with a $t$ statistic of 74.69 , suggesting that $\mathrm{r} 6,1$ is significantly related to $52 \mathrm{~W}$ but the adjusted $R$-squared indicates that $52 \mathrm{~W}$ only captures $21.9 \%$ of the variation in $\mathrm{r} 6,1$. This stage helps decompose $\mathrm{r} 6,1$ into two components: a candidate component, $\delta_{\mathrm{t}-1} 52 \mathrm{~W}_{\mathrm{i}, \mathrm{t}-1}$, which is the component of $\mathrm{r} 6,1$ that is related to $52 \mathrm{~W}$, and a residual component of $\mathrm{r} 6,1,\left(\mu_{\mathrm{t}-1}+\varphi_{\mathrm{i}, \mathrm{t}-1}\right)$, which is unrelated to $52 \mathrm{~W}$.

In the final stage, the momentum beta $\left(\beta_{\mathrm{t}}\right)$ in Stage 1 is decomposed as shown in Eq. (4): a candidate momentum beta, which is related to $52 \mathrm{~W}\left(\beta_{\mathrm{t}}^{52 \mathrm{~W}}\right)$, and a residual momentum beta, which is unrelated to $52 \mathrm{~W}\left(\beta_{\mathrm{t}}^{\mathrm{R}}\right)$. The time-series averages of $\beta_{\mathrm{t}}^{52 \mathrm{~W}}$ and $\beta_{\mathrm{t}}^{\mathrm{R}}$ are 0.0033 and 0.0050 , respectively. Given that the sum of the two coefficients $\left(\beta_{\mathrm{t}}^{52 \mathrm{~W}}\right.$ and $\left.\beta_{\mathrm{t}}^{\mathrm{R}}\right)$ equals coefficient $\beta_{\mathrm{t}}(0.0083)$ in Stage 1, the fraction of $\beta_{\mathrm{t}}$ contributed by $52 \mathrm{~W}$ is $39.76 \%\left(\beta_{\mathrm{t}}^{52 \mathrm{~W}} / \beta_{\mathrm{t}}=0.0033 / 0.0083\right)$, which is significant at the $1 \%$ level. That is, $52 \mathrm{~W}$ alone captures $39.76 \%$ of the momentum anomaly (i.e., the relation between past 6-month return and return in month $t$ ). However, $60.24 \%$ of the anomaly remains unexplained by 52W. The result follows George and Hwang (2004), who find that the 52W substantially explains momentum profits.

\subsection{The explanatory power of the candidate variable related to fundamental factors}

Panel B of Table 3 shows the results for candidate variables related to fundamental factors. The candidate momentum beta $\left(\beta_{\mathrm{t}}^{\mathrm{C}}\right)$ depends on both correlations between the candidate variable and past return as well as future return. The larger $\beta_{\mathrm{t}}^{\mathrm{C}}$ implies the higher explanatory power of the candidate variable. Stage 3 shows that $r 6,1$ is positively correlated with all fundamental variables (SUE, CAR, and SUR), suggesting that stocks with high past returns tend to be those with good news and stocks with low past returns are those with bad news. Panel B of Table 1 shows that all these variables are positively correlated with future return $\left(\mathrm{r}_{\mathrm{i}, \mathrm{t}}\right)$, consistent with earlier studies that good (bad) news induces 
high (low) returns (e.g., Abarbanell and Bernard, 1992; Bhushan, 1994). Taken together, all three fundamental variables would positively contribute to the momentum anomaly. Intuitively, high past return stocks associated with good news would earn high future returns, whereas low past return stocks associated with bad news would earn low future returns, which is consistent with the momentum. Thus, based on the news mechanism, the fundamental factors contribute significantly to the momentum.

As predicted, each fundamental variable captures a large portion of the anomaly, as shown in Stage 4. SUE offers the most explanatory power to the anomaly among the fundamental factors, which explains $59.18 \%$ of the anomaly. The other two fundamental factors (CAR and SUR) alone explain $30.77 \%$ and $20 \%$ of the anomaly, respectively. The findings suggest that fundamental factors contribute a large portion of momentum profits, but none fully captures the anomaly individually. Our results are consistent with previous studies. For example, Chan et al. (1996) find that earnings surprises capture a part of predictability of past returns to future returns. Chordia and Shivakumar (2006) show that earnings surprises subsumes the return predictability of past returns and Chen et al. (2014) find revenue surprises also capture a large portion of momentum profits. This study complements existing studies by focusing on quantifying contributions of these candidate variables to the momentum.

\subsection{The explanatory power of the candidate variable related to prospect theory and mental accounting}

Panel C of Table 3 investigates the explanatory power of PT/MA candidate proxied by CGO. Panel B of Table 1 shows that CGO is positively correlated with $r_{i, t}$. In Stage 3, the average coefficient on CGO is 0.2 and the adjusted $R$-squared shows that $12.3 \%$ of the variable of r6,1 is captured by CGO, suggesting that $\mathrm{r} 6,1$ is related to CGO. According to the decomposition method, CGO partially captures the momentum because the correlation between CGO and past return and its return predictability are both significantly positive. Stage 4 shows that CGO explains a significant fraction of the anomaly at $20 \%(t$-statistic $=3.26)$ and $80 \%$ of the anomaly remains unexplained. The result is consistent with Grinblatt and Han (2005) that CGO alone can explain a sizable fraction of momentum profits. However, under the decomposition framework, the variable cannot fully capture the anomaly and much of the anomaly remains unexplained.

\subsection{The explanatory power of the candidate variable related to firm-specific characteristics}

Panel D of Table 3 examines the candidate variables related to firm-specific characteristics. Among those characteristics, DISP has the largest contribution to momentum (11.9\%). The positive contribution of DISP is because of the large negative correlation between DISP and r6,1 and its negative future return predictability, resulting in a positive candidate momentum beta related to DISP. Intuitively, the negative correlation between r6,1 and DISP from Stage 3 implies that stocks with low (high) past returns tend to be those with high (low) dispersions. Diether et al. (2002) use DISP as a proxy for differences in investor opinions. According to Miller's (1977) overvaluation arguments, stocks should be overpriced when 
there are differences in opinions, resulting in underperformance of such stocks. Thus, stocks with low past returns (i.e., losers) are overpriced, leading to low future returns and thus contributing to momentum.

The second largest contributor to momentum in this group is COV, which only explains $2.35 \%$ of the anomaly. Although the rest of the firm-specific characteristics, such as TVOL, TURN, RGVOL, COGS, and IVOL, are highly correlated with past return, they all fail to capture the momentum. Specifically, the explained fraction is $-3.53 \%$ for TVOL, $-10.71 \%$ for TURN, $-1.96 \%$ for RGVOL, $0 \%$ for COGS, and $-1.19 \%$ for IVOL. ${ }^{18}$

The negative contribution of these variables is because they are significantly positively correlated with r6,1 as shown in Stage 3; however, their future return predictabilities are all negative. We take an example of TVOL. The average coefficient on TVOL $\left(\delta_{\mathrm{t}-1}\right)$ in Stage 3 is 2.25 , with a $t$-statistic $=6.73$, indicating TVOL is highly positively correlated with r6,1. However, the TVOL is negatively correlated with $\mathrm{r}_{\mathrm{i}, \mathrm{t}}$ (Panel B of Table 1), which is in contrast to the momentum anomaly. Thus, TVOL would not only have no explanatory power but also negatively contribute to the momentum. Intuitively, the significant positive correlation between TVOL and r6,1 implies that stocks with high past returns are those with high return volatility and stocks with low past returns are those with low return volatility. In conjunction with the return predictability of TVOL being negative, stocks with high past returns (winners) that are highly volatile would earn negative returns, whereas stocks with low past returns (losers) that are low volatile would earn positive returns, contradicting the momentum anomaly. Therefore, based on such a mechanism, TVOL would not capture any momentum effect.

Overall, the decomposition results of firm characteristics suggest that although each firm characteristic is highly correlated with stock past return, most of them have limited explanatory power to momentum. In relation to the literature, momentum returns are higher among firms with certain characteristics (e.g., Lee and Swaminathan, 2000). For example, Zhang (2006) finds that the momentum effect is stronger among firms with higher information uncertainty. While firm characteristics fail in explaining the momentum, they may serve as mediators to enhance the momentum effect. Section 3.7 investigates this issue further and finds that these characteristics serve as mediators to enhance momentum profitability.

\subsection{The explanatory power of the candidate variable related to other explanations}

Finally, candidate variables that do not belong to the other four candidate groups are examined. As

\footnotetext{
18 In unreported analysis, we find that credit rating has a negative contribution to momentum at $-0.81 \%$. However, the result of credit rating is obtained based on a relatively small sample, which is only one-third of the original sample and over a short sample period (1985-2016) due to the data availability of credit rating.
} 
shown in Panel E of Table 3, Stage 3 results show that past return $(\mathrm{r} 6,1)$ is significantly related to all three variables. However, the adjusted $R$-squared in all cases is less than $5 \%$, suggesting that a large variation of past return is not captured by these candidate variables. Stage 4 shows that all variables in this group fail to explain the anomaly as the explained fraction by each candidate variable is less than $10 \%$. Specifically, Industry r6,1 explains $7.87 \%$ of the momentum anomaly, which is consistent with Grundy and Martin (2001) that after skipping a month between momentum formation and holding periods, the industry factor merely explains the momentum. SK negatively contributes to the anomaly $(-3.49 \%)$ because it is positively correlated with $\mathrm{r} 6,1$ but its return predictability is negative. Finally, r12,7 only captures $4.82 \%$ of the anomaly. The small explained fraction by r12,7 is not surprising because the correlation between $\mathrm{r} 12,7$ and $\mathrm{r} 6,1$ is low in which the variation of $\mathrm{r} 6,1$ explained by r12,7 is only $0.9 \%$.

We acknowledge that the results may be sensitive to the definition of momentum. Our decomposition framework defines momentum as the relation between past 6-month return $\left(\mathrm{r} 6,1_{\mathrm{i}, \mathrm{t}-1}\right)$ and future return in $t\left(r_{i, t}\right)$. For example, r12,7 may capture a larger fraction of the momentum if it is defined using 12-month formation period because the correlation between r12,7 and past 12-month return would be mechanically increased. Thus, to ensure that our results are not driven by a particular definition of momentum, we rerun the decomposition analysis using various formation and holding periods in Section 5.3. We show that the results for all candidate variables remain qualitatively similar across different momentum definitions, except for the explanatory power of $r 12,7$ to the momentum with the 12-month formation period being increased due to the mechanically increased correlation between r12.7 and past 12-month return.

To conclude, according to the univariate analysis, the candidate variables related to the anchoring effect and fundamentals (52W and SUE) are the largest contributors to the momentum, accounting for more than one-third anomaly alone, followed by the variable related to PT/MA (CGO), which explain one-fifth of the anomaly. However, firm-specific characteristics and other candidate variables have very little power in explaining the anomaly.

\subsection{Interaction effects}

As discussed in Section 3.5, most firm-specific characteristics fail to explain a significant portion of the momentum anomaly. Studies have shown that momentum returns are higher among firms with certain characteristics. Momentum returns are higher among firms that have low analyst coverage (Hong et al., 2000; Zhang, 2006), high return volatility (Zhang, 2006), high dispersion in analyst forecasts (Zhang, 2006; Verardo, 2009), high trading volume (Lee and Swaminathan, 2000), high limits to arbitrage (Arena et al., 2008), high revenue growth volatility (Sagi and Seasholes, 2007), and low costs of goods sold (Sagi and Seasholes, 2007). Considering that these firm characteristics are used as 
proxies for the speed of information diffusion, information uncertainty, and limits to arbitrage, these findings are often interpreted as evidence in support of behavioral explanations of the momentum anomaly. These firm characteristics contribute to momentum as mediation effects. This section investigates how much of the anomaly can be captured by the interaction effects between past return and these conditioning variables.

A rank in deciles (CharRank) is assigned for each conditioning variable to each stock that reflects the sorting on a given firm characteristic, where the highest rank refers to the variable with the highest value. Next, both CharRank and the interaction term between CharRank and r6,1 are included in the decomposition analysis. After including the interaction term in the decomposition analysis, the average portion explained by the candidate variable and the interaction term should be large because r6,1 itself enters the interaction term, which is used to explain the momentum (the relation between $r 6,1$ and $r_{t}$ ). To alleviate this concern, we replace r6,1 with a decile rank (r6,1Rank), with the highest rank associated with the highest $\mathrm{r} 6,1 .^{19}$

[Insert Table 4 about here]

Table 4 presents the results. Stage 2 regressions show that the coefficients on the interaction terms between CharRank and r6,1 rank are of expected sign and statistically significant for most characteristics, indicating that the momentum is more pronounced for stocks with high return volatility, high trading volume, low analyst coverage, high revenue growth volatility, and high idiosyncratic volatility. The results are consistent with previous studies that the firm characteristics can be used to enhance momentum profitability. However, we find no evidence that the momentum is more pronounced for stocks with high dispersion in analyst forecasts and low cost of goods sold.

Stage 3 shows that the coefficients on the interaction terms are all positive and statistically significant, suggesting that r6,1 and interaction terms are highly positively correlated. The high-adjusted $\mathrm{R}$-square across all conditional variables indicates that a large proportion of variation in $\mathrm{r} 6,1$ can be captured by the interaction term as $r 6,1$ itself enters the interaction term. ${ }^{20}$ Stage 4 results show that the average portion of the momentum anomaly explained by the CharRank and the interaction between CharRank and r6,1Rank is $85.88 \%$ for TVOL, $69.05 \%$ for DISP, $72.62 \%$ for TURN, $18.82 \%$ for COV, $86.27 \%$ for RGVOL, $58.82 \%$ for COGS and $86.90 \%$ for IVOL, respectively. ${ }^{21}$ On average, $68.3 \%$ of

19 Our results are qualitatively similar using past 6-month return.

20 In Table 3, the variation of r6,1 that can be explained each firm-specific characteristic itself is low, which is on average below $5 \%$.

${ }^{21}$ In unreported results, we find that the momentum tends to be stronger among firms with low credit rating, consistent with Avramov et al. (2007). The crediting variable and its interaction term can explain $82.26 \%$ of the anomaly. However, the result of credit rating is obtained based on a small sample ( 963 stocks per month), which is only one-third of original sample and over a short sample period (1985-2016) due to the data availability of 
the anomaly can be explained by these variables and their interaction terms. While these firm-specific characteristics have limited explanatory power to momentum, they serve as mediators to enhance the profitability of momentum strategies. The interaction effects capture a significant portion of momentum returns.

\subsection{Multivariate analysis—evaluating all candidate variables simultaneously}

The results of the univariate analysis show the fraction of the anomaly explained by each candidate variable alone. This section presents the multivariate regression analysis used to assess the marginal contribution of each candidate variable after controlling for the other candidate variables. ${ }^{22}$ The analysis allows direct comparisons of the contributions of those variables and how much of the momentum anomaly is collectively explained by these variables.

Stage 4 decomposes the momentum beta $(\beta)$ into a number of candidate momentum betas $\left(\beta^{\mathrm{C}}\right)$ and a residual momentum beta $\left(\beta^{\mathrm{R}}\right)$. The existence of momentum implies a positive momentum beta and a positive candidate momentum beta shows that the candidate variable positively contributes to the anomaly, whereas the negative beta indicates that the variable fails to explain or negatively contributes to the momentum effect. Table 5 presents the results for multivariate regression analysis. Model 1 shows the results of the full sample and Models 2 and 3 present those of two equal subperiods. Owing to data availability of all candidate variables in the regression, the average number of stocks per month reduces to 985, which is about one-third of that in Model 1 of Table 2. As shown in Stage 2, the coefficient on r6,1 remains statistically significant at the $1 \%$ level after controlling for all candidate variables. Stage 4 shows that all candidate variables collectively account for $30.51 \%(=1-69.49 \%)$ of the momentum anomaly and $69.49 \%$ is left unexplained.

\section{[Insert Table 5 about here]}

We note that the explanatory power of most of the candidate variables is significantly lower than its contribution in the univariate analysis (Table 3), probably because the explanatory power of the candidate variable is partly subsumed by the other candidates in the multivariate setting. Among these candidate variables, the largest contributors are CGO and SUR, which both explain $11.86 \%$ of the anomaly, followed by CAR, IVOL, DISP, and 52W at 10.17\%, 8.47\%, 6.78\%, and 5.08\%, respectively. The candidate variables, including CGO, SUR, CAR, and $52 \mathrm{~W}$, are used as underreaction proxies in earlier studies, suggesting that the underreaction mechanism contributes significantly to the momentum anomaly. The contributions of DISP and IVOL are more consistent with the overreaction mechanism.

credit rating.

${ }^{22}$ In the multivariate regression, we exclude credit rating variable as it substantially reduces the number of observations in each cross-section. 
Specifically, Grinblatt and Han (2005) find that PT/MA lead to price underreaction to public information and hence momentum. Chordia and Shivakumar (2006) and Chen et al. (2014) show that investors underreact to earnings and revenue information, thus contributing to momentum. George and Hwang (2004) argue that the anchoring bias that investors use $52 \mathrm{~W}$ as an anchor to form beliefs about stock values leads to an underreaction to news. The return predictability of DISP, which contributes significantly to momentum, is consistent with Miller's (1977) overvaluation arguments in which DISP is a proxy for differences in investor opinions (Diether et al., 2002). The negative return predictability of IVOL is explained by the fact that stocks with high IVOL are overvalued, leading to lower future returns (e.g., Bali et al., 2011; Stambaugh et al., 2015).

However, most firm-specific characteristics and other candidate variables, such as TVOL, TURN, RGVOL, COGS, r12,7, and SK, fail to explain the anomaly in the multivariate analysis. The insignificant contribution of these variables suggests that although they are highly correlated with $\mathrm{r} 6,1$, they do not necessarily explain a significant fraction of the anomaly.

Considering the contribution of each group of candidate variables, Figure 1 plots the marginal contribution of each group of candidate variables (i.e., anchoring effect, fundamental, PT/MA, firmspecific characteristics, and others) and the residual component using bar charts. Panel A presents the results of the full sample period. The fundamental group has the largest explanatory power, accounting for $20.3 \%$ of the anomaly, followed by PT/MA at $11.9 \%$ and anchoring effect at $5.1 \%$. The variables related to firm-specific characteristics and other explanations have no contribution to momentum at $-1.69 \%$ and $-5.08 \%$, respectively.

[Insert Figure 1 about here]

Overall, the fundamental variables are the most successful in explaining momentum under our decomposition framework; consistent with the literature that underreaction to a firm's fundamental information is an important mechanism in driving momentum. However, they cannot fully capture the momentum anomaly. The second and third largest contributors are PT/MA and anchoring effect-induced underreaction. The firm characteristics and other variables such as industry momentum fail to explain the momentum. While most firm-specific characteristics provide no evidence in contributing to momentum based on their own return predictabilities, those variables can enhance momentum in which momentum profits are higher among stocks with certain characteristics, consistent with the literature. Finally, while these variables are important determinants of the anomaly, at least two-thirds of the anomaly still remains unexplained. 


\section{Market conditions and momentum crash}

\subsection{Different market conditions}

Studies have shown that the momentum effect depends on stock market conditions. For example, momentum returns are significantly higher following high sentiment, low economic uncertainty, and low volatility (e.g., Antoniou et al., 2013; Stivers and Sun, 2010; Wang and Xu, 2015). We repeat the multivariate analysis in subsamples with different market conditions to investigate the explanatory power of candidate variables under different market conditions that exhibit different degrees of the momentum effect. This helps assess whether a candidate variable offers the same explanatory power to the anomaly in different scenarios and whether a specific group of candidate variables contributes to or dampens the anomaly in a particular subsample, providing insights into dynamic determinants of the anomaly.

Three market condition measures are used: market sentiment, market volatility, and economic uncertainty. We measure investor sentiment using the monthly market-wide sentiment developed by Baker and Wurgler (2006). ${ }^{23}$ The market volatility is calculated as the standard deviation of daily returns over the past one year in each month. Regarding the economic uncertainty, we rely on the index developed by Jurado et al. (2015), which is defined as the conditional volatility of the unpredictable component of several economic variables. ${ }^{24}$

First, each month is classified as high or low market condition using each proxy. A high (low) market condition month refers to one in which the value of the index in the previous month belongs to the top (bottom) $30 \%$ of the time-series value for the sample period. We refer to market states with high (low) sentiment, low (high) volatility, and low (high) economic uncertainty as strong (weak) momentum conditions. We then compute the average betas of momentum $\left(\beta_{t}\right)$, candidate momentum $\left(\beta_{t}^{C}\right)$, and residual for high- and low-momentum condition months separately based on different market condition proxies. Table 6 reports the multivariate results. For brevity, only Stage 4 results are presented. The last row of each panel shows that the momentum effect is highly significant under all three strong momentum conditions, whereas it becomes insignificant under weak momentum conditions, consistent with the previous findings. Specifically, the coefficient in Stage 1 denoted as the total coefficient is $0.0084(t$-statistic $=2.00)$ and $0.0035(t$-statistic $=0.62)$ during high and low sentiment periods, 0.0131 $(t$-statistic $=3.43)$ and $0.0019(t$-statistic $=0.39)$ during low and high volatile periods, and $0.0064(t$ -

\footnotetext{
${ }^{23}$ The sentiment index is constructed using the first principal component on six measures of investor sentiment proxies: the first day returns and the number of IPOS, the closed-end discount, NYSE turnover, the equity share of total new issue, and dividend premium. The data are from Jeffery Wurgler's website: http://people.stern.nyu.edu/jwurgler/.

24 The economic uncertainty data are obtained from Sydney Ludvigson's website, https://www.sydneyludvigson.com/.
} 
statistic $=2.16)$ and $0.0084(t$-statistic $=1.62)$ during low and high uncertain periods, respectively.

[Insert Table 6 about here]

The explained fractions are then considered by candidate variables under momentum conditions. The total explained fraction is typically higher under strong momentum conditions than that under weak momentum conditions, except for economic uncertainty. For example, the total explained fractions are $51.19 \%(=1-48.81 \%)$ and $-45.71 \%$ during high and low sentiment periods, $39.69 \%$ and $-31.58 \%$ in low and high volatile markets, and $18.75 \%$ and $46.43 \%$ during low and high uncertain periods, respectively.

The multivariate analysis in Section 3.8 shows that the momentum beta is decomposed into a number of candidate momentum betas. The positive candidate momentum beta indicates that the candidate variable positively contributes to the anomaly, whereas the negative beta indicates the contrary. Most variables that positively contribute to the anomaly under strong momentum conditions become to contribute less or even negatively to the anomaly under weak conditions. The results suggest that the weakened momentum effect under weak momentum conditions may due to the dampened effects of those variables, which have negative candidate momentum betas. For example, the largest contributor of the anomaly under strong momentum conditions is $52 \mathrm{~W}$. However, it becomes to dampen the anomaly under all three weak momentum conditions.

Next, the contributions of different groups of candidate variables across market conditions are considered. The results in Table 6 are summarized in Figure 2, which plots the marginal contribution of each group of candidate variables and the residual component under strong and weak momentum conditions. The candidate variables together explain, on average, $36.5 \%$ of the anomaly under strong momentum conditions, which is higher than that of the unconditional momentum (30.5\%) in Table 5. However, the total explained fraction declines sharply to $-10.3 \%$ under weak momentum conditions. This is primarily due to the dampening effect of the anchoring effect component (52W) under weak momentum conditions. While it is the largest contributor to the anomaly in strong momentum conditions, its explanatory power not only disappears but also negatively contributes to the anomaly under weak momentum conditions. This is because in unreported results, we find that $52 \mathrm{~W}$, which is positively correlated with future return under strong momentum conditions turns to be negatively correlated with future return under weak momentum conditions. Given that $52 \mathrm{w}$ is positively correlated with r6,1 under both momentum conditions, its contribution changes from positive under strong momentum conditions to negative in weak momentum conditions, according to our decomposition method. Similarly, PT/MA explains a significant portion of the anomaly under strong momentum conditions, but its explanatory power almost disappears under weak momentum conditions. However, fundamental variables explain a large portion of the momentum profits under both momentum 
conditions. The candidate variables related to firm characteristics and other explanations, which negatively contribute to the anomaly under strong momentum conditions, significantly explain the anomaly under weak momentum conditions. The finding suggests the momentum attributed to these two components of variables performs well under weak momentum conditions.

[Insert Figure 2 about here]

In sum, table 6 shows that the explanatory power of candidate variables differs across momentum conditions. The anchoring effect variable seems to primarily weaken the momentum effect under weak momentum conditions. The explanatory power of PT/MA, which is significant under strong momentum conditions, largely disappears under weak momentum conditions. In contrast, the variables related to firm characteristics and other explanations turn to perform relatively well under weak momentum conditions and the explanatory power of fundamental explanations is relatively stable across momentum conditions. Consequently, these variables become dominant in explaining the anomaly under weak momentum conditions.

\subsection{Momentum crashes by candidate components}

Daniel and Moskowitz (2016) claim that momentum strategies experience infrequent and substantial losses when a market suddenly rebounds in a bear market, which make the strategy less desirable during such periods. When the market declines, the momentum portfolio tends to long lowbeta stocks (past winners) and to short high-beta stocks (past losers). Therefore, when the market suddenly rebounds, momentum crash occurs because the momentum portfolio has a conditionally large negative beta.

The evidence in previous section suggests that candidate variables related to firm characteristics and other variables that fail to explain momentum under strong momentum conditions contribute significantly under weak momentum conditions. However, the anchoring effect variable contributes the most to the anomaly under strong momentum conditions but has a strong dampening effect under weak momentum conditions. The behavior of these candidate variables leads to the question whether momentum crashes under weak momentum conditions are primarily attributed to the dampening effect of the anchoring effect variable and whether the momentum based on firm characteristics and other variables experiences crash. This allows us to identify the main drivers of momentum crashes during market rebound periods.

This section addresses this issue by considering the market beta and performance of the momentum portfolio based on each group of candidate variables during market rebounds. Figure 3 plots the market betas for momentum winners and losers by components over the full sample period, measured by regressing winner (loser) portfolio returns on market returns using past 24-month daily data. The 
momentum beta is the difference between winner and loser market betas. Following Daniel and Moskowitz (2016) to define market rebounds as positive contemporaneous and negative market return over the past 24 months, the shaded bars indicate market rebound months. Each component momentum strategy is constructed using the fitted return of momentum components (anchoring effect, fundamental, PT/MA, others, and the residual components) as ranking variables, instead of past 6-month return for the total momentum strategy. The fitted return of a particular candidate variable is calculated as the fraction of the total past 6 -month return explained by the candidate variable $\left(\delta_{\mathrm{t}-1}\right.$ Candidate $\left._{\mathrm{i}, \mathrm{t}-1}\right)$ in Stage 3 (Eq. (3)) and the fitted return of a particular component of the candidate variables is measured as the sum of the fitted returns of the candidate variables in that component. For example, the fundamental momentum strategy is developed using the sum of fitted returns explained by three fundamental variables in Eq. (3): the sum of $\delta_{1 \mathrm{t}-1} \mathrm{SUE}_{\mathrm{t}-1}, \delta_{2 \mathrm{t}-1} \mathrm{CAR}_{\mathrm{t}-1}$, and $\delta_{3, \mathrm{t}-1} \mathrm{SUR}_{\mathrm{t}-1}$. Following Jagadeesh and Titman (1993), in each month, all stocks are ranked into deciles based on the component fitted return. The portfolio with the highest fitted return in the top decile is called the "winner" component portfolio and that with the lowest fitted return in the bottom decile is called the "loser" component portfolio. The component momentum strategy takes a long position in the winner component portfolio and a short position in the loser component portfolio, held for one month. ${ }^{25}$

[Insert Figure 3 about here]

Next, the market betas of winner and loser portfolios of each component momentum strategy are calculated. Panel A of Figure 3 plots betas of winners and losers of the conventional or total momentum strategy. The betas of both winners and losers are volatile over the sample period and the beta of losers reaches far higher levels than that of winners during market rebounds where momentum crashes are likely to occur. The net effect is that the momentum portfolio that goes long winners and short losers (momentum beta) yields a significantly negative market exposure during market rebounds. When the market swings upward in bear markets, the negative beta of the momentum portfolio leads to huge losses, consistent with the findings of Daniel and Moskowitz (2016).

Panels B, C, D, E, F, and G plot betas of winners and losers based on the anchoring effect, fundamental, PT/MA, firm characteristics, others, and the residual components, respectively. The loser betas of all components, except for firm characteristics component, are always larger than those of winners during market rebounds (represented by shaded bars). Therefore, all momentum strategies based on the anchoring effect, fundamental, PT/MA, other, and residual components, except for firm characteristics component, yield negative market exposures during market rebounds, with the anchoring

25 To be consistent with the regression analysis shown in equation (1), these portfolios are held for a month, skipping a month between formation and holding periods to mitigate microstructure and liquidity biases (Jegadeesh and Titman, 2001). 
momentum beta being the most negative and persisting during all rebound periods. Those component momentum strategies are expected to experience crashes owing to their negative market betas, suggesting that the source of traditional momentum crashes may be attributed to the underperformance of those momentum components. However, because the firm characteristics momentum is neutral to the market exposures as the beta of winners is always larger than that of losers, the firm characteristics momentum is not expected to experience crashes. That is, the firm characteristics component would not significantly contribute to total momentum crashes.

Several formal tests are then conducted to examine our hypotheses. We first examine whether momentum crashes tend to occur during weak momentum periods. Panel A of Table 7 reports the results. The sentiment, market volatility, and economic uncertainty are significantly lower, higher, and higher during market rebound than during non-rebound periods, respectively, suggesting that momentum crashes are more likely to occur under weak momentum conditions. Because Section 4.1 shows that the anchoring effect variable dampens the momentum effect under weak momentum conditions and its momentum beta is the most negative during momentum crashes periods, we expect the momentum strategy related to the anchoring effect would expose strongly to the momentum crashes. Conversely, the momentum strategy related to firm characteristics and other variables would not experience crashes as these variables become dominant in capturing the total momentum when the momentum is weak.

\section{[Insert Table 7 about here]}

We next regress momentum beta on a market rebound dummy variable, which equals 1 in the presence of market rebounds and 0 otherwise. Panel B of Table 7 shows the results of momentum betas by its components. ${ }^{26}$ Over the sample period, the first row of Panel B shows that the average beta of the total momentum portfolio is 0 during market non-rebound, suggesting that the risk exposure (beta) of momentum portfolio is almost neutral during the non-rebound periods. However, the beta drops significantly by 0.4153 during market rebound periods, suggesting that the beta of the momentum portfolio is almost $42 \%$ lower during the market rebounds than that during market non-rebound. Thus, the overall momentum beta is -0.4152 during market rebounds, suggesting that the momentum portfolio performs badly when the market suddenly rebounds following a bear market. The finding is consistent with that of Daniel and Moskowitz (2016).

We then turn to consider momentum betas by their components. The second to sixth rows in Panel $\mathrm{B}$ of Table 7 present the results. The anchoring-, PT/MA-, and fundamental-based momentum strategies have significantly negative betas in the presence of market rebounds, suggesting that these component

\footnotetext{
${ }^{26}$ For brevity, the results for betas of winners and loser are not reported but are available from the authors on request.
} 
strategies would expose crashes during such periods, and such components may be the underlying sources that contribute considerably to momentum crashes. Specifically, the anchoring effect component momentum has the largest negative exposure to the market during market rebound in which its beta under market rebound is -0.7857 , which is significant at the $1 \%$ level. The result suggests that the total momentum crashes could be predominantly attributed to the anchoring component. The betas of fundamental and PT/MA components momentum are -0.2049 and -0.1349 during market rebounds, respectively, with both being statistically significant at the $1 \%$ level, suggesting that those two components momentum would also expose to crashes but are relatively weaker than the anchoring component.

Recall that anchoring effect, fundamentals, and PT/MA shown in Section 3 significantly contribute to the momentum anomaly. Our results indicate that these components become important drivers of momentum crashes when they occur. The findings suggest the momentum effect and crash emerge from the summation of performance of these factors, which is consistent with Ehsani and Linnainmaa (2020), who argue that momentum is not a distinct factor; instead, it is related to all other factors. However, consistent with our expectation, firm characteristics and others, which have positive betas although moderately, are neutral to momentum crashes, suggesting that those components merely contribute to momentum crashes during crash periods. It is not surprising to see the firm characteristics and others would not contribute to the momentum crashes because candidate variables in these two groups fail in capturing the momentum. Finally, the residual momentum yields a significantly negative beta $(-0.1857)$. However, the magnitude is relatively lower than the beta of the anchoring and fundamental component momentum and is largely reduced more than half compared with that of the total momentum $(-0.4152)$. The results indicate that the residual momentum experiences much weaker crashes than total, anchoring, and fundamental component momentum.

To further validate the hypotheses, the performance of each component momentum strategy is examined during market rebounds and non-rebound periods. Panel $\mathrm{C}$ of Table 7 reports the average monthly returns for total and component momentum strategies. The results are consistent with the hypotheses that anchoring momentum strategy suffers the largest crashes, followed by PT/MA and fundamental component momentum strategies. In contrast, firm characteristics and others component strategies perform well during market rebound periods. As shown in the first row of Panel C, the total momentum performs well during market non-rebound periods as its monthly return is $1 \%$, with a $t$ statistic being 4.58 . However, the return is $3.6 \%(t$-statistics $=4.12)$ lower per month during market rebounds than non-rebound periods. Overall, the momentum experience huge losses during market rebounds, with its returns being significant at $-2.60 \%$ per month, consistent with the finding of Daniel and Moskowitz (2016). Among the component momentum strategies, the anchoring momentum experiences the largest losses, which are $-4.43 \%$ per month, followed by the PT/MA momentum at 
$-2.51 \%$ per month. The momentum based on fundamental factors suffers relatively lower losses at $-1.5 \%$ than the anchoring, PT/MA, and total momentum, indicating that the fundamental momentum actually alleviates the momentum crash. The findings suggest that the total momentum crash is attributed mainly to those components, especially to the anchoring component. Contrastingly, the firm characteristics and other momentum strategies perform well during market rebounds. In particular, their returns are 3.37\% and $1.04 \%$ per month, respectively, during market rebounds, with both returns being statistically significant at the $10 \%$ level or higher. Moreover, the residual momentum experiences slight crashes by purging out the effects of all candidate variables from past returns in which its return is $-0.94 \%$ per month during market rebound periods, with a $t$-statistic of 4.02 . The residual momentum crash is reduced considerably than the traditional momentum ( $-2.6 \%$ per month), anchoring, fundamental, and PT/MA momentum crashes, suggesting that the residual momentum works better than those momentum strategies during market rebound periods. The finding suggests that the performance of momentum based on the residual component by purging out the factors that contribute to the momentum crashes can be largely improved during market rebounds periods. Examining the drivers of residual momentum is beyond the scope of our study, the question of what are the underlying mechanisms that drive the residual momentum remains open.

In relation to the related literature, Grundy and Martin (2001) find that traditional momentum has dynamic exposures to the Fama and French's (1993) factors and propose a dynamic hedging strategy that significantly improved the performance of the momentum. However, the feasible strategy uses ex post estimates of factor betas. Motivated by Grundy and Martin's (2001) finding, Blitz et al. (2011) show that the residual momentum strategy, developed by hedging out the Fama-French (1993) three factors perform significantly better than traditional momentum in the U.S because time-varying exposures to Fama-French factors are alleviated as residual returns are used as ranking variables to form the portfolios. Recently, Fan et al. (2021) find that the high uncertainty of momentum strategies results from the cross-sectional volatility of individual stocks. Stocks with high realized volatility over the formation period tend to lose momentum effect, while stocks with low realized volatility show a strong momentum. A generalized risk-adjusted momentum strategy mitigates the negative impact of high momentum risk. This study suggests that forming momentum portfolios by ranking stocks based on the residual component effectively and consistently alleviates the momentum crashes, which is intriguing and needs further studies.

Overall, our analysis provides insights in understanding the dynamic momentum crashes during market rebounds. The anchoring and PT/MA components are the most important drivers of total momentum crashes, in which those factors are also significant contributors to momentum returns, with the anchoring component being the largest contributor. Conversely, firm characteristics and others momentum strategies perform well during such periods. Momentum strategies formed based on the 
residual component significantly alleviate momentum crashes.

\section{Additional robustness checks}

This section reports a series of robustness tests. The robustness tests are applied for results during two subsample periods, during non-January months, using alternative formation and ranking periods of momentum and results at the portfolio level.

\subsection{Subperiod analysis}

To verify the stability of the explanatory power of candidate variables, the full sample is divided into equivalent lengths: from February 1976 to December 1995 and from January 1996 to December 2016. Models 2 and 3 of Table 5 show the results. The total fraction explained by the candidate variables increases (decreases) to $36.67 \%$ (16.67\%) in Model 2 (3). For most candidate variables, the explained fractions of the anomaly are significantly lower in the second half of the sample period than those in the first half of the sample period. The finding suggests the variables contribute significantly less to the anomaly in the second half of the sample period. Specifically, for the anchoring effect, $52 \mathrm{~W}$ explains $4.44 \%$ and $10 \%$ of the anomaly in first and second sample periods, respectively. The contribution of fundamental variables is $23.33 \%$ and $10 \%$ in the first and second subsamples, respectively, remaining the largest contributors to momentum. Moreover, the CGO's explanatory power is slightly higher in the first subsample period than during the second, which captures $13.33 \%$ and $10 \%$ of the anomaly, respectively. The less explanatory power of the largest contributors (fundamentals and CGO) in the second half of the sample can occur because of the following reasons: (1) McLean and Pontiff (2016) show that anomaly returns diminish after the anomaly is published by academic researchers. Thus, lower contribution of the candidate variables in the second subsample is probably because the momentum effect is attenuated in the second subsample from 1996 to 2016, owing to the publication of Jegadeesh and Titman (1993). Therefore, the fraction of the anomaly captured by the candidate variables is smaller in the second half period than that in the first half period; (2) the contribution of those candidate variables simply reduces in the second half of the subsample. Furthermore, most firm characteristics and other variables still fail to explain momentum during both subperiods.

Panel B of Figure 1 plots the marginal contribution of each group of candidate variables in two subsample periods. The fundamental group still has the largest explanatory power, followed by PT/MA and anchoring effect in both subsample periods. However, a considerable fraction of momentum remains unexplained by our candidate variables in both periods.

Overall, while there are slight differences in the explanatory power of candidate variables across the two subsample periods, the general pattern regarding the contribution of each group of candidate variables remains similar to the full sample period. 


\subsection{January effects}

Jegadeesh and Titman (1993) document a striking seasonality in momentum returns. They show that winners outperform losers in all months but January, in which loser stocks perform better than winner stocks. Therefore, we examine whether our results continue to hold by excluding the January from our sample. Table 8 reports the results. Model 1 reports the results of the full sample period and Models 2 and 3 report the results of two subsample periods. ${ }^{27}$ The results indicate that the contribution for candidate variables remains similar in non-January months. Table 8 shows that the candidate variables that explain much of the anomaly in full sample including January, namely, 52W, SUE, CAR, SUR, and CGO, all continue to capture substantially similar amounts of the anomaly in non-January months. Moreover, firm-specific and other variables such as RGVOL, COGS, TVOL, TURN, COV, and SK, still fail to capture momentum.

[Insert Table 8 about here]

Stage 4 of Table 8 shows that fundamentals continue to be the largest contributors to momentum among those variables, followed by the variables related to PT/MA and anchoring effect (CGO and $52 \mathrm{~W})$. The explanatory power of $52 \mathrm{~W}$ is more than doubled in non-January months compared with the full sample period including January and the contribution of CGO slightly increases in non-January months. Specifically, CGO and 52W, which explain $11.86 \%$ and $5.08 \%$ in the full period, can capture $15.49 \%$ and $12.68 \%$ in non-January months, respectively. However, variables related to firm characteristics and other explanations fail to explain the anomaly in non-January months. Collectively, all candidate variables capture $36.62 \%$ of the anomaly, which is slightly higher than that in the full sample period (30.51\%). There is still a large fraction of the anomaly $(63.38 \%)$ left unexplained in nonJanuary months. Thus, our main conclusions remain the same in non-January months.

\subsection{Alternative formation and holding periods}

Jegadeesh and Titman $(1993,2001)$ document that the momentum strategies are profitable using different formation $(\mathrm{J})$ and holding $(\mathrm{H})$ periods. Our analysis for the momentum anomaly so far is based on a 6-month formation and 1-month holding periods $(\mathrm{J}=6, \mathrm{H}=1)$. According to the decomposition method, the contribution of a candidate variable depends on the correlation between past return and the candidate variable and its return predictability. Thus, the candidate's contribution may vary if momentum formation or the holding periods are altered. For example, if a candidate variable has strong predictive power to future 1-month return but is not significantly correlated with past 6-month return, the variable would not qualify as a good candidate variable in explaining the momentum. To ensure our

27 The results of full sample and two subsamples are qualitatively similar. 
results are not driven by a particular definition of momentum, we consider alternative formation and holding periods, past 3-, 6-, or 12-month as formation period $(\mathrm{J}=3,6$, or 12) and future 3-, 6- or 12month period as the holding period $(\mathrm{H}=3,6$, or 12$)$. Table 9 reports the results of multivariate analysis: columns 1-3 relate to $(J=3, H=3)$ momentum; columns 4-6 to $(J=6, H=6)$ momentum; columns 79 to $(\mathrm{J}=12, \mathrm{H}=6)$ momentum; and columns $10-12$ to $(\mathrm{J}=12, \mathrm{H}=12)$ momentum. ${ }^{28}$ For brevity, we only report Stage 4 results. Overall, the results show that the general pattern of the contribution of different groups of candidates still holds when alternative formation and holding periods are used.

In the unreported results, the average coefficient of past returns remains significantly positive when regressing future returns on past returns, consistent with momentum strategies being profitable depending on different formation and holding periods. Table 9 shows that candidate variables that better explain the $(\mathrm{J}=6, \mathrm{H}=1)$ momentum in Table 5 continue to be promising in explaining the returns of alternative momentum strategies. Most firm-specific characteristics and other variables that fail to explain the $(\mathrm{J}=6, \mathrm{H}=1)$ momentum continue to fail to capture the alternative momentum, with the exception being r12,7 in momentum strategies using past 12 months as formation period. r12,7, which has no explanatory power to the $(\mathrm{J}=3, \mathrm{H}=3),(\mathrm{J}=6, \mathrm{H}=1)$, or $(\mathrm{J}=6, \mathrm{H}=6)$ momentum turns to capture $24.51 \%$ and $22.06 \%$ of fractions of the $(\mathrm{J}=12, \mathrm{H}=6)$ and $(\mathrm{J}=12, \mathrm{H}=12)$ momentum, respectively. The sharp increase is a result of a sharp mechanical increase in the correlation between r12,7 and past 12-month return because r12,7 itself is a part of the past 12-month return. ${ }^{29}$ Firm characteristics such as RGVOL, COGS, TVOL, and TURN, which fail to explain the $(\mathrm{J}=6, \mathrm{H}=1)$ momentum, continue to fail in explaining the alternative momentum strategies.

[Insert Table 9 about here]

Among the large contributors (52W, CAR, SUR, CGO, DISP and IVOL) to the ( $\mathrm{J}=6, \mathrm{H}=1$ ) momentum in Table 5, all but IVOL continue to perform well in the alternative momentum strategies. The explanatory power of these variables slightly increases for the $(\mathrm{J}=3, \mathrm{H}=3)$ momentum but decreases for the other momentum strategies. Specifically, on average, $52 \mathrm{~W}$ explains more than $10 \%$ of all alternative momentum strategies compared with $5.08 \%$ of the $(\mathrm{J}=6, \mathrm{H}=1)$ momentum. Particularly, $52 \mathrm{~W}$ performs the best in the $(\mathrm{J}=3, \mathrm{H}=3)$ momentum strategy, which captures $27.78 \%$ of the anomaly.

28 Using other combinations of formation and holding periods for momentum yields substantially similar results that are not reported for brevity but are available from the authors on request.

29 Appendix B shows that the explained fraction by a candidate variable also depends on the fraction of variation of past return explained by the candidate variable $\left(\frac{\operatorname{Var}\left[\delta_{t-1} \operatorname{Candidate}_{i, t-1}\right]}{\operatorname{Var}\left[\text { past } \operatorname{return}_{\mathrm{i}, \mathrm{t}-1}\right]}\right)$. Thus, a mechanical increase in the correlation between past 12-month return (which is used as past return variable) and r12,7 will, all else equal, would increase the fraction of the anomaly explained by r12,7. We thank the anonymous referees for bringing us to have a better discussion on the decomposition methodology and have a careful discussion on intermediate past return $(\mathrm{r} 12,7)$ and other alternative measures of momentum. 
The explanatory power of CGO drops moderately from $11.86 \%$ in the $(\mathrm{J}=6, \mathrm{H}=1)$ momentum to $8.51 \%$ in the alternative momentum strategies. The explanatory power of fundamental variables (SUR and CAR $)$ to $(\mathrm{J}=6, \mathrm{H}=1)$ momentum is similar to the $(3,3)$ momentum but is halved for the momentum with longer formation and holding periods. In addition, the contribution of both DISP and IVOL decreases for all alternative momentums.

In terms of the contribution of each group of candidate variables, the variables related to the anchoring effect, fundamentals, and PT/MA still seem to be promising in explaining the alternative momentum. Specifically, the anchoring effect, fundamentals, and PT/MA explain, on average, $10.93 \%$ to $27.78 \%, 5.86 \%$ to $17.37 \%$, and $6.39 \%$ to $11.81 \%$ of the anomaly, respectively. Although some firm characteristics and other variables perform slightly better in specific momentum strategies, they still fail to explain the momentum. Collectively, all candidate variables can capture $43.1 \%$ to $63.79 \%$ of the anomaly and the remaining unexplained is still large at $36.21 \%$ to $56.94 \%$. Although the total fraction captured by candidate variables in the alternative momentum is larger than that of the $(\mathrm{J}=6, \mathrm{H}=1)$ momentum, a nontrivial fraction of the momentum anomaly still remains unexplained, and the explanatory power of each group of candidate variables are robust to alternative momentum definitions.

Overall, while the contribution of most candidate variables slightly differs in different momentum strategies, our main conclusions are robust to the alternative definitions of momentum.

\subsection{Portfolio-level decomposition analysis}

The analysis we perform so far is at the individual stock level. The advantage of using stock-level analysis rather than portfolio-level analysis is that it is robust to data mining and captures more variations of variables. However, a potential concern when using stock-level decomposition is about the measurement errors at the stock level as many candidate variables are generated regressors. The measurement error at the stock level is not unique to our decomposition analysis, while it also affects the conventional approach (Stage 2 regression), which is commonly used in the literature. Hou and Loh (2016) argue that the measurement error in candidate variables leads to a downward bias in the mean and the standard error of the fractions of the momentum anomaly captured by candidate variables, but the $t$-statistics of the fractions are not affected.

To alleviate this concern, the portfolio-level decomposition analysis ${ }^{30}$ is performed, in which the continuous past 6-month return variable is transformed into past 6-month return sorted portfolios. If the measurement errors are not perfectly correlated across stocks, then one group of the stocks into portfolios may cancel out the errors. However, the portfolio-level analysis may result in information

30 We thank an anonymous referee for bringing this to our attention. 
loss as the cross-sectional variation in the estimated variable is reduced (Ang et al., 2020). Therefore, the correlation between a candidate variable and past 6-month return at the portfolio level would be mechanically increased, resulting in an upward bias in the fraction of the momentum anomaly captured by the candidate variable.

The portfolio-level analysis is conducted by following Hou and Loh (2016). Each month, we construct portfolios by sorting individual stocks into 200 portfolios based on their past 6 -month return measured at $t-1$, and we value-weight stocks' returns when calculating portfolio returns. The portfoliolevel candidate variable is computed by taking the value-weighted average of the corresponding stocks' candidate variable in that portfolio. Table 10 presents the portfolio-level univariate results. Our key findings remain unaltered. For example, the candidate variables related to anchoring effect, fundamentals, and PT/MA continue to be the largest contributors of the momentum anomaly, although the fractions explained by $52 \mathrm{~W}$ and fundamental variables slightly decrease. The variables related to firm-specific characteristics that fail to capture the anomaly in the stock-level univariate analysis still cannot capture any momentum in the portfolio-level analysis. The variables related to other explanations (r12,7 and Industry $\mathrm{r} 6,1)$, which account for less than $10 \%$ of the anomaly individually, now can alone capture more than $15 \%$ of the anomaly. We find that the large increase in their contributions to the momentum primarily arises from the mechanical increase in their correlations with past 6-month return at the portfolio level. Although the explanatory power of the two variables sharply increases, their contributions are still comparably lower than that of the variables related to the anchoring effect, fundamentals, and PT/MA.

[Insert Table 10 about here]

When considering all variables simultaneously in the portfolio-level decomposition analysis, our conclusions largely hold except for 52W. Table 11 presents the multivariate results at the portfolio level. Variables related to PT/MA and fundamentals continue to be promising in explaining the momentum, which capture $27.3 \%$ and $15.2 \%$ of the anomaly, respectively. The larger contribution of PT/MA is also because of a large mechanical increase in its correlation with past 6-month return at the portfolio level. Moreover, 52W, which captures a sizeable portion of the anomaly, now fails to capture the momentum anomaly at the portfolio-level analysis. Variables related to firm-specific characteristics and other explanations that fail to explain the anomaly at the individual stock level continue to show little success in explaining the anomaly at the portfolio level. Collectively, candidate variables account for $36.36 \%$ of the anomaly and there is still a large fraction of the anomaly remains unexplained, which is similar to the results at the stock level.

[Insert Table 11 about here] 
Overall, our key findings are robust to the decomposition analysis at the portfolio level, which alleviates the concern of measurement errors at the individual stock level. The fundamental and PT/MA variables continue to be the largest contributors to the momentum anomaly, while firm-specific characteristics and other explanations still show little success in capturing the anomaly. Moreover, $52 \mathrm{~W}$ has limited contribution in the portfolio multivariate analysis. Although the total fraction explained by the candidate variables at the portfolio level is larger than that at the individual stock level, a nontrivial fraction of the momentum anomaly remains unexplained.

\section{Conclusion}

This study systematically and comprehensively evaluates and quantifies competing explanations for momentum. The momentum beta is decomposed into a number of momentum betas related to different groups of candidate variables, including the anchoring effect measured by 52-week-high return; fundamental-related components: earnings surprises, returns around earnings announcements, and revenue surprises; prospect theory and mental accounting candidate measured by the variable of capital gains overhang; firm characteristics related to limits to arbitrage and information uncertainty, such as volatility, turnover, analyst coverage, and dispersion in analyst forecasts; and other well-known explanatory variables of momentum, including past 7- to 12-month returns, past industry returns, and skewness. We then assess their explanatory power under different market conditions (classified by sentiment, economic uncertainty, and volatility) and further quantify their impacts on momentum crashes. At last, we evaluate the robustness of these explanations under subperiods, non-January months, alternative formation and holding periods and at the portfolio level.

The fundamental factors are ranked top among all candidate variables in capturing momentum at $20 \%$, followed by prospect theory and mental accounting at $12 \%$ and anchoring effect at $5 \%$. This is consistent with Novy-Marx (2015) that momentum is fundamental momentum. Overall, the variables examined only explain $31 \%$, while $69 \%$ of momentum remains unexplained. We find evidence that the explanatory power of candidate variables differs across momentum conditions. Under market conditions with strong momentum performance, the examined variables collectively explain $37 \%$ of momentum. Under weak momentum conditions, the anchoring effect variable primarily weakens the momentum effect. The explanatory power of prospect theory and mental accounting, which is significant under strong momentum conditions, largely disappears under weak momentum conditions. Conversely, the variables related to firm characteristics and other explanations perform relatively well under weak momentum conditions and the explanatory power of fundamental explanations is relatively stable across market conditions. Consequently, these variables become to be dominant in explaining the anomaly under weak momentum conditions. Furthermore, we find that the anchoring and prospect theory and mental accounting components are important drivers of total momentum crashes in which 
those factors are also significant contributors to momentum returns, with the anchoring component being the largest contributor. Conversely, firm characteristics and others momentum strategies perform well during such periods. The momentum strategies formed based on the residual component significantly alleviate the momentum crashes. Finally, our results largely hold in various robustness tests.

Overall, all existing explanations still leave a sizable fraction of the momentum unexplained. Our findings explain the sources of momentum in which it lays the foundation for researchers to have a fundamental and theoretical understanding of momentum. It better informs policy makers to improve market stability and efficiency. Investors can also improve the performance of momentum strategy and better implement and manage the risk associated with the momentum strategy by diversifying it with value investment (Asness et al., 2014), and combining it with risk-adjusted momentum (Fan et al., 2021). Future research could explore these topics. 


\section{References}

ABARBANELL, J.S. \& BERNARD, V.L., 1992. Tests of analysts' overreaction/underreaction to earnings information as an explanation for anomalous stock price behavior. The Journal of Finance, 47(3), pp.1181-1207.

ANG, A., LIU, J., \& SSCHWARZ, K. 2020. Using stocks or portfolios in tests of factor models. Unpublished working paper.

ANTONIOU, C., DOUKAS, J. A. \& SUBRAHMANYAM, A. 2013. Cognitive dissonance, sentiment, and momentum. Journal of Financial and Quantitative Analysis, 48, 245-275.

ARENA, M. P., HAGGARD, K. S. \& YAN, X. 2008. Price momentum and idiosyncratic volatility. Financial Review, 43, 159-190.

ASNESS, C. S., FRAZZINI, A., ISRAEL, R. \& MOSKOWITZ, T. J. 2014. Fact, Fiction, and Momentum Investing. The Journal of Portfolio Management, 40 (5), 75-92.

ASNESS, C. S., MOSKOWITZ, T. J. \& PEDERSEN, L. H. 2013. Value and momentum everywhere. The Journal of Finance, 68, 929-985.

AVRAMOV, D., CHORDIA, T., JOSTOVA, G. \& PHILIPOV, A. 2007. Momentum and credit rating. The Journal of Finance, 62, 2503-2520.

BAKER, M., \& WURGLER, J. 2006. Investor sentiment and the cross-section of stock returns. The Journal of Finance, 61(4), 1645-1680.

BALI, T.G., CAKICI, N. \& WHITELAW, R.F., 2011. Maxing out: Stocks as lotteries and the crosssection of expected returns. Journal of Financial Economics, 99(2), pp.427-446.

BARBERIS, N. \& HUANG, M. 2008. Stocks as lotteries: The implications of probability weighting for security prices. American Economic Review, 98, 2066-2100.

BARBERIS, N., SHLEIFER, A. \& VISHNY, R., 'A model of investor sentiment', Journal of Financial Economics, Vol. 49, 1998, pp. 307-43.

BARROSO, P. \& SANTA-CLARA, P. 2015. Momentum has its moments. Journal of Financial Economics, 116, 111-120.

BLITZ, D., HUIJ, J. \& MARTENS, M. 2011. Residual momentum. Journal of Empirical Finance, 18, 506-521.

BHUSHAN, R., 1994. An informational efficiency perspective on the post-earnings announcement drift. Journal of Accounting and Economics, 18(1), pp.45-65.

CHAN, L. K., JEGADEESH, N. \& LAKONISHOK, J. 1996. Momentum strategies. The Journal of Finance, 51, 1681-1713.

CHANG, R. P., KO, K.-C., NAKANO, S. \& RHEE, S. G. 2018. Residual momentum in Japan. Journal of Empirical Finance, 45, 283-299. 
CHEN, H.Y., CHEN, S.S., HSIN, C.W. and LEE, C.F., 2014. Does revenue momentum drive or ride earnings or price momentum?. Journal of Banking \& Finance, 38, pp.166-185.

CHORDIA, T. \& SHIVAKUMAR, L. 2002. Momentum, business cycle, and time-varying expected returns. The Journal of Finance, 57, 985-1019.

CHORDIA, T. \& SHIVAKUMAR, L. 2006. Earnings and price momentum. Journal of Financial Economics, 80, 627-656.

COOPER, M. J., GUTIERREZ JR, R. C. \& HAMEED, A. 2004. Market states and momentum. The Journal of Finance, 59, 1345-1365.

DANIEL, K., HIRSHLEIFER, D. \& SUBRAHMANYAM, A. 1998. Investor psychology and security market under-and overreactions. The Journal of Finance, 53, 1839-1885.

DANIEL, K. \& MOSKOWITZ, T. 2016. Momentum crashes. Journal of Financial Economics, 122, 221-247.

DANIEL, K., GRINBLATT, M., TITMAN, S., \& WERMERS, R. 1997. Measuring mutual fund performance with characteristic-based benchmarks. The Journal of finance, 52(3), 1035-1058.

DIETHER, K. B., MALLOY, C. J., \& SCHERBINA, A. 2002. Differences of opinion and the cross section of stock returns. The Journal of Finance, 57(5), 2113-2141.

EHSANI, S. \& LINNAINMAA, J.T., 2020. Factor momentum and the momentum factor (No. w25551). National Bureau of Economic Research.

FAMA, E. F. \& FRENCH, K. R. 1993. Common risk factors in the returns on stocks and bonds. Journal of Financial Economics, 33, 3-56.

FAMA, E. F. \& LITTERMAN, R. 2012. An experienced view on markets and investing. Financial Analysts Journal, 68, 15-19.

FAN, M., KEARNEY, F., LI, Y. \& LIU, J. 2021. Momentum and the Cross-Section of Stock Volatility Available at SSRN: https://ssrn.com/abstract=3541766.

FRAZZINI, A., 2006. The disposition effect and underreaction to news. The Journal of Finance, 61(4), 2017-2046.

GOYAL, A., \& WAHAL, S. 2015. Is Momentum an Echo? Journal of Financial and Quantitative Analysis, 50(6), 1237-1267.

GEORGE, T. J. \& HWANG, C. Y. 2004. The 52-week high and momentum investing. The Journal of Finance, 59, 2145-2176.

GRINBLATT, M. \& HAN, B. 2005. Prospect theory, mental accounting, and momentum. Journal of Financial Economics, 78, 311-339.

GRUNDY, B. D. \& MARTIN, J. S. M. 2001. Understanding the nature of the risks and the source of the rewards to momentum investing. Review of Financial Studies, 14, 29-78.

HONG, H., LIM, T. \& STEIN, J. C. 2000. Bad news travels slowly: Size, analyst coverage, and the profitability of momentum strategies. The Journal of Finance, 55, 265-295. 
HONG, H. \& STEIN, J. C. 1999. A unified theory of underreaction, momentum trading, and overreaction in asset markets. The Journal of Finance, 54, 2143-2184.

HOU, K. \& LOH, R. K. 2016. Have we solved the idiosyncratic volatility puzzle? Journal of Financial Economics, 121, 167-194.

JEGADEESH, N. \& TITMAN, S. 1993. Returns to buying winners and selling losers: Implications for stock market efficiency. The Journal of Finance, 48, 65-91.

JEGADEESH, N. \& TITMAN, S. 2001. Profitability of momentum strategies: An evaluation of alternative explanations. The Journal of Finance, 56, 699-720.

JEGADEESH, N. \& TITMAN, S. 2011. Momentum. Annual review of Financial Economics, 3, 493509.

JURADO, K., LUDVIGSON, S. C., \& Ng, S. 2015. Measuring uncertainty. American Economic Review, 105(3), 1177-1216.

KAHNEMAN, D. \& TVERSKY,A., 1979. Prospect theory: an analysis of decision under risk. Econometrica 47, 263-291.

LEE, C. M. \& SWAMINATHAN, B. 2000. Price momentum and trading volume. The Journal of Finance, 55, 2017-2069.

LIU, M., LIU, Q. \& MA, T., 2011. The 52-week high momentum strategy in international stock markets. Journal of International Money and Finance, 30(1), pp.180-204.

MCLEAN, R. D. 2010. Idiosyncratic risk, long-term reversal, and momentum. Journal of Financial and Quantitative Analysis, 45, 883-906.

MCLEAN, R.D. \& PONTIFF, J., 2016. Does academic research destroy stock return predictability?. The Journal of Finance, 71(1), pp.5-32.

MILLER, E. M. 1977. Risk, uncertainty, and divergence of opinion. The Journal of finance, 32(4), $1151-1168$.

MOSKOWITZ, T. J. \& GRINBLATT, M. 1999. Do industries explain momentum? The Journal of Finance, 54, 1249-1290.

NEWEY, W. K. \& WEST, K. D. 1987. A simple, positive semi-definite, heteroskedasticity and autocorrelationconsistent covariance matrix. National Bureau of Economic Research Cambridge, Mass., USA.

NOVY-MARX, R. 2012. Is momentum really momentum? Journal of Financial Economics, 103, 429453.

NOVY-MARX, R. 2015. Fundamentally, momentum is fundamental momentum. NBER working papers. Available at https://www.nber.org/papers/w20984.

SADKA, R. 2006. Momentum and post-earnings-announcement drift anomalies: The role of liquidity risk. Journal of Financial Economics, 80, 309-349. 
SAGI, J. S., \& SEASHOLES, M. S. 2007. Firm-specific attributes and the cross-section of momentum. Journal of Financial Economics, 84(2), 389-434.

SHLEIFER, A., \& VISHNY, R. W. 1997. The limits of arbitrage. The Journal of finance, 52(1), 35-55.

STAMBAUGH, R.F., YU, J. \& YUAN, Y., 2015. Arbitrage asymmetry and the idiosyncratic volatility puzzle. The Journal of Finance, 70(5), pp.1903-1948.

STIVERS, C. \& SUN, L. 2010. Cross-sectional return dispersion and time variation in value and momentum premiums. Journal of Financial and Quantitative Analysis, 45, 987-1014.

THALER, R., 1980. Toward a positive theory of consumer choice. Journal of Economic Behavior and Organization 1,39-60.

TVERSKY, A. \& KAHNEMAN, D., 1992. Advances in prospect theory: Cumulative representation of uncertainty. Journal of Risk and uncertainty, 5(4), pp.297-323.

VERARDO, M., 2009. Heterogeneous beliefs and momentum profits. Journal of Financial and Quantitative Analysis, 44, 795-822.

WANG, K. Q. \& XU, J. 2015. Market volatility and momentum. Journal of Empirical Finance, 30, 7991.

ZHANG, X. F. 2006. Information uncertainty and stock returns. The Journal of Finance, 61, 105-137. 


\section{Appendix A. Definitions of key variables}

This appendix provides the details for constructing risk-adjusted stock return and various candidate variables.

$r$ : stock $i$ 's characteristic-adjusted return which is adjusted by book-to-market ratio and firm size. At the end of June in each year, stocks are grouped to quintiles based on book-tomarket ratio and are also grouped to quintiles based on market value independently. Then adjusted return is raw return minus corresponding portfolio return in each month. Book-tomarket ratio is defined as the book value divided by market value. The market value is calculated as the price times the number of shares outstanding of the stock in pervious year end. Book equity is total assets minus total liabilities, plus balance sheet deferred taxes and investment tax credits, then minus book value of preferred stock in previous fiscal year. Book value of preferred stock is preferred stock liquidation value if available, or redemption value if available, or carrying value if available. Firm size is the market value at the end of June. The market value is calculated as the price times the number of shares.

r6,1: past 6-month return skipping the most recent one month.

\section{Candidate variables:}

$52 \mathrm{~W}$ : the nearness to the 52 -week high stock price, defined as the ratio between the stock price at the end of month $t$ and the highest stock price during the past 12 months. The sample period starts from August 1963.

$S U E$ : the earnings surprise, defined as unexpected earnings of stock $i$ scaled by its stock price 10 days prior to the earnings announcement.

$$
\mathrm{SUE}_{\mathrm{i}}=\frac{\mathrm{E}_{\mathrm{i}, \mathrm{t}}-\mathrm{E}_{\mathrm{i}, \mathrm{t}-4}}{\sigma_{\mathrm{i}, \mathrm{t}}}
$$

where $\mathrm{E}_{\mathrm{i}, \mathrm{t}}$ is the actual earnings for stock $i$ in quarter $t, \mathrm{E}_{\mathrm{i},-4}$ is the actural earnings for stock $i$ in quarter $t-4$, and $\sigma_{\mathrm{i}, \mathrm{t}}$ is the standard deviation of earnings over previous eight quarters. This measure requires to use Compustat quarterly data, thus the sample period starts from February 1974.

$C A R$ : the cumulative abnormal return around the earnings announcement, defined as stock cumulative return for a particular stock during the earnings announcement event window from 
day -1 to +1 centred on the earnings announcement date. The abnormal return is stock raw return in excess of market return. The sample period is from February 1974.

$S U R$ : the revenue surprise, defined as the unexpected revenue of firm $i$ scaled by the standard deviation of revenue

$$
\mathrm{SUR}_{\mathrm{i}}=\frac{\mathrm{REV}_{\mathrm{i}, \mathrm{t}}-\mathrm{REV}_{\mathrm{i}, \mathrm{t}-4}}{\sigma_{\mathrm{i}, \mathrm{t}}^{R}}
$$

Where $\mathrm{REV}_{\mathrm{i}, \mathrm{t}}$ is revenue for stock $i$ in quarter $t, \mathrm{REV}_{\mathrm{i}, \mathrm{t}-4}$ is the revenue for stock $i$ in quarter $t-4$, and $\sigma_{\mathrm{i}, \mathrm{t}}^{R}$ is the standard deviation of revenue growth over previous eight quarters. The sample period starts from February 1974 since Compustat quarterly data is used.

$C G O$ : The capital gains overhang variable in month $t$, following Grinblatt and Han (2005):

$$
\mathrm{CGO}_{\mathrm{t}}=\frac{\mathrm{P}_{\mathrm{t}-2}-\mathrm{RP}_{\mathrm{t}-1}}{\mathrm{P}_{\mathrm{t}-2}}
$$

where $\mathrm{P}_{\mathrm{t}-2}$ is the stock price at the end of the second-to-last week of month $t$, and

$$
\mathrm{RP}_{\mathrm{t}}=\frac{1}{\mathrm{~K}} \sum_{\mathrm{n}=1}^{260}\left(\mathrm{~V}_{\mathrm{t}-\mathrm{n}} \prod_{\tau}^{\mathrm{n}-1}\left(1-\mathrm{V}_{\mathrm{t}-\mathrm{n}+\tau}\right)\right) \mathrm{P}_{\mathrm{t}-1-\mathrm{n}}
$$

where $\mathrm{P}_{\mathrm{t}}$ is the stock price at the end of week $t ; \mathrm{V}_{\mathrm{t}}$ is stock turnover in week $t ; \mathrm{K}$ is a constant that makes the weights on past prices sum to one. The weight is the term in brackets, which is the probability that the stock was last bought at week $t$-n and has not been traded since. Weekly turnover is calculated as weekly trading volume divided by the number of shares outstanding. To be included in the sample, a stock must have at least 100 weeks of non-missing data in the previous 5 years. At last, the monthly CGO is the average of weekly CGO within each month. The sample period starts from August 1963.

TVOL: total volatility is standard deviation of returns in each month (minimum 15 days are required). The sample period starts from August 1963.

$D I S P$ : dispersion is standard deviation of analyst earnings forecasts scaled by stock price. The sample starts from February 1976.

TURN: turnover is the average of daily turnover in the past 120 days. Daily turnover is number of traded shares divided by number of outstanding shares. The sample period starts from August 1963.

COV: analyst coverage is number of analysts. The sample period starts from February 1976. 
RGVOL: revenue growth volatility is the volatility of firm revenue growth in the past 10 quarters (minimum 5 quarters are required). Firm revenue growth is revenue in current quarter divided by revenue in lagged 4 quarter and minus 1. The sample starts from February 1974.

COGS: cost of goods sold is quarterly cost of goods divided by quarterly total assets. The sample starts from February 1974.

IVOL: idiosyncratic volatility is the standard deviation of residuals from regression on daily return on daily market return in each month (minimum 15 days are required). The sample period starts from August 1963.

r12,7: stock $i$ 's past 7- to 12- month return, defined as the cumulative return from month $t-12$ to $t-7$. The sample period starts from August 1963.

Industry $r_{6,1}$ : the industry past 6-month return in month $t$, defined as the cumulative return from month $t-6$ to $t-1$ of an industry based on 2-digit SIC code. The sample period starts from August 1963.

SK: skewness of raw daily return in month $t$. The sample period starts from August 1963.

Appendix B. The explained fraction of momentum and the fraction of past return variance explained by the candidate

In this section, we show that the explained fraction of momentum depends on the fraction of the variation of past return (e.g., r6,1) explained by the candidate variable. We first substitute Eq. (3) into Eq. (2) and get:

$$
\begin{aligned}
r_{i, t}= & \widetilde{\alpha}_{t}+\widetilde{\beta_{t}^{R}} \text { past } \text { return }_{i, t-1}+\widetilde{\beta_{t}^{C}} \text { candidate }_{i, t-1}+\widetilde{\varepsilon}_{i, t} \\
& =\widetilde{\alpha}_{t}+\widetilde{\beta_{t}^{R}}\left(\mu_{t-1}+\delta_{t-1} \text { Candidate }_{i, t-1}+\varphi_{i, t-1}\right)+\widetilde{\beta_{t}^{C}} \text { candidate }_{i, t-1}+\widetilde{\varepsilon}_{i, t} \\
& =\widetilde{\alpha}_{t}+\widetilde{\beta_{t}^{R}}\left(\mu_{t-1}+\varphi_{i, t-1}\right)+\left(\widetilde{\beta_{t}^{C}}+\delta_{t-1} \widetilde{\beta_{t}^{R}}\right) \text { candidate }_{i, t-1}+\widetilde{\varepsilon}_{i, t} \\
& =\widetilde{\pi}_{t}+\widetilde{\beta_{t}^{C}} \text { candidate }_{i, t-1}+\widetilde{\varepsilon}_{i, t}
\end{aligned}
$$

where $\widetilde{\pi}_{\mathrm{t}}$ equals to $\widetilde{\alpha}_{\mathrm{t}}+\widetilde{\beta_{\mathrm{t}}^{\mathrm{R}}}\left(\mu_{\mathrm{t}-1}+\varphi_{\mathrm{i}, \mathrm{t}-1}\right)$ and $\overline{\beta_{t}^{C}}$ equals to $\widetilde{\beta_{\mathrm{t}}^{\mathrm{C}}}+\delta_{\mathrm{t}-1} \widetilde{\beta_{\mathrm{t}}^{\mathrm{R}}}$. 
Thus, based on Eq. (5), we obtain:

$$
\begin{aligned}
& \overline{\beta_{t}^{C}} \\
& =\frac{\operatorname{Cov}\left[\mathrm{r}_{\mathrm{i}, \mathrm{t}}, \text { Candidate }_{\mathrm{i}, \mathrm{t}-1}\right]}{\operatorname{Var}\left[\text { Candidate }_{\mathrm{i}, \mathrm{t}-1}\right]}
\end{aligned}
$$

Then we can rewrite explained fraction by the candidate variable $\left(\beta_{\mathrm{t}}^{\mathrm{C}}\right)$ from Eq. (4) using Eq. (6) as follows:

$$
\begin{aligned}
& \beta_{\mathrm{t}}^{\mathrm{C}}=\frac{\operatorname{Cov}\left[\mathrm{r}_{\mathrm{i}, \mathrm{t}}, \delta_{\mathrm{t}-1} \text { Candidate }_{\mathrm{i}, \mathrm{t}-1}\right]}{\operatorname{Var}\left[\text { past } \text { return }_{\mathrm{i}, \mathrm{t}-1}\right]}
\end{aligned}
$$

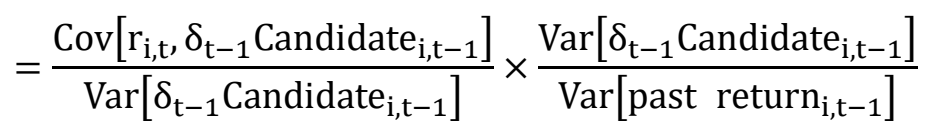

$$
\begin{aligned}
& =\frac{\overline{\beta_{t}^{C}}}{\delta_{\mathrm{t}-1}} \\
& \times \frac{\operatorname{Var}\left[\delta_{\mathrm{t}-1} \text { Candidate }_{\mathrm{i}, \mathrm{t}-1}\right]}{\operatorname{Var}\left[\text { past } \operatorname{return}_{\mathrm{i}, \mathrm{t}-1}\right]}
\end{aligned}
$$

The Eq. (7) suggests that $\beta_{\mathrm{t}}^{\mathrm{C}}$ depends on both the component of the candidate variable that is correlated with future return $\left(\overline{\beta_{t}^{C}}\right)$ and the fraction of the variation of past return explained by the candidate variable $\left(\frac{\operatorname{Var}\left[\delta_{\mathrm{t}-1} \operatorname{Candidate}_{\mathrm{i}, \mathrm{t}-1}\right]}{\operatorname{Var}\left[\text { past return } \mathrm{r}_{\mathrm{i}, \mathrm{t}-1}\right]}\right)$. Thus, if the correlation between past return and the candidate variable increases, all else equal, the fraction of the anomaly explained by the candidate variable would increase. 
Figure 1

This figure plots the average fraction of different candidate groups in full sample (Panel A) and two sub-periods (Panel B). We group the candidates into five groups: Anchoring, Fundamental, PT/MA, Firm characteristics and Others. Anchoring includes 52W. Fundamental includes SUE, CAR and SUE. PT/MA includes CGO. Firm characteristics includes TVOL, DISP, TURN, COV, RGVOL, COGS and IVOL. Others include industry return from month t-6 to t-1, r12,7 and skewness. Resid is the residual fraction of momentum, which is unexplained by candidate variables. We sum up the fractions of individual candidates in each category and then compute the average fraction. The full sample period is from February 1976 to December 2016. The two sub-periods are from February 1976 to December 1995 and from January 1996 to December 2016, respectively.

Panel A. Full sample period

$120 \%$

$100 \%$

$80 \%$

$60 \%$

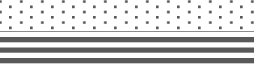

$40 \%$
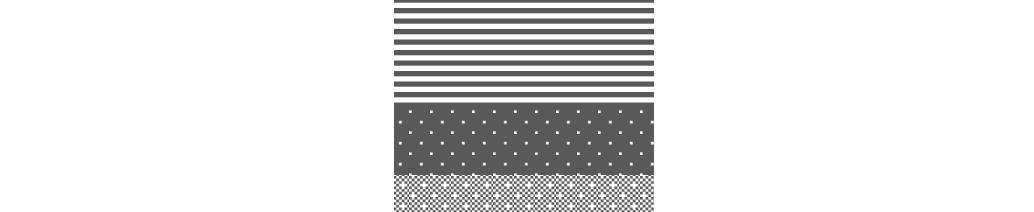

$\therefore \because \because:$ Anchoring

= Fundamental

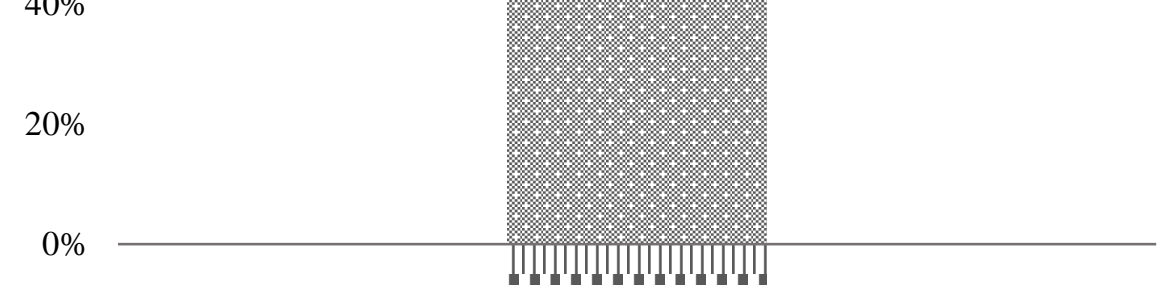

$\therefore \mathrm{PT} / \mathrm{MA}$

Firm characteristics

IIIIII Others

Resid

$-20 \%$

Panel B. Two sub-periods

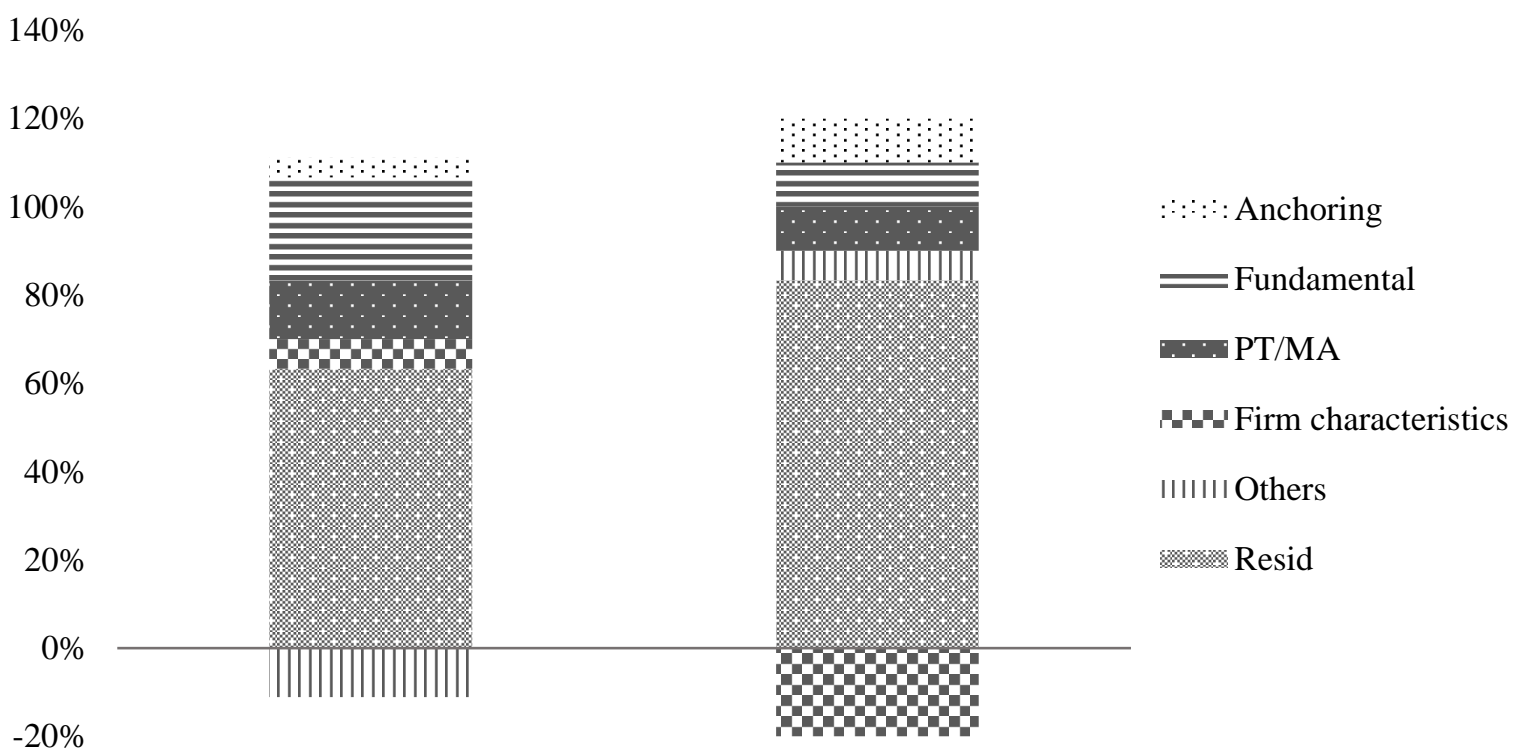

$-40 \%$

$1976-1995$

1996 - 2016 


\section{Figure 2}

This figure plots the average fraction across different candidate groups for both strong momentum condition and weak momentum condition. Strong momentum conditions include high sentiment, low market volatility and low uncertainty. Weak momentum conditions include low sentiment, high market volatility and high uncertainty. The fractions are from Table 5. We group the candidates into five groups: Anchoring, Fundamental, PT/MA, Firm characteristics and Others. Anchoring includes 52W. Fundamental includes SUE, CAR and SUE. PT/MA includes CGO. Firm characteristics includes TVOL, DISP, TURN, COV, RGVOL, COGS and IVOL. Others include industry return from month t-6 to t-1, r12,7 and skewness. Resid is the residual fraction of momentum, which is unexplained by candidate variables. We sum up the fractions of individual candidates in each category in a subsample and then compute the average fraction across subsamples.

$250 \%$

$200 \%$

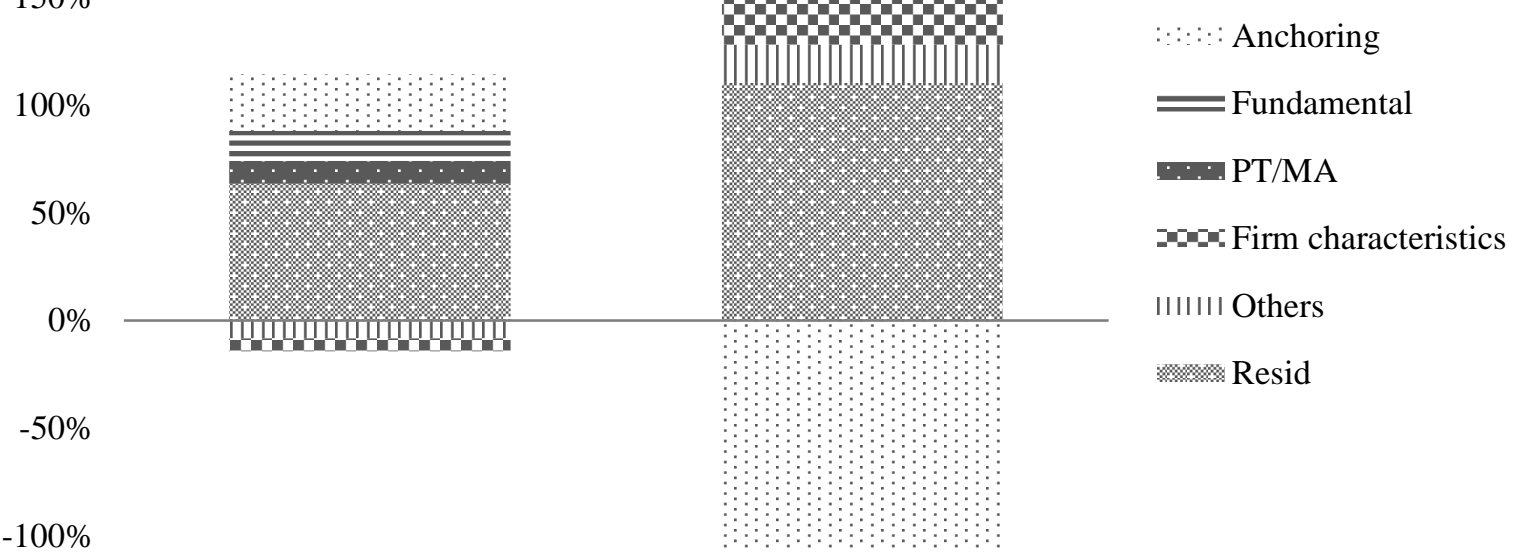

$-150 \%$

Strong momentum conditions $\quad$ Weak momentum conditions 
Figure 3

This figure plots rolling beta of winner and loser portfolios. For panel A, in each month, stocks are divided into deciles based on past 6-month return skipping the most recent one month, then we estimate beta of winner portfolio (top decile) from regression of winner portfolio returns on market portfolio returns over the past 24 months and similarly we estimate beta of loser portfolio (bottom decile). The shaded bars indicate rebound months. Rebound month is the month that has positive contemporaneous return and negative return in the past 24 months. From Panels B to F, we repeat the process but use momentum component as rank variable to determine component winner and loser portfolios. Candidates are grouped into five groups: Anchoring, Fundamental, PT/MA, Firm characteristics and Others. Anchoring includes 52W. Fundamental includes SUE, CAR and SUE. PT/MA includes CGO. Firm characteristics include TVOL, DISP, TURN, COV, RGVOL, COGS and IVOL. Others include industry return from month t-6 to t-1, r12,7 and skewness. Resid is residual component. For example, Fundamental component, we sum up the fitted return explained by SUE, CAR and SUR, then rank stocks into deciles based on the fitted value.

Panel A: Past 6-month return

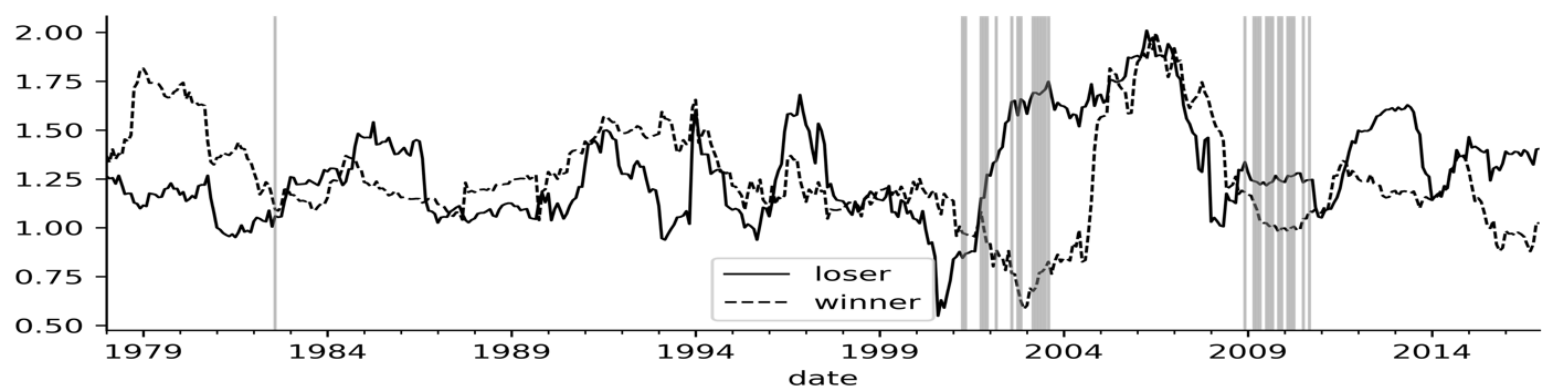

Panel B: Anchoring component

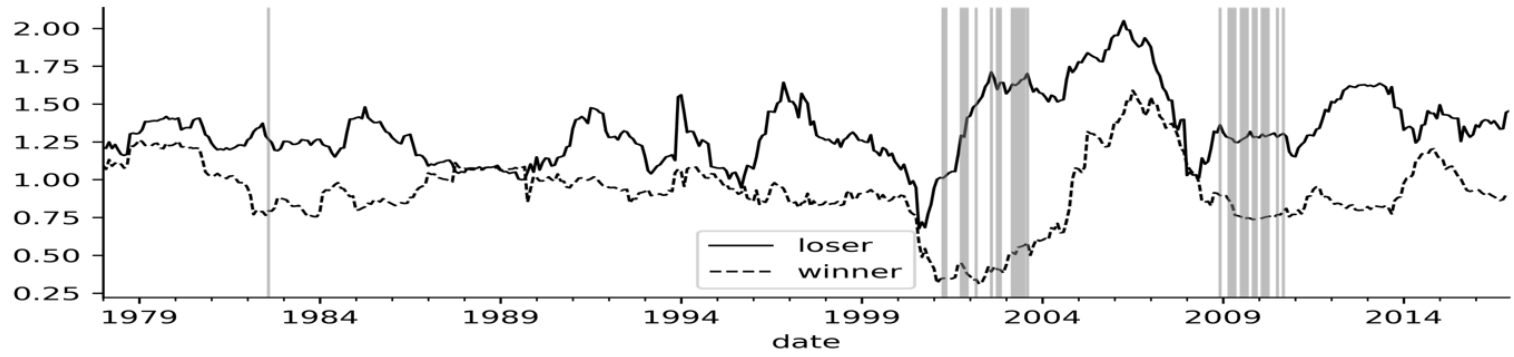

Panel C: Fundamental component

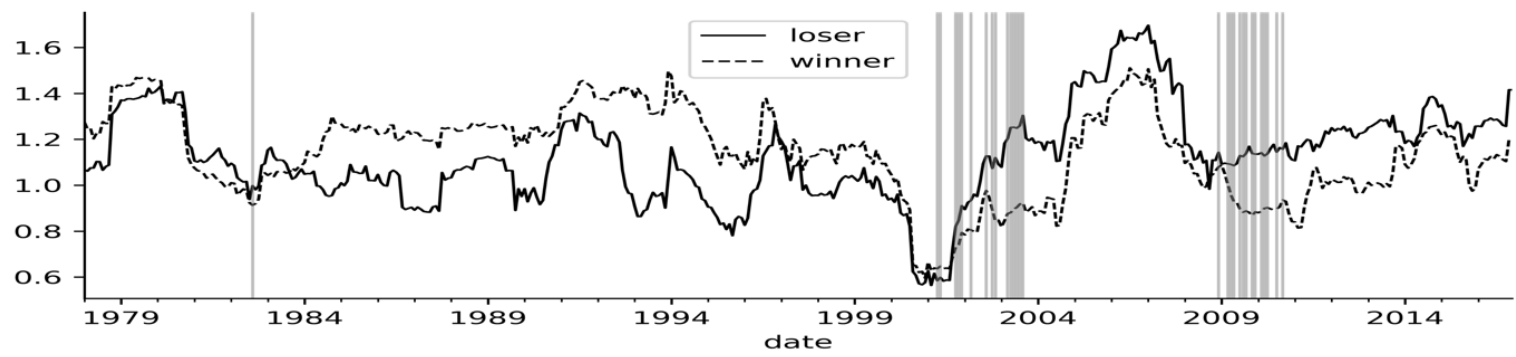


Panel D: PT/MA component

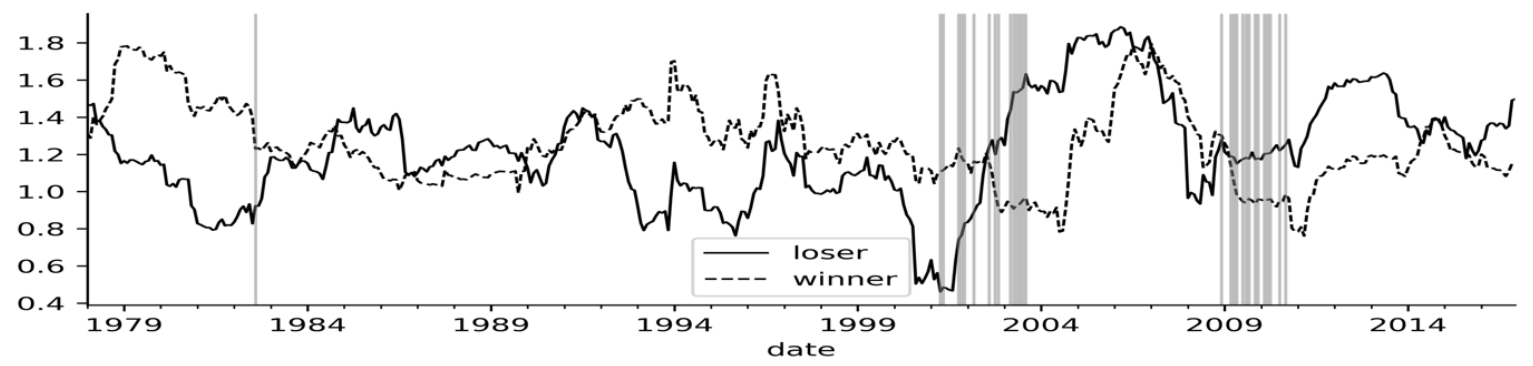

Panel E: Firm characteristics component

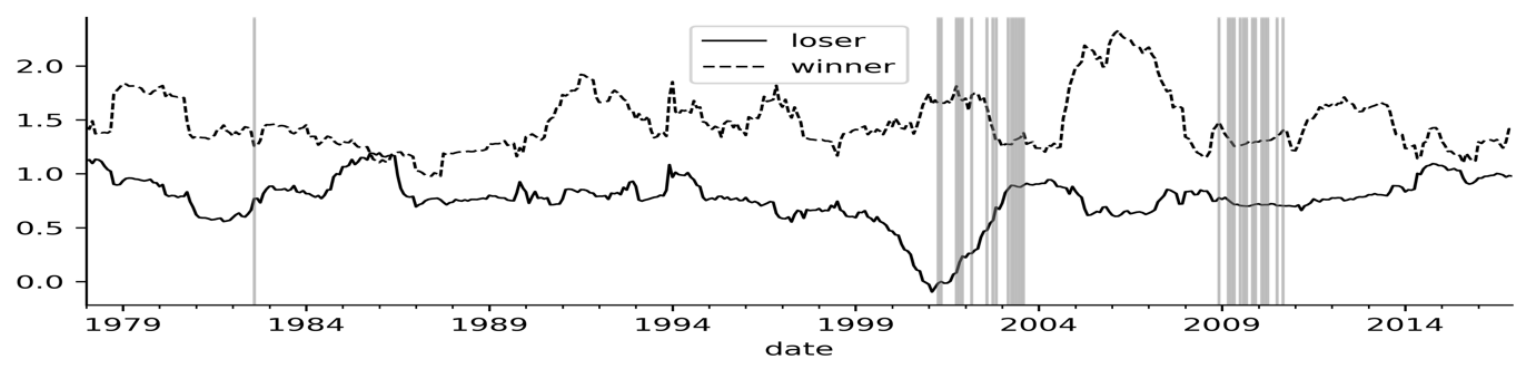

Panel F: Others component

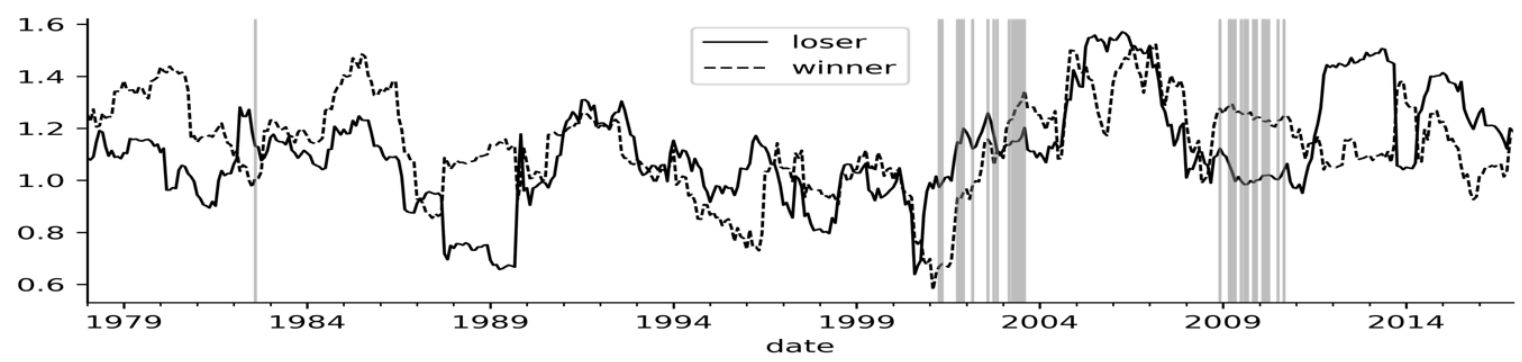

Panel G: Resid component

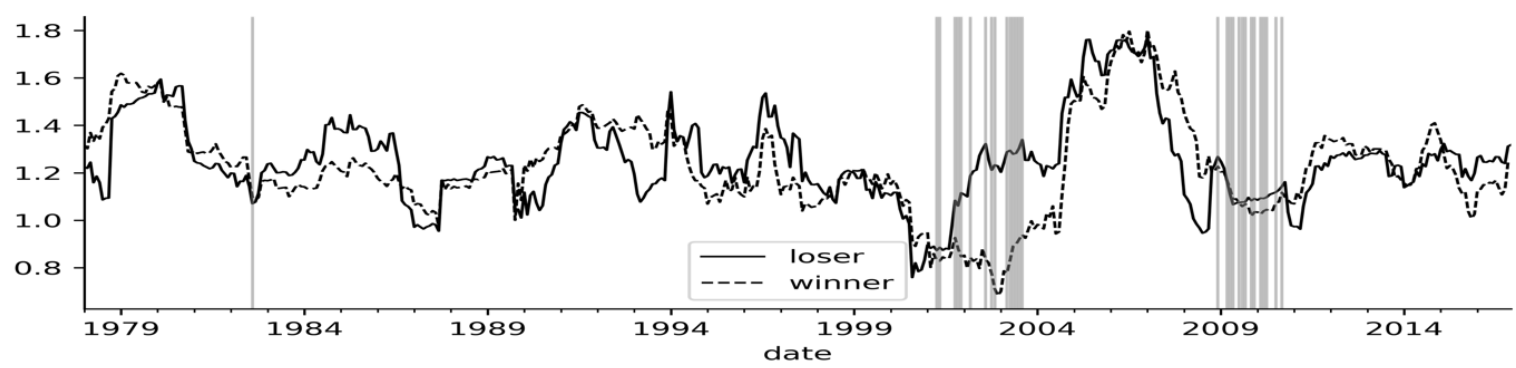


Table 1. Summary statistics and correlations.

This table reports summary statistics and correlations from July 1963 to December 2016. Panel A shows the summary statistics and Panel B reports Pearson correlations. The data is from CRSP and Compustat. US domestic common shares are included and stocks with price less than 5 dollars are excluded. Further, we trim data at $1 \%$ and $99 \%$ percentile. Return $\mathrm{r}$ is the stock monthly return adjusted by book-to-market ratio and market value. r6,1 is the past 6-month return skipping the most recent one month. 52W (52-week-high) is the stock price divided by the highest price in the past 52 weeks in each month. $r 12,7$ is the cumulative return from month t-12 to month $\mathrm{t}-7$ in each month. SUE is the most recent standardized unexpected earnings surprise in each month. CAR is the cumulative abnormal return from one day before and one day after earnings announcement date and abnormal return is stock return minus market return. SUR is the most recent standardized unexpected revenue surprise in each month. CGO is capital gains overhang following Grinblatt and Han (2005). TVOL (total volatility) is standard deviation of returns in each month (minimum 15 days are required). TURN (turnover) is the average of daily turnover in the past 120 days. Daily turnover is number of traded shares divided by number of outstanding shares. DISP (dispersion) is standard deviation of analyst earnings forecasts scaled by stock price. COV (analyst coverage) is number of analysts. RGVOL (revenue growth volatility) is the volatility of firm revenue growth in the past 10 quarters (minimum 5 quarters are required). Firm revenue growth is revenue in current quarter divided by revenue in lagged 4 quarter and minus 1 . COGS (cost of goods sold) is quarterly cost of goods divided by quarterly total assets. IVOL (idiosyncratic volatility) is the standard deviation of residuals from regression on daily return on daily market return in each month (minimum 15 days are required). Industry r6,1 is the past 6-month return in an industry (based on 2 -digit SIC code) in each month. Skew is the skewness of raw daily returns in a month.

Panel A: summary statistics

\begin{tabular}{|c|c|c|c|c|c|c|c|}
\hline & mean & std & $1 \%$ percentile & $25 \%$ percentile & $50 \%$ percentile & $75 \%$ percentile & $99 \%$ percentile \\
\hline $\mathrm{r}$ & -0.001 & 0.117 & -0.288 & -0.060 & -0.005 & 0.051 & 0.350 \\
\hline r6,1 & 0.116 & 0.437 & -0.546 & -0.093 & 0.060 & 0.242 & 1.521 \\
\hline $52 \mathrm{~W}$ & \multicolumn{5}{|c|}{ Anchoring effect } & 0.935 & 1.000 \\
\hline \multicolumn{8}{|c|}{ Fundamental candidates } \\
\hline SUE & 0.134 & 1.145 & -2.469 & -0.550 & 0.112 & 0.790 & 3.016 \\
\hline CAR & 0.005 & 0.063 & -0.161 & -0.029 & 0.002 & 0.036 & 0.186 \\
\hline SUR & 1.185 & 1.717 & -1.916 & -0.035 & 0.961 & 2.263 & 6.033 \\
\hline \multicolumn{8}{|c|}{ Prospect theory and mental accounting candidate } \\
\hline $\mathrm{CGO}$ & -0.102 & 0.530 & -2.148 & -0.282 & 0.020 & 0.230 & 0.661 \\
\hline \multicolumn{8}{|c|}{ Firm characteristics } \\
\hline TVOL & 0.025 & 0.014 & 0.006 & 0.015 & 0.022 & 0.032 & 0.073 \\
\hline DISP & 0.008 & 0.031 & 0.000 & 0.001 & 0.002 & 0.005 & 0.108 \\
\hline TURN & 0.004 & 0.005 & 0.000 & 0.001 & 0.003 & 0.006 & 0.025 \\
\hline $\mathrm{COV}$ & 7.566 & 7.115 & 1 & 2 & 5 & 10 & 31 \\
\hline RGVOL & 0.242 & 0.340 & 0.026 & 0.079 & 0.142 & 0.265 & 1.847 \\
\hline COGS & 0.176 & 0.167 & 0.002 & 0.049 & 0.135 & 0.251 & 0.790 \\
\hline IVOL & 0.023 & 0.013 & 0.005 & 0.013 & 0.020 & 0.029 & 0.067 \\
\hline \multicolumn{8}{|c|}{ Others } \\
\hline $\mathrm{r} 12,7$ & 0.095 & 0.297 & -0.469 & -0.090 & 0.058 & 0.232 & 1.105 \\
\hline Industry r6,1 & 0.106 & 0.136 & -0.194 & 0.018 & 0.099 & 0.188 & 0.470 \\
\hline SK & 0.433 & 0.979 & -2.171 & -0.050 & 0.332 & 0.816 & 3.870 \\
\hline
\end{tabular}


Continued

Panel B: correlations

\begin{tabular}{|c|c|c|c|c|c|c|c|c|c|c|c|c|c|c|c|c|c|}
\hline & $\mathrm{r}$ & r6,1 & $52 \mathrm{~W}$ & SUE & CAR & SUR & CGO & TVOL & DISP & TURN & $\mathrm{COV}$ & RGVOL & COGS & IVOL & $\mathrm{r} 12,7$ & Industry r6,1 & SK \\
\hline $\mathrm{r}$ & 1 & 0.020 & 0.027 & 0.032 & 0.027 & 0.022 & 0.012 & -0.023 & -0.024 & -0.003 & 0.000 & -0.009 & 0.007 & -0.023 & 0.016 & 0.012 & -0.003 \\
\hline r6,1 & 0.020 & 1 & 0.391 & 0.150 & 0.116 & 0.061 & 0.283 & 0.034 & -0.058 & 0.111 & -0.043 & 0.043 & 0.041 & 0.038 & 0.005 & 0.341 & 0.219 \\
\hline $52 \mathrm{~W}$ & 0.027 & 0.391 & 1 & 0.293 & 0.099 & 0.066 & 0.458 & -0.347 & -0.133 & -0.126 & 0.052 & -0.101 & -0.039 & -0.334 & 0.112 & 0.235 & 0.127 \\
\hline SUE & 0.032 & 0.150 & 0.293 & 1 & 0.151 & 0.291 & 0.204 & -0.048 & -0.076 & 0.002 & 0.004 & -0.015 & 0.031 & -0.049 & 0.131 & 0.008 & 0.068 \\
\hline CAR & 0.027 & 0.116 & 0.099 & 0.151 & 1 & 0.089 & 0.058 & 0.032 & -0.037 & 0.019 & -0.008 & -0.004 & 0.020 & 0.030 & 0.011 & 0.012 & 0.175 \\
\hline SUR & 0.022 & 0.061 & 0.066 & 0.291 & 0.089 & 1 & 0.191 & -0.021 & -0.102 & 0.049 & 0.085 & -0.113 & 0.092 & -0.022 & 0.140 & -0.015 & 0.001 \\
\hline CGO & 0.012 & 0.283 & 0.458 & 0.204 & 0.058 & 0.191 & 1 & -0.179 & -0.143 & 0.033 & -0.007 & 0.002 & 0.020 & -0.165 & 0.261 & 0.143 & 0.051 \\
\hline TVOL & -0.023 & 0.034 & -0.347 & -0.048 & 0.032 & -0.021 & -0.179 & 1 & 0.125 & 0.264 & -0.188 & 0.185 & 0.054 & 0.969 & 0.013 & -0.004 & 0.064 \\
\hline DISP & -0.024 & -0.060 & -0.133 & -0.076 & -0.037 & -0.102 & -0.143 & 0.125 & 1 & 0.028 & -0.062 & 0.110 & -0.016 & 0.133 & -0.060 & -0.007 & 0.021 \\
\hline TURN & -0.003 & 0.111 & -0.126 & 0.002 & 0.019 & 0.049 & 0.033 & 0.264 & 0.028 & 1 & 0.177 & 0.125 & -0.031 & 0.208 & 0.082 & 0.045 & -0.041 \\
\hline $\mathrm{COV}$ & 0.000 & -0.040 & 0.052 & 0.004 & -0.008 & 0.085 & -0.007 & -0.188 & -0.062 & 0.177 & 1 & -0.1 & -0.086 & -0.236 & -0.017 & -0.024 & -0.107 \\
\hline RGVOL & -0.009 & 0.043 & -0.101 & -0.015 & -0.004 & -0.113 & 0.002 & 0.185 & 0.110 & 0.125 & -0.100 & 1 & -0.092 & 0.191 & 0.029 & 0.019 & 0.040 \\
\hline COGS & 0.007 & 0.041 & -0.039 & 0.031 & 0.020 & 0.092 & 0.020 & 0.054 & -0.016 & -0.031 & -0.086 & -0.092 & 1 & 0.069 & 0.038 & 0.037 & 0.029 \\
\hline IVOL & -0.023 & 0.038 & -0.334 & -0.049 & 0.030 & -0.022 & -0.165 & 0.969 & 0.133 & 0.208 & -0.236 & 0.191 & 0.069 & 1 & 0.008 & 0.015 & 0.080 \\
\hline $\mathrm{r} 12,7$ & 0.016 & 0.005 & 0.112 & 0.131 & 0.011 & 0.140 & 0.261 & 0.013 & -0.06 & 0.082 & -0.017 & 0.029 & 0.038 & 0.008 & 1 & -0.050 & -0.036 \\
\hline Industry r6,1 & 0.012 & 0.341 & 0.235 & 0.008 & 0.012 & -0.015 & 0.143 & -0.004 & -0.007 & 0.045 & -0.024 & 0.019 & 0.037 & 0.015 & -0.050 & 1 & 0.100 \\
\hline SK & -0.003 & 0.219 & 0.127 & 0.068 & 0.175 & 0.001 & 0.051 & 0.064 & 0.021 & -0.041 & -0.107 & 0.040 & 0.029 & 0.080 & -0.036 & 0.1 & 1 \\
\hline
\end{tabular}


Table 2. Momentum and stock returns.

This table reports coefficient of past 6-month return and all candidate variables. The coefficient is estimated from Fama-MacBeth (1973) regression. Specifically, we run cross-sectional regression of stock return adjusted by book-to-market ratio and market value on past 6-month return and other candidate variable in each month, and then we calculate the time-series average of slopes from cross-sectional regression. The $t$-statistics (in parentheses) are based on Newey-West standard error. r6,1 is the past 6-month return skipping the most recent one month. 52W (52-week-high) is the stock price divided by the highest price in the past 52 weeks in each month. r12,7 is the cumulative return from month t-12 to month t-7 in each month. SUE is the most recent standardized unexpected earnings surprise in each month. CAR is cumulative abnormal return from one day before and one day after earnings announcement date and abnormal return is stock return minus market return. SUR is the most recent standardized unexpected revenue surprise in each month. CGO is capital gains overhang following Grinblatt and Han (2005). TVOL (total volatility) is standard deviation of returns in each month (minimum 15 days are required). TURN (turnover) is the average of daily turnover in the past 120 days. Daily turnover is number of traded shares divided by number of outstanding shares. DISP (dispersion) is standard deviation of analyst earnings forecasts scaled by stock price. COV (analyst coverage) is number of analysts. RGVOL (revenue growth volatility) is the volatility of firm revenue growth in the past 10 quarters (minimum 5 quarters are required). Firm revenue growth is revenue in current quarter divided by revenue in lagged 4 quarter and minus 1. COGS (cost of goods sold) is quarterly cost of goods divided by quarterly total assets. IVOL (idiosyncratic volatility) is the standard deviation of residuals from regression on daily return on daily market return in each month (minimum 15 days are required). Industry r6,1 is the past 6-month return in an industry (based on 2-digit SIC code) in each month. Skew is the skewness of raw daily returns in a month. $*, * *$, and $* * *$ indicate significance level at the $10 \%, 5 \%$ and $1 \%$ respectively.

\begin{tabular}{|c|c|c|c|c|c|c|c|c|}
\hline & Model 1 & Model 2 & Model 3 & Model 4 & Model 5 & Model 6 & Model 7 & Model 8 \\
\hline Intercept & $\begin{array}{c}-0.0020 \text { **** } \\
(-3.30)\end{array}$ & $\begin{array}{c}-0.0115 * * * \\
(-6.43)\end{array}$ & $\begin{array}{c}-0.0017^{* * *} \\
(-2.29)\end{array}$ & $\begin{array}{c}-0.0016^{* *} \\
(-2.16)\end{array}$ & $\begin{array}{c}-0.0031^{* * *} \\
(-4.30)\end{array}$ & $\begin{array}{c}-0.0014^{* *} \\
(-2.03)\end{array}$ & $\begin{array}{c}0.0039^{* * * *} \\
(3.08)\end{array}$ & $\begin{array}{l}-0.0011 \\
(-1.45)\end{array}$ \\
\hline $\mathrm{r} 6,1$ & $\begin{array}{c}0.0084 * * * * \\
(4.91)\end{array}$ & $\begin{array}{c}0.0061 \text { **** } \\
(4.32)\end{array}$ & $\begin{array}{c}0.0020 \\
(1.02)\end{array}$ & $\begin{array}{c}0.0037 * \\
(1.85)\end{array}$ & $\begin{array}{c}0.0041^{* *} \\
(2.04)\end{array}$ & $\begin{array}{c}0.0056 * * * \\
(3.50)\end{array}$ & $\begin{array}{c}0.0089 * * * \\
(5.62)\end{array}$ & $\begin{array}{c}0.0075 * * * \\
(3.27)\end{array}$ \\
\hline $52 \mathrm{~W}$ & & $\begin{array}{c}0.0121 * * * \\
(4.56)\end{array}$ & & & & & & \\
\hline SUE & & & $\begin{array}{c}0.0031 * * * \\
(17.48)\end{array}$ & & & & & \\
\hline CAR & & & & $\begin{array}{c}0.0511 * * * \\
(16.78)\end{array}$ & & & & \\
\hline SUR & & & & & $\begin{array}{c}0.0014 * * * \\
(9.89)\end{array}$ & & & \\
\hline CGO & & & & & & $\begin{array}{c}0.0015^{* *} \\
(2.22)\end{array}$ & & \\
\hline TVOL & & & & & & & $\begin{array}{c}-0.2538 * * * \\
(-7.71)\end{array}$ & \\
\hline DISP & & & & & & & & $\begin{array}{c}-0.0992 * * * \\
(-8.39)\end{array}$ \\
\hline Avg adj $R^{2}$ & 0.010 & 0.015 & 0.012 & 0.012 & 0.012 & 0.015 & 0.018 & 0.015 \\
\hline Avg stock & 2726 & 2640 & 2214 & 2112 & 1961 & 1815 & 2677 & 2027 \\
\hline Start date & 196308 & 196308 & 197402 & 197402 & 197402 & 196308 & 196308 & 197602 \\
\hline End date & 201612 & 201612 & 201612 & 201612 & 201612 & 201612 & 201612 & 201612 \\
\hline
\end{tabular}




\begin{tabular}{|c|c|c|c|c|c|c|c|c|}
\hline & Model 9 & Model 10 & Model 11 & Model 12 & Model 13 & Model 14 & Model 15 & Model 16 \\
\hline Intercept & $\begin{array}{c}-0.0005 \\
(-0.55)\end{array}$ & $\begin{array}{c}-0.0017^{*} \\
(-1.91)\end{array}$ & $\begin{array}{c}-0.0005 \\
(-0.64)\end{array}$ & $\begin{array}{c}-0.0028 * * * \\
(-3.40)\end{array}$ & $\begin{array}{c}0.0036^{* * * *} \\
(3.29)\end{array}$ & $\begin{array}{c}-0.0027 * * * \\
(-3.94)\end{array}$ & $\begin{array}{c}-0.0029^{* * * *} \\
(-3.11)\end{array}$ & $\begin{array}{c}-0.0014^{* *} \\
(-2.31)\end{array}$ \\
\hline $\mathrm{r} 6,1$ & $\begin{array}{c}0.0099 * * * \\
(5.97)\end{array}$ & $\begin{array}{c}0.0084^{* * * * *} \\
(3.89)\end{array}$ & $\begin{array}{c}0.0052 * * \\
(2.57)\end{array}$ & $\begin{array}{c}0.0068^{* * * *} \\
(3.36)\end{array}$ & $\begin{array}{c}0.0088^{* * * *} \\
(5.34)\end{array}$ & $\begin{array}{c}0.0080^{* * * *} \\
(4.67)\end{array}$ & $\begin{array}{c}0.0085^{* * * *} \\
(6.03)\end{array}$ & $\begin{array}{c}0.0093 * * * \\
(5.24)\end{array}$ \\
\hline TURN & $\begin{array}{c}-0.6702 * * * \\
(-3.52)\end{array}$ & & & & & & & \\
\hline $\mathrm{COV}$ & & $\begin{array}{c}-0.0000 \\
(-0.54)\end{array}$ & & & & & & \\
\hline RGVOL & & & $\begin{array}{c}-0.0035 * * * \\
(-3.67)\end{array}$ & & & & & \\
\hline COGS & & & & $\begin{array}{c}0.0051^{* * * *} \\
(2.97)\end{array}$ & & & & \\
\hline IVOL & & & & & $\begin{array}{c}-0.2717 * * * \\
(-8.94)\end{array}$ & & & \\
\hline $\mathrm{r} 12,7$ & & & & & & $\begin{array}{c}0.0074 * * * \\
(5.83)\end{array}$ & & \\
\hline Industry r6,1 & & & & & & & $\begin{array}{c}0.0096^{*} \\
(1.86)\end{array}$ & \\
\hline SK & & & & & & & & $\begin{array}{c}-0.0013^{* * * *} \\
(-6.68)\end{array}$ \\
\hline Avg adj $R^{2}$ & 0.021 & 0.012 & 0.012 & 0.013 & 0.016 & 0.014 & 0.013 & 0.011 \\
\hline Avg stock & 2509 & 2353 & 1997 & 2490 & 2677 & 2634 & 2674 & 2678 \\
\hline Start date & 196308 & 197602 & 197402 & 197402 & 196308 & 196308 & 196308 & 196308 \\
\hline End date & 201612 & 201612 & 201612 & 201612 & 201612 & 201612 & 201612 & 201612 \\
\hline
\end{tabular}


Table 3. Decompose momentum: univariate analysis.

This table reports slopes of decomposed components and fractions of each candidate. In stage 1 , the regression model is $r_{i t}=\alpha_{t}+\beta_{t} r 6,1_{i t-1}+\varepsilon_{i t}$. In stage 2 , a candidate variable is added to the regression model: $r_{i, t}=\widetilde{\alpha}_{t}+\widetilde{\beta_{t}^{R}} r 6,1_{i, t-1}+\widetilde{\beta_{t}^{C}}$ candidate $e_{i, t-1}+\widetilde{\varepsilon}_{i, t}$. In stage 3, we run regression of past 6 -month return on candidate variable: r6, $1_{\mathrm{i}, \mathrm{t}-1}=\mu_{\mathrm{t}-1}+\delta_{\mathrm{t}-1}$ Candidate $_{\mathrm{i}, \mathrm{t}-1}+\varphi_{\mathrm{i}, \mathrm{t}-1}$, then past 6-month return is decomposed to two orthogonal components: $\delta_{\mathrm{t}-1}$ candidate $_{\mathrm{it}-1}$ and $\mu_{\mathrm{t}-1}+\varphi_{\mathrm{it}-1}$. In stage 4 , the coefficient $\beta_{\mathrm{t}}$ is decomposed as $\beta_{\mathrm{t}}=\frac{\operatorname{Cov}\left[\mathrm{r}_{\mathrm{t}}, \mathrm{r} 6,1_{\mathrm{it}-1}\right]}{\operatorname{Var}\left[\mathrm{r} 6,1_{\mathrm{it}-1}\right]}=\frac{\operatorname{Cov}\left[\mathrm{r}_{\mathrm{it}}, \delta_{\mathrm{t}-1} \mathrm{candidate}_{\mathrm{it}-1}\right]}{\operatorname{Var}\left[\mathrm{r} 6,1_{\mathrm{it}-1}\right]}+\frac{\operatorname{Cov}\left(\left[\mathrm{r}_{\mathrm{it}},\left(\mu_{\mathrm{t}-1}+\varphi_{\mathrm{it}-1}\right)\right]\right.}{\operatorname{Var}\left[\mathrm{r} 6,1_{\mathrm{it}-1}\right]}=\beta_{\mathrm{t}}^{\mathrm{C}}+\beta_{\mathrm{t}}^{\mathrm{R}}$. The time-series average of $\beta_{\mathrm{t}}^{\mathrm{C}}$ divided by the time-series

average of $\beta_{t}$ then measures the fraction of candidate contribution and the time-series average of $\beta_{t}^{R}$ divided by the time-series average of $\beta_{t}$ measures the fraction of residual contribution. The standard errors of the fractions are based on multivariate delta method. r6,1 is past 6-month return skipping the most recent one month. 52W (52-week-high) is the stock price divided by the highest price in the past 52 weeks in each month. $\mathrm{r} 12,7$ is the cumulative return from month t-12 to month t-7 in each month. SUE is the most recent standardized unexpected earnings surprise in each month. CAR is cumulative abnormal return from one day before and one day after earnings announcement date and abnormal return is stock return minus market return. SUR is the most recent standardized unexpected revenue surprise in each month. CGO is capital gains overhang following Grinblatt and Han (2005). TVOL (total volatility) is standard deviation of returns in each month (minimum 15 days are required). TURN (turnover) is the average of daily turnover in the past 120 days. Daily turnover is number of traded shares divided by number of outstanding shares. DISP (dispersion) is standard deviation of analyst earnings forecasts scaled by stock price. COV (analyst coverage) is number of analysts. RGVOL (revenue growth volatility) is the volatility of firm revenue growth in the past 10 quarters (minimum 5 quarters are required). Firm revenue growth is revenue in current quarter divided by revenue in lagged 4 quarter and minus 1 . COGS (cost of goods sold) is quarterly cost of goods divided by quarterly total assets. IVOL (idiosyncratic volatility) is the standard deviation of residuals from regression on daily return on daily market return in each month (minimum 15 days are required). Industry r6, 1 is the past 6-month return in an industry (based on 2 -digit SIC code) in each month. Skew is the skewness of raw daily returns in a month. $*, * *$, and $* * *$ indicate significance level at the $10 \%, 5 \%$ and $1 \%$ respectively.

\begin{tabular}{|c|c|c|c|c|c|c|c|c|c|c|c|c|}
\hline \multirow{4}{*}{$\frac{\text { Stage }}{1}$} & \multirow{3}{*}{$\begin{array}{c}\text { Description } \\
\text { Return on } \mathrm{r} 6,1\end{array}$} & \multirow{4}{*}{$\begin{array}{c}\text { Variable } \\
\text { Intercept } \\
\text { r6,1 }\end{array}$} & \multirow{2}{*}{\multicolumn{2}{|c|}{$\frac{\text { Panel A: Anchoring }}{52 \mathrm{~W}}$}} & \multicolumn{6}{|c|}{ Panel B: Fundamental } & \multicolumn{2}{|c|}{ Panel C: PT/MA } \\
\hline & & & & & \multicolumn{2}{|c|}{ SUE } & \multicolumn{2}{|c|}{ CAR } & \multicolumn{2}{|c|}{ SUR } & \multicolumn{2}{|c|}{ CGO } \\
\hline & & & $-0.0018 * * *$ & $(-2.98)$ & $-0.0014 *$ & $(-1.90)$ & $-0.0015^{* *}$ & $(-2.03)$ & $-0.0013^{*}$ & $(-1.82)$ & $-0.0014 * *$ & $(-2.22)$ \\
\hline & & & $0.0083 * * *$ & $(5.20)$ & $0.0049 * *$ & $(2.47)$ & $0.0052 * * *$ & $(2.60)$ & $0.0050 * *$ & $(2.48)$ & $0.0065 * * *$ & (3.57) \\
\hline \multirow[t]{3}{*}{2} & Add candidate & Intercept & $-0.0115 * * *$ & $(-6.43)$ & $-0.0017 * *$ & $(-2.29)$ & $-0.0016^{* *}$ & $(-2.16)$ & $-0.0031 * * *$ & $(-4.30)$ & $-0.0014 * *$ & $(-2.03)$ \\
\hline & & $\mathrm{r} 6,1$ & $0.0061 * * *$ & $(4.32)$ & 0.0020 & $(1.02)$ & $0.0037^{*}$ & $(1.85)$ & $0.0041^{* *}$ & $(2.04)$ & $0.0056^{* * * *}$ & $(3.50)$ \\
\hline & & Candidate & $0.0121 * * *$ & $(4.56)$ & $0.0031 * * *$ & (17.48) & $0.0511 * * *$ & (16.78) & $0.0014 * * *$ & $(9.89)$ & $0.0015 * *$ & $(2.22)$ \\
\hline \multirow[t]{3}{*}{3} & $\mathrm{r} 6,1$ on & Intercept & $-0.5599 * * *$ & $(-54.82)$ & $0.1045^{* * *}$ & (11.53) & $0.1052 * * *$ & (12.08) & $0.0903 * * *$ & $(9.49)$ & $0.1120 * * *$ & (15.96) \\
\hline & candidate & Candidate & $0.8518 * * *$ & (74.69) & $0.0552 * * *$ & (45.34) & $0.7312 * * *$ & (39.45) & $0.0203^{* * *} *$ & (22.07) & $0.1997 * * *$ & $(35.32)$ \\
\hline & & Avg adj. $R^{2}$ & 0.219 & & 0.047 & & 0.025 & & 0.017 & & 0.123 & \\
\hline \multirow[t]{7}{*}{4} & Decompose & Candidate compo. & 0.0033 & & 0.0029 & & 0.0016 & & 0.0010 & & 0.0013 & \\
\hline & r6, 1 coeff. & Candidate frac. & $39.76 \% * * *$ & $(5.01)$ & $59.18 \%$ *** & $(2.94)$ & $30.77 \% * * *$ & $(2.93)$ & $20.00 \% * * *$ & $(2.95)$ & $20.00 \% * * *$ & $(3.26)$ \\
\hline & In Stage 1 & Residual compo. & 0.0050 & & 0.0020 & & 0.0036 & & 0.0040 & & 0.0052 & \\
\hline & & Residual frac. & $60.24 \% * * *$ & (7.55) & $40.82 \% * *$ & $(2.06)$ & $69.23 \% * * *$ & $(6.41)$ & $80.00 \% * * *$ & (11.83) & $80.00 \%$ *** & (12.31) \\
\hline & Avg stock/month & & 2640 & & 2214 & & 2112 & & 1961 & & 1815 & \\
\hline & Start date & & 196308 & & 197402 & & 197402 & & 197402 & & 196308 & \\
\hline & End date & & 201612 & & 201612 & & 201612 & & 201612 & & 201612 & \\
\hline
\end{tabular}


Continued

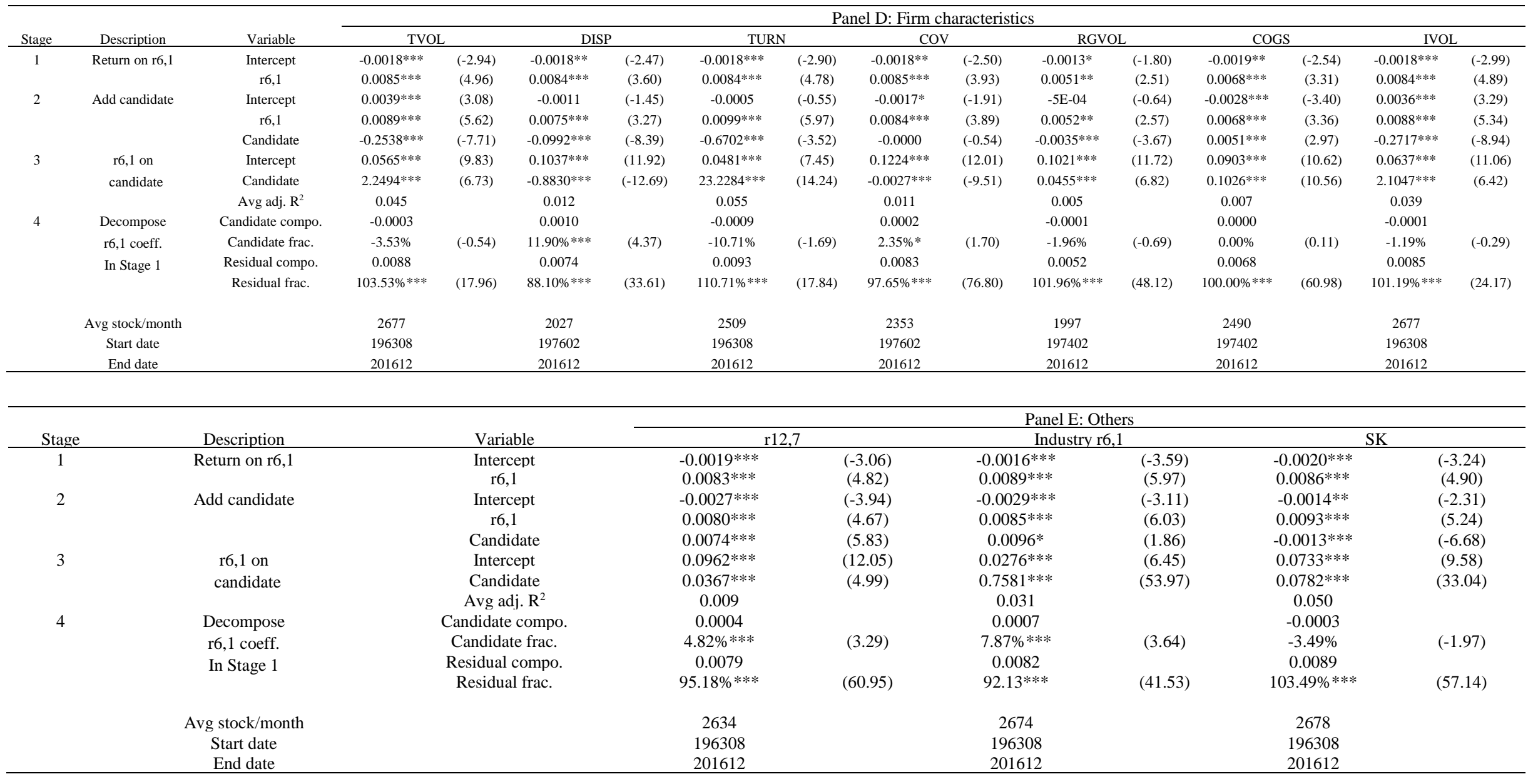


Table 4. Decompose momentum: interaction effects

This table reports slopes of decomposed components and fractions of each candidate with its interaction (candidates include both candidate per se and its interaction with past 6-month return). Past 6-month return and candidate variables are ranked into deciles. CharRank is the decile rank of a candidate variable and r6,1Rank is the decile rank of past 6-month return. The standard errors of the fractions are based on multivariate delta method. r6,1 is past 6-month return skipping the most recent one month. TVOL (total volatility) is standard deviation of returns in each month (minimum 15 days are required). TURN (turnover) is the average of daily turnover in the past 120 days. Daily turnover is number of traded shares divided by number of outstanding shares. DISP (dispersion) is standard deviation of analyst earnings forecasts scaled by stock price. COV (analyst coverage) is number of analysts. RGVOL (revenue growth volatility) is the volatility of firm revenue growth in the past 10 quarters (minimum 5 quarters are required). Firm revenue growth is revenue in current quarter divided by revenue in lagged 4 quarter and minus 1 . COGS (cost of goods sold) is quarterly cost of goods divided by quarterly total assets. IVOL (idiosyncratic volatility) is the standard deviation of residuals from regression on daily return on daily market return in each month (minimum 15 days are required). $*, * *$, and $* * *$ indicate significance level at the $10 \%, 5 \%$ and $1 \%$ respectively.

\begin{tabular}{|c|c|c|c|c|c|c|c|c|c|c|}
\hline \multirow{2}{*}{$\begin{array}{l}\text { Stage } \\
1\end{array}$} & \multirow{2}{*}{$\begin{array}{c}\text { Description } \\
\text { Return on r6,1 }\end{array}$} & \multirow{2}{*}{$\begin{array}{l}\text { Variable } \\
\text { Intercept }\end{array}$} & \multicolumn{2}{|c|}{ TVOL } & \multicolumn{2}{|c|}{ DISP } & \multicolumn{2}{|c|}{ TURN } & \multicolumn{2}{|c|}{$\mathrm{COV}$} \\
\hline & & & $-0.0018 * * *$ & $(-2.94)$ & $-0.0018 * *$ & $(-2.47)$ & $-0.0018 * * *$ & $(-2.90)$ & $-0.0018 * *$ & $(-2.50)$ \\
\hline & & r6,1Rank & $0.0085^{* * *}$ & $(4.96)$ & $0.0084 * * *$ & $(3.60)$ & $0.0084 * * *$ & $(4.78)$ & $0.0085^{* * *}$ & (3.93) \\
\hline \multirow[t]{4}{*}{2} & \multirow[t]{4}{*}{ Add candidate } & Intercept & $0.0022 *$ & (1.93) & $0.0045^{* * *}$ & $(4.02)$ & -0.0001 & $(-0.05)$ & $-0.0014 *$ & $(-1.79)$ \\
\hline & & r6,1Rank & $0.0039 * * *$ & $(2.96)$ & $0.0065 * * *$ & $(3.23)$ & $0.0078 * * *$ & $(5.74)$ & $0.0106^{* * *}$ & $(5.70)$ \\
\hline & & CharRank & $-0.0012 * * *$ & $(-6.26)$ & $-0.0011^{*} * *$ & $(-4.89)$ & $-0.0004 *$ & $(-1.75)$ & 0.0001 & $(1.31)$ \\
\hline & & CharRank*r6,1Rank & $0.0001 * * *$ & $(5.26)$ & -0.0000 & $(-0.19)$ & $0.0000 * *$ & (1.98) & $-0.0000^{*}$ & $(-1.83)$ \\
\hline \multirow[t]{4}{*}{3} & \multirow{4}{*}{$\begin{array}{l}\text { r6,1 on } \\
\text { candidate }\end{array}$} & Intercept & $0.0562 * * *$ & (9.79) & $0.1219 * * *$ & (14.67) & $0.0476 * * *$ & (7.49) & $0.1187 * * *$ & (12.44) \\
\hline & & CharRank & $-0.0644 * * *$ & $(-79.52)$ & $-0.0700 * * *$ & $(-50.92)$ & $-0.0632 * * *$ & $(-70.99)$ & $-0.0377 * * *$ & $(-42.94)$ \\
\hline & & CharRank*r6,1Rank & $0.0134 * * *$ & $(59.17)$ & $0.0128 * * *$ & $(51.80)$ & $0.0131 * * *$ & $(57.30)$ & $0.0067 * * *$ & $(46.46)$ \\
\hline & & Avg adj. $R^{2}$ & 0.667 & & 0.636 & & 0.675 & & 0.359 & \\
\hline \multirow[t]{9}{*}{4} & \multirow{6}{*}{$\begin{array}{l}\text { Decompose } \\
\text { r6, } 1 \text { coeff. } \\
\text { In Stage } 1\end{array}$} & CharRank compo. & 0.003 & & 0.0085 & & -0.0004 & & 0.0009 & \\
\hline & & CharRank frac. & $35.29 \% * * *$ & $(2.87)$ & $101.19 \% * * *$ & $(4.64)$ & $-4.76 \%$ & $(-0.30)$ & $10.59 \%$ & $(1.33)$ \\
\hline & & CharRank*r6,1Rank compo. & 0.0043 & & -0.0027 & & 0.0065 & & 0.0007 & \\
\hline & & CharRank*r6,1Rank frac. & $50.59 \% * * *$ & $(4.42)$ & $-32.14 \%$ & $(-1.41)$ & $77.38 \% * * *$ & $(5.78)$ & $8.24 \%$ & $(0.68)$ \\
\hline & & Residual compo. & 0.0012 & & 0.0026 & & 0.0023 & & 0.0069 & \\
\hline & & Residual frac. & $14.12 \% * * *$ & $(4.34)$ & $30.95 \% * * *$ & $(5.13)$ & $27.38 \% * * *$ & $(6.37)$ & $81.18 \% * * *$ & (7.69) \\
\hline & Avg stock/month & & 2677 & & 2027 & & 2509 & & 2353 & \\
\hline & Start date & & 196308 & & 197602 & & 196308 & & 197602 & \\
\hline & End date & & 201612 & & 201612 & & 201612 & & 201612 & \\
\hline
\end{tabular}




\begin{tabular}{|c|c|c|c|c|c|c|c|c|}
\hline \multirow{2}{*}{$\begin{array}{c}\text { Stage } \\
1\end{array}$} & \multirow{2}{*}{$\begin{array}{c}\text { Description } \\
\text { Return on } \mathrm{r} 6,1\end{array}$} & \multirow{2}{*}{$\begin{array}{l}\text { Variable } \\
\text { Intercept }\end{array}$} & \multicolumn{2}{|c|}{ RGVOL } & \multicolumn{2}{|c|}{ COGS } & \multicolumn{2}{|c|}{ IVOL } \\
\hline & & & $-0.0013^{*}$ & $(-1.80)$ & $-0.0019 * *$ & $(-2.54)$ & $-0.0018 * * *$ & $(-2.99)$ \\
\hline & & r6,1Rank & $0.0051^{* *}$ & $(2.51)$ & $0.0068 * * *$ & $(3.31)$ & $0.0084 * * *$ & $(4.89)$ \\
\hline \multirow[t]{4}{*}{2} & \multirow[t]{4}{*}{ Add candidate } & Intercept & 0.0014 & $(1.25)$ & $-0.0029 * * *$ & $(-2.79)$ & $0.0022 * *$ & $(2.04)$ \\
\hline & & r6,1Rank & 0.0018 & $(1.01)$ & $0.0072 * * *$ & $(3.61)$ & $0.0037 * * *$ & (2.59) \\
\hline & & CharRank & $-0.0008 * * *$ & $(-4.16)$ & 0.0002 & $(1.11)$ & $-0.0012 * * *$ & $(-6.93)$ \\
\hline & & CharRank*r6,1Rank & $0.0001 * * *$ & $(3.41)$ & 0.0000 & $(0.76)$ & $0.0001 * * *$ & $(5.54)$ \\
\hline \multirow[t]{4}{*}{3} & \multirow{4}{*}{$\begin{array}{l}\mathrm{r} 6,1 \text { on } \\
\text { candidate }\end{array}$} & Intercept & $0.0843 * * *$ & $(10.37)$ & $0.0897 * * *$ & (11.11) & $0.0580 * * *$ & $(9.84)$ \\
\hline & & CharRank & $-0.0698 * * *$ & $(-52.54)$ & $-0.0715 * * *$ & $(-52.29)$ & $-0.0648 * * *$ & $(-77.90)$ \\
\hline & & CharRank*r6,1Rank & $0.0136^{* * *}$ & $(47.30)$ & $0.0136^{* * *}$ & $(49.04)$ & $0.0135 * * *$ & $(58.40)$ \\
\hline & & Avg adj. $\mathbf{R}^{2}$ & 0.627 & & 0.592 & & 0.667 & \\
\hline \multirow[t]{9}{*}{4} & \multirow{6}{*}{$\begin{array}{l}\text { Decompose } \\
\text { r6,1 coeff. } \\
\text { In Stage } 1\end{array}$} & CharRank compo. & 0.0022 & & -0.0028 & & 0.0032 & \\
\hline & & CharRank frac. & $43.14 \% *$ & $(1.83)$ & $-41.18 \%$ & $(-2.40)$ & $38.10 \% * * *$ & (3.46) \\
\hline & & CharRank*r6,1Rank compo. & 0.0022 & & 0.0068 & & 0.0041 & \\
\hline & & CharRank*r6,1Rank frac. & $43.14 \% * *$ & $(2.02)$ & $100.00 \% * * *$ & $(6.63)$ & $48.81 \%$ **** & $(4.81)$ \\
\hline & & Residual compo. & 0.0007 & & 0.0028 & & 0.0011 & \\
\hline & & Residual frac. & $13.73 \% *$ & $(1.79)$ & $41.18 \% * * *$ & $(5.89)$ & $13.10 \% * * *$ & (3.93) \\
\hline & Avg stock/month & & 1997 & & 2490 & & 2677 & \\
\hline & Start date & & 197402 & & 197402 & & 196308 & \\
\hline & End date & & 201612 & & 201612 & & 201612 & \\
\hline
\end{tabular}


Table 5. Decompose momentum: multivariate analysis.

This table reports slopes of decomposed components and fractions of each candidate. In stage 1, the regression model is $r_{i t}=\alpha_{t}+\beta_{t} r 6,1_{i t-1}+\varepsilon_{i t}$. In stage 2, a candidate variable is added to the regression model: $r_{i, t}=\widetilde{\alpha}_{t}+$ $\widetilde{\beta_{\mathrm{t}}^{\mathrm{R}}} \mathrm{r} 6,1_{\mathrm{i}, \mathrm{t}-1}+\sum_{\mathrm{k}=1}^{\mathrm{n}} \widetilde{\beta_{\mathrm{kt}}^{\mathrm{C}}}$ candidate $_{\mathrm{ki}, \mathrm{t}-1}+\widetilde{\varepsilon}_{\mathrm{i}, \mathrm{t}}$. In stage 3, we run regression of past 6-month return on candidate variable: $\mathrm{r} 6,1_{\mathrm{it}-1}=\mu_{\mathrm{t}-1}+\sum_{\mathrm{k}=1}^{\mathrm{n}} \delta_{\mathrm{kt}-1}$ candidate $_{\mathrm{kit}-1}+\varphi_{\mathrm{it}-1}$, then past 6-month return is decomposed into orthogonal components: $\delta_{1 \mathrm{t}-1}$ candidate $_{1 \mathrm{it}-1}, \delta_{2 \mathrm{t}-1}$ candidate $_{2 \mathrm{it}-1}, \ldots, \delta_{\mathrm{nt}-1}$ candidate $_{\mathrm{nit}-1}$ and $\mu_{\mathrm{t}-1}+\varphi_{\mathrm{it}-1}$.

In stage 4 , the coefficient $\beta_{\mathrm{t}}$ is decomposed as $\beta_{\mathrm{t}}=\frac{\operatorname{Cov}\left[\mathrm{r}_{\mathrm{it}}, \mathrm{r} 6,1_{\mathrm{it}-1}\right]}{\operatorname{Var}\left[\mathrm{r} 6,1_{\mathrm{it}-1}\right]}=\sum_{\mathrm{k}=1}^{\mathrm{n}} \frac{\operatorname{Cov}\left[\mathrm{r}_{\mathrm{it}}, \delta_{\mathrm{kt}-1} \mathrm{candidate}_{\mathrm{kit}-1}\right]}{\operatorname{Var}\left[\mathrm{r} 6,1_{\mathrm{it}-1}\right]}+$ $\frac{\operatorname{Cov}\left(\left[\mathrm{r}_{\mathrm{it}},\left(\mu_{\mathrm{t}-1}+\varphi_{\mathrm{it}-1}\right)\right]\right.}{\operatorname{Var}\left[\mathrm{r} 6,1_{\mathrm{it}-1}\right]}=\sum_{\mathrm{k}=1}^{\mathrm{n}} \beta_{\mathrm{kt}}^{\mathrm{C}}+\beta_{\mathrm{t}}^{\mathrm{R}}$. The standard errors of the fractions are based on multivariate delta method.

r6,1 is past 6-month return skipping the most recent one month. 52W (52-week-high) is the stock price divided by the highest price in the past 52 weeks in each month. r12,7 is the cumulative return from month t-12 to month $\mathrm{t}-7$ in each month. SUE is the most recent standardized unexpected earnings surprise in each month. CAR is cumulative abnormal return from one day before and one day after earnings announcement date and abnormal return is stock return minus market return. SUR is the most recent standardized unexpected revenue surprise in each month. CGO is capital gains overhang following Grinblatt and Han (2005). TVOL (total volatility) is standard deviation of returns in each month (minimum 15 days are required). TURN (turnover) is the average of daily turnover in the past 120 days. Daily turnover is number of traded shares divided by number of outstanding shares. DISP (dispersion) is standard deviation of analyst earnings forecasts scaled by stock price. COV (analyst coverage) is number of analysts. RGVOL (revenue growth volatility) is the volatility of firm revenue growth in the past 10 quarters (minimum 5 quarters are required). Firm revenue growth is revenue in current quarter divided by revenue in lagged 4 quarter and minus 1. COGS (cost of goods sold) is quarterly cost of goods divided by quarterly total assets. IVOL (idiosyncratic volatility) is the standard deviation of residuals from regression on daily return on daily market return in each month (minimum 15 days are required). Industry r6,1 is the past 6month return in an industry (based on 2-digit SIC code) in each month. Skew is the skewness of raw daily returns in a month. $*, * *$, and $* * *$ indicate significance level at the $10 \%, 5 \%$ and $1 \%$ respectively.

\begin{tabular}{|c|c|c|c|c|c|c|c|c|}
\hline \multirow[b]{2}{*}{ Stage } & & & \multicolumn{2}{|c|}{ Model 1} & \multicolumn{2}{|c|}{ Model 2} & \multicolumn{2}{|c|}{ Model 3} \\
\hline & & & coeff & $\mathrm{t}$ & coeff & $\mathrm{t}$ & coeff & $\mathrm{t}$ \\
\hline \multirow[t]{2}{*}{1} & Return on & Intercept & -0.0008 & $(-1.45)$ & $-0.0015^{* *}$ & $(-2.29)$ & -0.0002 & $(-0.22)$ \\
\hline & r6,1 & $\mathrm{r} 6,1$ & $0.0059 * * *$ & $(2.61)$ & $0.0090 * * *$ & $(2.65)$ & 0.0030 & $(0.99)$ \\
\hline \multirow[t]{17}{*}{2} & Add & Intercept & $0.0103^{* * *}$ & $(4.46)$ & $0.0140 * * *$ & $(4.28)$ & $0.0067 * *$ & (2.08) \\
\hline & candidates & r6, 1 & $0.0072 * * *$ & $(3.93)$ & $0.0102 * * *$ & $(3.66)$ & $0.0044 *$ & (1.84) \\
\hline & & $52 \mathrm{~W}$ & $-0.0101 * * *$ & $(-4.66)$ & $-0.0144 * * *$ & $(-4.80)$ & $-0.0060^{*}$ & $(-1.95)$ \\
\hline & & SUE & $0.0015^{* * *}$ & $(9.14)$ & $0.0020 * * *$ & $(8.56)$ & $0.0010 * * *$ & $(4.56)$ \\
\hline & & CAR & $0.0272 * * *$ & $(7.20)$ & $0.0332 * * *$ & $(5.40)$ & $0.0214 * * *$ & $(4.85)$ \\
\hline & & SUR & $0.0003 * *$ & $(2.45)$ & $0.0006^{* * *}$ & $(3.37)$ & 0.0001 & $(0.43)$ \\
\hline & & CGO & $-0.0017 * *$ & $(-2.28)$ & -0.0015 & $(-1.34)$ & $-0.0018^{*}$ & $(-1.94)$ \\
\hline & & TVOL & -0.1404 & $(-1.03)$ & 0.0433 & $(0.22)$ & -0.3153 & $(-1.64)$ \\
\hline & & DISP & $-0.1020 * * *$ & $(-5.18)$ & $-0.0818 * * *$ & $(-5.21)$ & $-0.1213 * * *$ & $(-3.43)$ \\
\hline & & TURN & -0.1977 & $(-1.13)$ & -0.4531 & $(-1.36)$ & 0.0454 & $(0.36)$ \\
\hline & & $\mathrm{COV}$ & $-0.0001 * * *$ & $(-2.65)$ & $-0.0002 * * *$ & $(-3.35)$ & -0.0000 & $(-0.53)$ \\
\hline & & RGVOL & -0.0005 & $(-0.39)$ & 0.0013 & $(0.64)$ & -0.0022 & $(-1.55)$ \\
\hline & & COGS & 0.0011 & $(0.60)$ & 0.0015 & $(0.55)$ & 0.0008 & $(0.30)$ \\
\hline & & IVOL & 0.0022 & $(0.02)$ & -0.2487 & $(-1.25)$ & 0.2411 & $(1.34)$ \\
\hline & & $\mathrm{r} 12,7$ & $0.0060^{* * *}$ & (3.98) & $0.0098^{* * *} *$ & $(4.10)$ & 0.0023 & $(1.29)$ \\
\hline & & Industry r6,1 & 0.0022 & $(0.46)$ & 0.0029 & $(0.45)$ & 0.0016 & $(0.22)$ \\
\hline & & SK & $-0.0007 * * *$ & $(-2.70)$ & $-0.0010^{* *}$ & $(-2.53)$ & -0.0004 & $(-1.20)$ \\
\hline
\end{tabular}


Continued

\begin{tabular}{|c|c|c|c|c|c|c|c|c|c|c|c|}
\hline \multirow[b]{2}{*}{ Stage } & & & & \multicolumn{2}{|c|}{ Model 1} & \multicolumn{3}{|c|}{ Model 2} & \multicolumn{3}{|c|}{ Model 3} \\
\hline & & & & coeff & $\mathrm{t}$ & \multicolumn{2}{|c|}{ coeff } & $\mathrm{t}$ & \multicolumn{2}{|c|}{ coeff } & $\mathrm{t}$ \\
\hline \multirow[t]{17}{*}{3} & r6,1 on & \multicolumn{2}{|c|}{ Intercept } & $-0.6557 * * *$ & $(-35.04)$ & & $392 * * *$ & $(-27.59)$ & \multicolumn{2}{|c|}{$-0.8618 * * *$} & $(-42.56)$ \\
\hline & candidates & \multicolumn{2}{|c|}{$52 \mathrm{~W}$} & $0.7290 * * *$ & $(37.01)$ & & $990 * * *$ & (28.18) & \multicolumn{2}{|c|}{$0.9384 * * *$} & $(43.51)$ \\
\hline & & \multicolumn{2}{|c|}{ SUE } & -0.0002 & $(-0.36)$ & & .0005 & $(-0.44)$ & \multicolumn{2}{|c|}{-0.0000} & $(-0.02)$ \\
\hline & & \multicolumn{2}{|c|}{ CAR } & $0.2469 * * *$ & (18.18) & & $708 * * *$ & (20.59) & \multicolumn{2}{|c|}{$0.1290^{* * *}$} & (9.59) \\
\hline & & \multicolumn{2}{|c|}{ SUR } & $0.0106^{* * *}$ & (25.39) & & $125^{* * *}$ & $(23.02)$ & \multicolumn{2}{|c|}{$0.0088^{* * *} *$} & (15.02) \\
\hline & & \multicolumn{2}{|c|}{ CGO } & $0.0704 * * *$ & $(20.84)$ & & $925 * * *$ & (17.47) & \multicolumn{2}{|c|}{$0.0494 * * *$} & $(15.01)$ \\
\hline & & \multicolumn{2}{|c|}{ TVOL } & $6.8836^{* * *}$ & (14.30) & & $727 * * *$ & (10.81) & \multicolumn{2}{|c|}{$6.7035^{* * *}$} & $(9.52)$ \\
\hline & & \multicolumn{2}{|c|}{ DISP } & $-0.3017 * * *$ & $(-7.16)$ & & $727 * * *$ & $(-11.06)$ & \multicolumn{2}{|c|}{$-0.1389 * *$} & $(-2.03)$ \\
\hline & & TUR & & $13.9020 * * *$ & $(15.45)$ & & $514 * * *$ & (13.08) & 7.665 & $* * *$ & $(15.72)$ \\
\hline & & $\mathrm{CO}$ & & $-0.0022 * * *$ & $(-14.87)$ & & $021 * * *$ & $(-10.32)$ & -0.00 & **** & $(-10.77)$ \\
\hline & & RGV & & $0.0234 * * *$ & (7.15) & & $218 * * *$ & (4.04) & 0.025 & $* * *$ & (6.59) \\
\hline & & $\mathrm{COC}$ & & $0.0355^{* * *}$ & $(8.71)$ & & $295 * * *$ & (4.33) & 0.041 & $* * *$ & $(9.05)$ \\
\hline & & IVO & & $-4.3471^{* * *} *$ & $(-9.88)$ & & $800 * * *$ & $(-11.00)$ & -2.60 & $* * *$ & $(-4.10)$ \\
\hline & & $\mathrm{r} 12$, & & $-0.1386^{* * *}$ & $(-16.00)$ & & $078 * * *$ & $(-10.75)$ & -0.16 & $* * *$ & $(-12.49)$ \\
\hline & & Industry & & $0.3687 * * *$ & (39.43) & & $667 * * *$ & $(35.07)$ & 0.332 & $* * *$ & $(24.13)$ \\
\hline & & SK & & $0.0367 * * *$ & $(35.06)$ & & $364 * * *$ & $(22.86)$ & 0.036 & $* * *$ & $(27.07)$ \\
\hline & & Avg ad & & 0.439 & & & .419 & & 0.4 & & \\
\hline & & & & Model 1 & & & Model 2 & & & Model 3 & \\
\hline Stage & & & coeff & frac & $\mathrm{t}$ & coeff & frac & $\mathrm{t}$ & coeff & frac & $\mathrm{t}$ \\
\hline 4 & Decompose & $52 \mathrm{~W}$ & 0.0003 & $5.08 \%$ & $(0.29)$ & 0.0004 & $4.44 \%$ & $(0.33)$ & 0.0003 & $10.00 \%$ & $(0.16)$ \\
\hline & r6,1 coeff. & SUE & -0.0001 & $-1.69 \%$ & $(-1.17)$ & -0.0001 & $-1.11 \%$ & $(-0.73)$ & -0.0001 & $-3.33 \%$ & $(-0.89)$ \\
\hline & In Stage 1 & CAR & 0.0006 & $10.17 \% * * *$ & (2.79) & 0.0010 & $11.11 \% * * *$ & (2.98) & 0.0001 & $3.33 \%$ & $(0.98)$ \\
\hline & & SUR & 0.0007 & $11.86 \% * * *$ & (2.97) & 0.0012 & $13.33 \% * * *$ & $(3.00)$ & 0.0003 & $10.00 \%$ & (1.16) \\
\hline & & CGO & 0.0007 & $11.86 \% * * *$ & (2.90) & 0.0012 & $13.33 \% * * *$ & (2.84) & 0.0003 & $10.00 \%$ & $(1.22)$ \\
\hline & & TVOL & -0.0011 & $-18.64 \%$ & $(-1.13)$ & -0.0020 & $-22.22 \%$ & $(-1.40)$ & -0.0003 & $-10.00 \%$ & $(-0.24)$ \\
\hline & & DISP & 0.0004 & $6.78 \% * * * *$ & (2.64) & 0.0006 & $6.67 \% * * *$ & (2.68) & 0.0002 & $6.67 \%$ & $(1.00)$ \\
\hline & & TURN & -0.0001 & $-1.69 \%$ & $(-0.14)$ & 0.0001 & $1.11 \%$ & $(0.25)$ & -0.0003 & $-10.00 \%$ & $(-0.43)$ \\
\hline & & $\mathrm{COV}$ & 0.0003 & $5.08 \% * *$ & $(2.22)$ & 0.0005 & $5.56 \% * *$ & (2.07) & 0.0002 & $6.67 \%$ & $(0.94)$ \\
\hline & & RGVOL & -0.0001 & $-1.69 \%$ & $(-1.27)$ & -0.0001 & $-1.11 \%$ & $(-0.86)$ & -0.0001 & $-3.33 \%$ & $(-0.74)$ \\
\hline & & COGS & 0.0000 & $0.00 \%$ & $(0.70)$ & -0.0000 & $-0.00 \%$ & $(-0.07)$ & 0.0001 & $3.33 \%$ & (0.79) \\
\hline & & IVOL & 0.0005 & $8.47 \%$ & $(0.76)$ & 0.0015 & $16.67 \%$ & (1.43) & -0.0004 & $-13.33 \%$ & $(-0.47)$ \\
\hline & & $\mathrm{r} 12,7$ & -0.0005 & $-8.47 \%$ & $(-1.75)$ & -0.0012 & $-13.33 \%$ & $(-2.35)$ & 0.0000 & $0.00 \%$ & $(0.10)$ \\
\hline & & Industry r6,1 & 0.0002 & $3.39 \%$ & $(0.58)$ & 0.0003 & $3.33 \%$ & $(0.48)$ & 0.0001 & $3.33 \%$ & $(0.34)$ \\
\hline & & SK & -0.0000 & $-0.00 \%$ & $(-0.30)$ & -0.0001 & $-1.11 \%$ & $(-0.74)$ & 0.0001 & $3.33 \%$ & $(0.41)$ \\
\hline & & Resid & 0.0041 & $69.49 \% * * *$ & (4.18) & 0.0057 & $63.33 \% * * *$ & (4.45) & 0.0025 & $83.33 \%$ & (1.42) \\
\hline & Avg stock & & 985 & & & 762 & & & 1197 & & \\
\hline & start date & & 197602 & & & 197602 & & & 199601 & & \\
\hline & end date & & 201612 & & & 199512 & & & 201612 & & \\
\hline
\end{tabular}


Table 6. Subsample analysis: market conditions

This table reports slopes of decomposed components and fractions of each candidate in different subsamples. Subsamples are divided based on 3 market conditions: sentiment, market volatility and uncertainty. The cutoff points are $30 \%$ and $70 \%$ percentile, so three groups are split for each condition variable. Sentiment data is from Wurgler's website. Market volatility is the standard deviation of daily returns over the past one year in each month. Uncertainty data is from Ludvigson's website. In stage 1 , the regression model is $r_{i t}=\alpha_{t}+\beta_{t} r 6,1_{i t-1}+\varepsilon_{i t}$. In stage 2 , a candidate variable is added to the regression model: $r_{i, t}=\widetilde{\alpha}_{t}+\widehat{\beta_{t}^{R}} r 6,1_{i, t-1}+$ $\sum_{\mathrm{k}=1}^{\mathrm{n}} \widetilde{\beta_{\mathrm{kt}}^{\mathrm{c}}}$ candidate $\mathrm{kit}_{\mathrm{i}-1}+\widetilde{\varepsilon}_{\mathrm{i}, \mathrm{t}}$. In stage 3 , we run regression of past 6 -month return on candidate variable: $\mathrm{r} 6,1_{\mathrm{it}-1}=\mu_{\mathrm{t}-1}+\sum_{\mathrm{k}=1}^{\mathrm{n}} \delta_{\mathrm{kt}-1}$ candidate $\mathrm{kit}_{-1}+\varphi_{\mathrm{it}-1}$, then past 6 -month return is decomposed into orthogonal components: $\delta_{1 \mathrm{t}-1}$ candidate $_{1 \mathrm{it}-1}, \delta_{2 \mathrm{t}-1}$ candidate $_{2 \mathrm{it}-1}, \ldots, \delta_{\mathrm{nt}-1}$ candidate $_{\mathrm{nit}-1}$ and $\mu_{\mathrm{t}-1}+\varphi_{\mathrm{it}-1}$. In stage 4 , the coefficient $\beta_{\mathrm{t}}$ is decomposed as

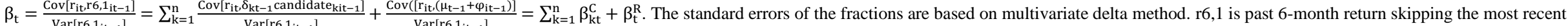
one month. $52 \mathrm{~W}$ (52-week-high) is the stock price divided by the highest price in the past 52 weeks in each month. r 12,7 is the cumulative return from month $\mathrm{t}-12$ to month $\mathrm{t}-7 \mathrm{in}$ each month. SUE is the most recent standardized unexpected earnings surprise in each month. CAR is cumulative abnormal return from one day before and one day after earnings announcement date and abnormal return is stock return minus market return. SUR is the most recent standardized unexpected revenue surprise in each month. CGO is capital gains overhang following Grinblatt and Han (2005). TVOL (total volatility) is standard deviation of returns in each month (minimum 15 days are required). TURN (turnover) is the average of daily turnover in the past 120 days. Daily turnover is number of traded shares divided by number of outstanding shares. DISP (dispersion) is standard deviation of analyst earnings forecasts scaled by stock price. COV (analyst coverage) is number of analysts. RGVOL (revenue growth volatility) is the volatility of firm revenue growth in the past 10 quarters (minimum 5 quarters are required). Firm revenue growth is revenue in current quarter divided by revenue in lagged 4 quarter and minus 1 . COGS (cost of goods sold) is quarterly cost of goods divided by quarterly total assets. IVOL (idiosyncratic volatility) is the standard deviation of residuals from regression on daily return on daily market return in each month (minimum 15 days are required). Industry r6,1 is the past 6-month return in an industry (based on 2-digit SIC code) in each month. Skew is the skewness of raw daily returns in a month. *, **, and $* * *$ indicate significance level at the $10 \%, 5 \%$ and $1 \%$ respectively.

\begin{tabular}{|c|c|c|c|c|c|c|c|c|c|c|c|c|c|c|c|c|c|c|}
\hline & \multicolumn{3}{|c|}{ High sentiment } & \multicolumn{3}{|c|}{ Low sentiment } & \multicolumn{3}{|c|}{ High market volatility } & \multicolumn{3}{|c|}{ Low market volatility } & \multicolumn{3}{|c|}{ High uncertainty } & \multicolumn{3}{|c|}{ Low uncertainty } \\
\hline & coeff & fraction & $\mathrm{t}$ & coeff & fraction & $\mathrm{t}$ & coeff & fraction & $\mathrm{t}$ & coeff & fraction & $\mathrm{t}$ & coeff & fraction & $\mathrm{t}$ & coeff & fraction & $\mathrm{t}$ \\
\hline $52 \mathrm{~W}$ & 0.0032 & $38.10 \% *$ & $(1.77)$ & -0.0072 & $-205.7 \%$ & $(-0.57)$ & -0.0020 & $-105.30 \%$ & $(-0.24)$ & 0.0018 & $13.74 \%$ & $(1.61)$ & -0.0005 & $-5.95 \%$ & $(-0.13)$ & 0.0017 & $26.56 \%$ & (1.38) \\
\hline SUE & -0.0000 & $-0.00 \%$ & $(-0.30)$ & -0.0004 & $-11.40 \%$ & $(-0.63)$ & -0.0001 & $-5.30 \%$ & $(-0.36)$ & -0.0002 & $-1.53 \%$ & $(-0.81)$ & -0.0002 & $-2.38 \%$ & $(-1.18)$ & -0.0003 & $-4.69 \%$ & $(-1.46)$ \\
\hline CAR & 0.0009 & $10.71 \%$ ** & $(2.04)$ & 0.0007 & $20.00 \%$ & $(0.70)$ & 0.0003 & $15.79 \%$ & $(0.39)$ & 0.0007 & $5.34 \% * * *$ & (3.46) & 0.0009 & $10.71 \% *$ & $(1.71)$ & 0.0006 & $9.37 \% * *$ & (2.36) \\
\hline SUR & 0.0007 & $8.33 \% *$ & $(1.81)$ & 0.0004 & $11.43 \%$ & $(0.69)$ & 0.0001 & $5.26 \%$ & $(0.35)$ & 0.0009 & $6.87 \% * * *$ & $(2.96)$ & 0.0009 & $10.71 \% *$ & $(1.77)$ & 0.0005 & $7.81 \% * *$ & $(2.06)$ \\
\hline CGO & 0.0014 & $16.67 \% * *$ & $(2.20)$ & 0.0005 & $14.29 \%$ & $(0.90)$ & -0.0003 & $-15.80 \%$ & $(-0.28)$ & 0.0022 & $16.79 \% * * * *$ & $(4.02)$ & 0.0006 & $7.14 \%$ & $(0.99)$ & -0.0001 & $-1.56 \%$ & $(-0.38)$ \\
\hline TVOL & -0.0011 & $-13.10 \%$ & $(-0.42)$ & -0.0009 & $-25.70 \%$ & $(-0.36)$ & 0.0028 & $147.37 \%$ & $(0.41)$ & -0.0043 & $-32.82 \%$ & $(-1.73)$ & -0.0002 & $-2.38 \%$ & $(-0.14)$ & -0.0018 & $-28.12 \%$ & $(-0.85)$ \\
\hline DISP & 0.0005 & $5.95 \%$ ** & $(2.13)$ & 0.0002 & $5.71 \%$ & $(0.59)$ & 0.0002 & $10.53 \%$ & $(0.40)$ & 0.0004 & $3.05 \% * *$ & $(2.11)$ & 0.0006 & $7.14 \% *$ & $(1.74)$ & 0.0002 & $3.12 \%$ & (1.45) \\
\hline TURN & -0.0010 & $-11.90 \%$ & $(-1.02)$ & 0.0015 & $42.86 \%$ & $(0.73)$ & 0.0003 & $15.79 \%$ & $(0.28)$ & 0.0002 & $1.53 \%$ & $(0.28)$ & -0.0002 & $-2.38 \%$ & $(-0.17)$ & -0.0001 & $-1.56 \%$ & $(-0.12)$ \\
\hline $\mathrm{COV}$ & 0.0001 & $1.19 \%$ & $(0.59)$ & 0.0014 & $40.00 \%$ & $(0.69)$ & 0.0003 & $15.79 \%$ & $(0.37)$ & 0.0011 & $8.40 \% * *$ & $(2.32)$ & 0.0004 & $4.76 \%$ & $(1.21)$ & 0.0003 & $4.69 \%$ & (1.23) \\
\hline RGVOL & -0.0000 & $-0.00 \%$ & $(-0.38)$ & -0.0000 & $-0.00 \%$ & $(-0.24)$ & -0.0000 & $-0.00 \%$ & $(0.29)$ & -0.0002 & $-1.53 \%$ & $(-1.41)$ & 0.0001 & $1.19 \%$ & $(0.91)$ & -0.0001 & $-1.56 \%$ & $(-0.85)$ \\
\hline COGS & -0.0000 & $-0.00 \%$ & $(-0.25)$ & -0.0001 & $-2.90 \%$ & $(-0.40)$ & 0.0002 & $10.53 \%$ & $(0.38)$ & -0.0001 & $-0.76 \%$ & $(-0.92)$ & 0.0003 & $3.57 \%$ & $(1.42)$ & -0.0001 & $-1.56 \%$ & $(-0.62)$ \\
\hline IVOL & 0.0005 & $5.95 \%$ & $(0.24)$ & 0.0013 & $37.14 \%$ & $(0.52)$ & -0.0026 & $-136.80 \%$ & $(-0.41)$ & 0.0033 & $25.19 \% *$ & (1.69) & 0.0000 & $0.00 \%$ & $(0.02)$ & 0.0010 & $15.62 \%$ & $(0.59)$ \\
\hline $\mathrm{r} 12,7$ & -0.0005 & $-5.95 \%$ & $(-1.06)$ & -0.0004 & $-11.40 \%$ & $(-0.43)$ & 0.0003 & $15.79 \%$ & $(0.25)$ & -0.0013 & $-9.92 \%$ & $(-3.09)$ & 0.0007 & $8.33 \%$ & $(0.73)$ & -0.001 & $-15.62 \%$ & $(-1.68)$ \\
\hline Industry r6,1 & -0.0002 & $-2.38 \%$ & $(-0.23)$ & 0.0009 & $25.71 \%$ & $(0.82)$ & -0.0000 & $-0.00 \%$ & $(-0.08)$ & 0.0004 & $3.05 \%$ & $(0.89)$ & 0.0008 & $9.52 \%$ & $(1.38)$ & -0.0000 & $-0.00 \%$ & $(-0.06)$ \\
\hline SK & -0.0002 & $-2.38 \%$ & $(-0.81)$ & 0.0005 & $14.29 \%$ & $(0.72)$ & -0.0001 & $-5.30 \%$ & $(-0.27)$ & 0.0003 & $2.29 \%$ & (1.44) & -0.0003 & $-3.57 \%$ & $(-1.02)$ & 0.0004 & $6.25 \% *$ & (1.77) \\
\hline Resid & 0.0041 & $48.81 \% * * *$ & (3.14) & 0.0051 & $145.71 \%$ & $(0.82)$ & 0.0025 & $131.58 \%$ & $(0.47)$ & 0.0079 & $60.31 \% * * *$ & $(5.90)$ & 0.0045 & $53.57 \% * *$ & (2.53) & 0.0052 & $81.25 \% * * *$ & (3.76) \\
\hline Total & $0.0084 * *$ & & $(2.00)$ & 0.0035 & & $(0.62)$ & 0.0019 & & $(0.39)$ & $0.0131 * * *$ & & (3.43) & 0.0084 & & $(1.62)$ & $0.0064 * * *$ & & (2.16) \\
\hline
\end{tabular}


Table 7. Momentum components and momentum crashes.

The table reports market rebound, portfolio beta and momentum profits. Market rebound is a dummy variable that equals to 1 if positive current monthly return and negative return over the past 24-month and 0 otherwise. Panel A shows market conditions including sentiment, market volatility and uncertainty for rebound and non-rebound periods. Sentiment data is from Wurgler's website. Market volatility is the standard deviation of daily returns over the past one year in each month. Uncertainty data is from Ludvigson's website. Panels B and C shows the results of regression of momentum beta difference between loser and winner portfolios on market rebound, and regression of momentum profits on market rebound, respectively. We estimate beta of winner portfolio (top decile) from regression of winner portfolio returns on market portfolio returns over the past 24 months and similarly we estimate beta of loser portfolio (bottom decile). Winner or loser portfolios are constructed by past 6-month return (total) and five components (past return components, fundamental components, prospect theory and mental accounting components, other components) and a residual decomposed as that in Table 5. We group the candidates into five groups: Anchoring, Fundamental, PT/MA, Firm characteristics and Others. Anchoring includes 52W. Fundamental includes SUE, CAR and SUE. PT/MA includes CGO. Firm characteristics include TVOL, DISP, TURN, COV, RGVOL, COGS and IVOL. Others include industry return from month t-6 to t-1, r12,7 and skewness. Resid is residual. For example, Fundamental component, we sum up the fitted return explained by SUE, CAR and SUR, then rank stocks into deciles based on the fitted value. $a$ is intercept and $b$ is slope of market rebound. t-statistics are reported in parentheses for a and b, F-statistics (Wald test) is reported for $\mathrm{a}+\mathrm{b} . *, * *$, and $* * *$ indicate significance level at the $10 \%, 5 \%$ and $1 \%$ respectively.

Panel A: market rebound and market conditions

\begin{tabular}{cccc}
\hline & sentiment & market volatility & uncertainty \\
\hline non-rebound (0) & 0.0839 & 0.0089 & 0.6617 \\
rebound (1) & -0.5598 & 0.0162 & 0.7467 \\
diff (1-0) & $-0.6437 * * *$ & $0.0073 * * *$ & $0.0850^{* * *}$ \\
$\mathrm{t}$ & $(-3.65)$ & $(7.90)$ & $(5.42)$ \\
\hline
\end{tabular}

Panel B: market rebound and momentum beta by components (winner - loser)

\begin{tabular}{|c|c|c|c|}
\hline & $\mathrm{a}$ & $\mathrm{b}$ & $a+b$ \\
\hline Total & $\begin{array}{c}0.0000 \\
(0.00)\end{array}$ & $\begin{array}{c}-0.4153 * * * \\
(-6.91)\end{array}$ & $\begin{array}{c}-0.4152 * * * \\
(50.83)\end{array}$ \\
\hline Anchoring compo. & $\begin{array}{c}-0.3758 * * * \\
(-29.54)\end{array}$ & $\begin{array}{c}-0.4099 * * * \\
(-8.03)\end{array}$ & $\begin{array}{c}-0.7857 * * * \\
(252.53)\end{array}$ \\
\hline Fundamental compo. & $\begin{array}{c}0.0294 * * * \\
\quad(3.10)\end{array}$ & $\begin{array}{c}-0.2344 * * * \\
(-6.15)\end{array}$ & $\begin{array}{c}-0.2049 * * * \\
(30.84)\end{array}$ \\
\hline PT/MA compo. & $\begin{array}{c}0.0577 * * * \\
(3.40)\end{array}$ & $\begin{array}{c}-0.1926 * * * \\
(-2.83)\end{array}$ & $\begin{array}{c}-0.1349 * * \\
(4.19)\end{array}$ \\
\hline Firm characteristics compo. & $\begin{array}{c}0.7058 * * * \\
(38.99)\end{array}$ & $\begin{array}{c}0.0867 \\
(1.19)\end{array}$ & $\begin{array}{c}0.7925 * * * \\
(126.91)\end{array}$ \\
\hline Others compo. & $\begin{array}{c}0.0252 * * * \\
(2.58)\end{array}$ & $\begin{array}{c}0.0434 \\
(1.10)\end{array}$ & $\begin{array}{c}0.0686^{*} \\
(3.25)\end{array}$ \\
\hline Resid compo. & $\begin{array}{c}-0.0141 * * \\
(-2.06)\end{array}$ & $\begin{array}{c}-0.1716^{* * * *} \\
(-6.24)\end{array}$ & $\begin{array}{c}-0.1857 * * * \\
(48.63)\end{array}$ \\
\hline
\end{tabular}

Panel C: market rebound and momentum profits by components (momentum profits)

\begin{tabular}{|c|c|c|c|}
\hline & $\mathrm{a}$ & $\mathrm{b}$ & $a+b$ \\
\hline Total & $\begin{array}{c}0.0100 * * * \\
(4.58)\end{array}$ & $\begin{array}{c}-0.0360 * * * \\
(-4.12)\end{array}$ & $\begin{array}{c}-0.0260 * * * \\
(9.48)\end{array}$ \\
\hline Anchoring compo. & $\begin{array}{l}0.0053 * * * \\
(2.91)\end{array}$ & $\begin{array}{c}-0.0497 * * * \\
(-6.74)\end{array}$ & $\begin{array}{c}-0.0443 \text { *** } \\
(38.55)\end{array}$ \\
\hline Fundamental compo. & $\begin{array}{c}0.0077 * * * \\
\quad(6.43)\end{array}$ & $\begin{array}{c}-0.0227 * * * \\
(-4.74)\end{array}$ & $\begin{array}{c}-0.0150 * * * \\
(10.47)\end{array}$ \\
\hline PT/MA compo. & $\begin{array}{c}0.0040 * * \\
(2.23)\end{array}$ & $\begin{array}{c}-0.0291 * * * \\
(-4.03)\end{array}$ & $\begin{array}{c}-0.0251 * * * \\
(12.88)\end{array}$ \\
\hline Firm characteristics compo. & $\begin{array}{c}-0.0024 \\
(-0.91)\end{array}$ & $\begin{array}{c}0.0361 * * * \\
(3.44)\end{array}$ & $\begin{array}{c}0.0337 * * * \\
(11.02)\end{array}$ \\
\hline Others compo. & $\begin{array}{c}-0.0019 \\
(-1.20)\end{array}$ & $\begin{array}{c}0.0123^{*} \\
(1.89)\end{array}$ & $\begin{array}{c}0.0104 * \\
(2.71)\end{array}$ \\
\hline Resid compo. & $\begin{array}{c}0.0075^{* * * *} \\
(6.19)\end{array}$ & $\begin{array}{c}-0.0169 * * * \\
(-3.48)\end{array}$ & $\begin{array}{c}-0.0094 * * \\
(4.02)\end{array}$ \\
\hline
\end{tabular}


Table 8. Exclude January months

This table reports slopes of decomposed components and fractions of each candidate excluding January. In stage 1, the regression model is $r_{i t}=\alpha_{t}+\beta_{t} r 6,1_{i t-1}+\varepsilon_{i t}$. In stage 2 , a candidate variable is added to the regression model: $\mathrm{r}_{\mathrm{i}, \mathrm{t}}=\widetilde{\alpha}_{\mathrm{t}}+\widetilde{\beta_{\mathrm{t}}^{\mathrm{K}}} \mathrm{r} 6,1_{\mathrm{i}, \mathrm{t}-1}+\sum_{\mathrm{k}=1}^{\mathrm{n}} \widetilde{\beta_{\mathrm{kt}}^{\mathrm{C}}}$ candidate $\mathrm{ki}_{\mathrm{i}-1}+\tilde{\varepsilon}_{\mathrm{i}, \mathrm{t}}$. In stage 3 , we run regression of past 6-month return on candidate variable: $\mathrm{r} 6,1_{\mathrm{it}-1}=\mu_{\mathrm{t}-1}+$ $\sum_{\mathrm{k}=1}^{\mathrm{n}} \delta_{\mathrm{kt}-1}$ candidate $_{\mathrm{kit}-1}+\varphi_{\mathrm{it}-1}$, then past 6-month return is decomposed into orthogonal components: $\delta_{1 \mathrm{t}-1}$ candidate $_{1 \mathrm{it}-1}, \delta_{2 \mathrm{t}-1}$ candidate $_{2 \mathrm{it}-1}, \ldots, \delta_{\mathrm{nt}-1} \mathrm{candidate}_{\mathrm{nit}-1}$ and $\mu_{\mathrm{t}-1}+\varphi_{\mathrm{it}-1}$.

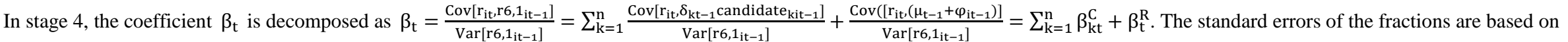

multivariate delta method. $\mathrm{r} 6,1$ is past 6-month return skipping the most recent one month. $52 \mathrm{~W}$ (52-week-high) is the stock price divided by the highest price in the past 52 weeks in each month. r12,7 is the cumulative return from month t-12 to month t-7 in each month. SUE is the most recent standardized unexpected earnings surprise in each month. CAR is cumulative abnormal return from one day before and one day after earnings announcement date and abnormal return is stock return minus market return. SUR is the most recent standardized unexpected revenue surprise in each month. CGO is capital gains overhang following Grinblatt and Han (2005). TVOL (total volatility) is standard deviation of returns in each month (minimum 15 days are required). TURN (turnover) is the average of daily turnover in the past 120 days. Daily turnover is number of traded shares divided by number of outstanding shares. DISP (dispersion) is standard deviation of analyst earnings forecasts scaled by stock price. COV (analyst coverage) is number of analysts. RGVOL (revenue growth volatility) is the volatility of firm revenue growth in the past 10 quarters (minimum 5 quarters are required). Firm revenue growth is revenue in current quarter divided by revenue in lagged 4 quarter and minus 1 . COGS (cost of goods sold) is quarterly cost of goods divided by quarterly total assets. IVOL (idiosyncratic volatility) is the standard deviation of residuals from regression on daily return on daily market return in each month (minimum 15 days are in an industry (based on 2-digit SIC code) in each month. Skew is the skewness of raw daily returns in a month. $*, * *$, and $* * *$ indicate significance level at the $10 \%, 5 \%$ and $1 \%$ respectively.

\begin{tabular}{|c|c|c|c|c|c|c|c|c|}
\hline \multirow[b]{2}{*}{ Stage } & & & \multicolumn{2}{|c|}{ Model 1} & \multicolumn{2}{|c|}{ Model 2} & \multicolumn{2}{|c|}{ Model 3} \\
\hline & & & coeff & $\mathrm{t}$ & coeff & $\mathrm{t}$ & coeff & $\mathrm{t}$ \\
\hline \multirow[t]{2}{*}{1} & Return on & Intercept & -0.0005 & $(-0.93)$ & $-0.0012 *$ & $(-1.91)$ & 0.0001 & $(0.12)$ \\
\hline & $\mathrm{r} 6,1$ & $\mathrm{r} 6,1$ & $0.0071 * * *$ & (3.13) & $0.0113 * * *$ & $(3.41)$ & 0.0031 & (1.01) \\
\hline \multirow[t]{17}{*}{2} & Add & Intercept & $0.0113^{* * *}$ & $(4.65)$ & $0.0159^{* * *}$ & $(4.71)$ & $0.0069^{* *}$ & $(2.01)$ \\
\hline & candidates & $\mathrm{r} 6,1$ & $0.0081 * * *$ & $(4.31)$ & $0.0121 * * *$ & $(4.33)$ & $0.0042 *$ & (1.73) \\
\hline & & $52 \mathrm{~W}$ & $-0.0106 * * *$ & $(-4.77)$ & $-0.0162 * * *$ & $(-5.39)$ & -0.0051 & $(-1.63)$ \\
\hline & & SUE & $0.0015^{* * *}$ & $(8.69)$ & $0.0021 * * *$ & $(8.58)$ & $0.0009 * * *$ & $(4.05)$ \\
\hline & & CAR & $0.0277 * * *$ & (7.08) & $0.0343 * * *$ & $(5.38)$ & $0.0213^{* * *}$ & (4.69) \\
\hline & & SUR & $0.0004 * * *$ & (3.09) & $0.0007 * * *$ & $(3.74)$ & 0.0002 & $(0.97)$ \\
\hline & & CGO & -0.0005 & $(-0.63)$ & 0.0000 & $(0.03)$ & -0.0009 & $(-0.99)$ \\
\hline & & TVOL & -0.1870 & $(-1.35)$ & -0.0330 & $(-0.17)$ & $-0.3342 *$ & $(-1.69)$ \\
\hline & & DISP & $-0.1147 * * *$ & $(-5.98)$ & $-0.0937 * * *$ & $(-5.84)$ & $-0.1347 * * *$ & $(-3.94)$ \\
\hline & & TURN & -0.2787 & $(-1.56)$ & -0.4965 & $(-1.47)$ & -0.0704 & $(-0.54)$ \\
\hline & & $\mathrm{COV}$ & $-0.0001^{* * * *}$ & $(-2.96)$ & $-0.0002 * * *$ & $(-3.33)$ & -0.0000 & $(-0.94)$ \\
\hline & & RGVOL & -0.0012 & $(-0.94)$ & 0.0003 & $(0.13)$ & $-0.0026^{*}$ & $(-1.81)$ \\
\hline & & COGS & 0.0008 & $(0.44)$ & 0.0013 & $(0.50)$ & 0.0003 & $(0.13)$ \\
\hline & & IVOL & 0.0886 & $(0.66)$ & -0.1427 & $(-0.73)$ & $0.3098^{*}$ & (1.68) \\
\hline & & $\mathrm{r} 12,7$ & $0.0068 * * *$ & $(4.17)$ & $0.0111 * * *$ & $(4.27)$ & 0.0027 & (1.39) \\
\hline & & Industry r6,1 & 0.0027 & $(0.54)$ & 0.0045 & $(0.66)$ & 0.0010 & $(0.14)$ \\
\hline & & SK & $-0.0008 * * *$ & $(-3.04)$ & $-0.0010^{* *}$ & $(-2.60)$ & -0.0005 & $(-1.65)$ \\
\hline
\end{tabular}




\begin{tabular}{|c|c|c|c|c|c|c|c|c|c|c|c|}
\hline \multicolumn{12}{|c|}{ Continued } \\
\hline \multirow{2}{*}{ Stage } & & & & \multicolumn{2}{|c|}{ Model 1} & \multicolumn{3}{|c|}{ Model 2} & \multicolumn{3}{|c|}{ Model 3} \\
\hline & & & & coeff & $\mathrm{t}$ & & eff & $\mathrm{t}$ & & & $\mathrm{t}$ \\
\hline \multirow[t]{17}{*}{3} & $\mathrm{r} 6,1$ on & Intercept & & $-0.6560 * * *$ & $(-33.65)$ & & $85 * * *$ & $(-26.30)$ & -0.8 & & $(-41.60)$ \\
\hline & candidates & $52 \mathrm{~W}$ & & $0.7284 * * *$ & (35.39) & & $72 * * *$ & $(26.80)$ & 0.9 & & $(42.12)$ \\
\hline & & SUE & & -0.0003 & $(-0.38)$ & & 004 & $(-0.38)$ & & & $(-0.13)$ \\
\hline & & CAR & & $0.2397 * * *$ & (16.57) & & $74 * * *$ & (19.18) & 0.1 & & $(8.30)$ \\
\hline & & SUR & & 0.0106 *** & (24.19) & & $24 * * *$ & (21.74) & 0.0 & & (14.38) \\
\hline & & $\mathrm{CGO}$ & & $0.0705^{* * *}$ & (20.23) & & $24 * * *$ & (16.97) & 0.0 & & (14.59) \\
\hline & & TVOL & & $6.9254 * * *$ & (13.67) & & $52 * * *$ & (10.57) & 6.6 & & $(8.94)$ \\
\hline & & DISP & & $-0.2992 * * *$ & $(-6.96)$ & & $00 * * *$ & $(-10.66)$ & & & $(-1.84)$ \\
\hline & & TURN & & $14.1035 * * *$ & (14.79) & & $04 * * *$ & (12.57) & 7.7 & & (15.25) \\
\hline & & $\mathrm{COV}$ & & $-0.0022 * * *$ & $(-14.40)$ & & $21 * * *$ & $(-10.16)$ & -0.0 & & $(-10.30)$ \\
\hline & & RGVOL & & $0.0228 * * *$ & $(6.62)$ & & $2 * * * *$ & $(3.57)$ & 0.0 & & $(6.33)$ \\
\hline & & COGS & & $0.0363 * * *$ & $(8.61)$ & & $0^{* * * *}$ & (4.19) & 0.0 & & $(8.97)$ \\
\hline & & IVOL & & $-4.3472 * * *$ & $(-9.39)$ & & $86 * * *$ & $(-10.65)$ & -2.5 & & $(-3.83)$ \\
\hline & & $\mathrm{r} 12,7$ & & $-0.1425 * * *$ & $(-15.41)$ & & $89 * * *$ & $(-10.48)$ & -0.1 & & $(-12.06)$ \\
\hline & & Industry r6,1 & & $0.3707 * * *$ & $(38.00)$ & & 6 6**** & (33.65) & 0.3 & & $(23.27)$ \\
\hline & & SK & & $0.0371 * * *$ & (34.01) & & $1 * * *$ & (22.17) & 0.0 & & (26.35) \\
\hline & & Avg adj $R^{2}$ & \multicolumn{3}{|c|}{0.436} & \multicolumn{3}{|c|}{0.417} & \multicolumn{2}{|c|}{0.454} & \\
\hline & & & & Model 1 & & & Model 2 & & & Model 3 & \\
\hline \multirow{20}{*}{$\frac{\text { Stage }}{4}$} & & & coeff & frac & $\mathrm{t}$ & coeff & frac & $\mathrm{t}$ & coeff & frac & $\mathrm{t}$ \\
\hline & Decompose & $52 \mathrm{~W}$ & 0.0009 & $12.68 \%$ & $(0.84)$ & 0.0009 & $7.96 \%$ & $(0.95)$ & 0.0008 & $25.81 \%$ & $(0.50)$ \\
\hline & r6,1 coeff. & SUE & -0.0001 & $-1.41 \%$ & $(-1.33)$ & -0.0001 & $-0.88 \%$ & $(-0.76)$ & -0.0001 & $-3.20 \%$ & $(-0.95)$ \\
\hline & In Stage 1 & CAR & 0.0006 & $8.45 \% * * *$ & (3.29) & 0.0011 & $9.73 \% * * *$ & (3.67) & 0.0001 & $3.23 \%$ & (1.00) \\
\hline & & SUR & 0.0009 & $12.68 \% * * *$ & (3.56) & 0.0014 & $12.39 \% * * *$ & $(3.70)$ & 0.0004 & $12.90 \%$ & (1.20) \\
\hline & & $\mathrm{CGO}$ & 0.0011 & $15.49 \% * * *$ & (3.77) & 0.0019 & $16.81 \% * * *$ & $(3.90)$ & 0.0004 & $12.90 \%$ & (1.32) \\
\hline & & TVOL & -0.0011 & $-15.49 \%$ & $(-1.09)$ & -0.0019 & $-16.81 \%$ & $(-1.39)$ & -0.0003 & $-9.70 \%$ & $(-0.23)$ \\
\hline & & DISP & 0.0004 & $5.63 \% * * *$ & (3.15) & 0.0007 & $6.19 \% * * *$ & (3.33) & 0.0002 & $6.45 \%$ & (1.04) \\
\hline & & TURN & -0.0002 & $-2.82 \%$ & $(-0.39)$ & 0.0002 & $1.77 \%$ & $(0.25)$ & -0.0005 & $-16.10 \%$ & $(-0.65)$ \\
\hline & & $\mathrm{COV}$ & 0.0003 & $4.23 \%$ ** & (2.43) & 0.0005 & $4.42 \% * *$ & (2.15) & 0.0002 & $6.45 \%$ & (1.00) \\
\hline & & RGVOL & -0.0001 & $-1.41 \%$ & $(-1.65)$ & -0.0001 & $-0.88 \%$ & $(-1.24)$ & -0.0001 & $-3.20 \%$ & $(-0.81)$ \\
\hline & & COGS & 0.0000 & $0.00 \%$ & $(0.42)$ & -0.0000 & $-0.00 \%$ & $(-0.05)$ & 0.0001 & $3.23 \%$ & $(0.65)$ \\
\hline & & IVOL & 0.0004 & $5.63 \%$ & $(0.56)$ & 0.0013 & $11.50 \%$ & (1.35) & -0.0005 & $-16.10 \%$ & $(-0.57)$ \\
\hline & & $\mathrm{r} 12,7$ & -0.0007 & $-9.86 \%$ & $(-2.12)$ & -0.0014 & $-12.39 \%$ & $(-2.84)$ & -0.0000 & $-0.00 \%$ & $(-0.08)$ \\
\hline & & Industry r6,1 & 0.0002 & $2.82 \%$ & $(0.65)$ & 0.0003 & $2.65 \%$ & $(0.59)$ & 0.0001 & $3.23 \%$ & $(0.29)$ \\
\hline & & SK & -0.0000 & $-0.00 \%$ & $(-0.35)$ & -0.0001 & $-0.88 \%$ & $(-0.72)$ & 0.0000 & $0.00 \%$ & $(0.29)$ \\
\hline & & Resid & 0.0045 & $63.38 \% * * *$ & $(5.11)$ & 0.0066 & $58.41 \%$ **** & (5.59) & 0.0023 & $74.19 \%$ & (1.55) \\
\hline & Avg stock & & 977 & & & 757 & & & 1188 & & \\
\hline & start date & & 197602 & & & 197602 & & & 199601 & & \\
\hline & end date & & 201612 & & & 199512 & & & 201612 & & \\
\hline
\end{tabular}


Table 9. Alternative formation period $(\mathrm{J})$ and holding period $(\mathrm{H})$

This table reports slopes of decomposed components and fractions of each candidate across different formation $(\mathrm{J})$ and holding periods $(\mathrm{H})$. There are four different combinations of formation and holding periods: $(3,3),(6,6),(12,6)$ and $(12,12)$. In stage 1, the regression model is $r_{\mathrm{H}, \mathrm{it}}=\alpha_{\mathrm{t}}+\beta_{\mathrm{t}} \mathrm{r}, 1_{\mathrm{it}-1}+\varepsilon_{\mathrm{it}}$. In stage 2 , a candidate variable is added to the regression model: $\mathrm{r}_{\mathrm{H}, \mathrm{i}, \mathrm{t}}=$ $\widetilde{\alpha}_{\mathrm{t}}+\widetilde{\beta_{\mathrm{t}}^{\mathrm{R}}} \mathrm{r} \mathrm{J}, 1_{\mathrm{i}, \mathrm{t}-1}+\sum_{\mathrm{k}=1}^{\mathrm{n}} \widetilde{\beta_{\mathrm{kt}}^{\mathrm{C}}}$ candidate ${ }_{\mathrm{kit}, \mathrm{t}-1}+\tilde{\varepsilon}_{\mathrm{i}, \mathrm{t}}$. In stage 3 , we run regression of past 6-month return on candidate variable: $\mathrm{rJ}, 1_{\mathrm{it}-1}=\mu_{\mathrm{t}-1}+\sum_{\mathrm{k}=1}^{\mathrm{n}} \delta_{\mathrm{kt}-1}$ candidate $\mathrm{kit}-1+\varphi_{\mathrm{it}-1}$, then past 6-month return is decomposed into orthogonal components: $\delta_{1 \mathrm{t}-1}$ candidate $_{1 \mathrm{it}-1}, \delta_{2 \mathrm{t}-1}$ candidate $_{2 \mathrm{it}-1}, \ldots, \delta_{\mathrm{nt}-1}$ candidate $_{\text {nit- } 1}$ and $\mu_{\mathrm{t}-1}+\varphi_{\mathrm{it}-1}$. In stage 4 , the coefficient $\beta_{\mathrm{t}}$ is decomposed

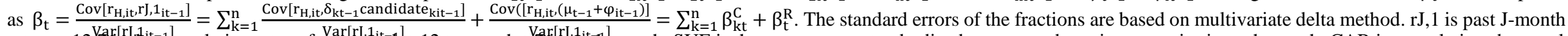

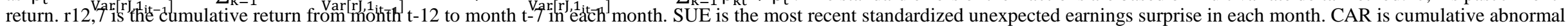
return from one day before and one day after earnings announcement date and abnormal return is stock return minus market return. SUR is the most recent standardized unexpected revenue

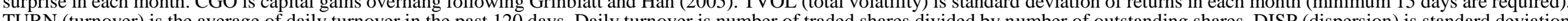
ThN (ust of analyst earnings forecasts scaled by stock price. COV (analyst coverage) is number of analysts. RGVOL (revenue growth volatility) is the volatility of firm revenue growth in the past 10 quarters (mided by qu quarters are required). FL (idiosyncrite volatity) is the goods dived by qu 5 (n) days are required). Industry 16,1 is the past 6 -month significance level at the $10 \%, 5 \%$ and $1 \%$ respectively.

\begin{tabular}{|c|c|c|c|c|c|c|c|c|c|c|c|c|}
\hline & \multicolumn{3}{|c|}{$(3,3)$} & \multicolumn{3}{|c|}{$(6,6)$} & \multicolumn{3}{|c|}{$(12,6)$} & \multicolumn{3}{|c|}{$(12,12)$} \\
\hline & coeff & frac & $\mathrm{t}$ & coeff & frac & $\mathrm{t}$ & coeff & frac & $\mathrm{t}$ & coeff & frac & $\mathrm{t}$ \\
\hline $52 \mathrm{~W}$ & 0.0040 & $27.78 \% * *$ & $(2.13)$ & 0.0062 & $13.51 \%$ ** & $(2.43)$ & 0.0047 & $13.09 \% * * *$ & $(3.17)$ & 0.0053 & $10.93 \%$ *** & $(2.92)$ \\
\hline SUE & -0.002 & $-12.50 \%$ & $(-2.67)$ & -0.0006 & $-1.31 \%$ & $(-2.71)$ & -0.0004 & $-1.11 \%$ & $(-3.64)$ & -0.0003 & $-0.62 \%$ & $(-2.28)$ \\
\hline CAR & 0.0026 & $18.06 \%$ *** & $(2.90)$ & 0.0018 & $3.92 \% * * *$ & (7.06) & 0.0009 & $2.51 \% * * *$ & $(6.88)$ & 0.0013 & $2.68 \% * * *$ & (7.40) \\
\hline SUR & 0.0017 & $11.81 \%$ *** & $(2.67)$ & 0.0029 & $6.32 \% * * *$ & $(7.73)$ & 0.0016 & $4.46 \% * * *$ & $(8.21)$ & 0.002 & $4.12 \% * * *$ & (6.96) \\
\hline CGO & 0.0017 & $11.81 \% * * *$ & $(2.80)$ & 0.0042 & $9.15 \% * * *$ & $(5.83)$ & 0.0024 & $6.69 \% * * *$ & $(6.20)$ & 0.0031 & $6.39 \% * * *$ & (5.74) \\
\hline TVOL & -0.003 & $-18.75 \%$ & $(-0.94)$ & -0.0005 & $-1.09 \%$ & $(-0.24)$ & -0.0005 & $-1.39 \%$ & $(-0.44)$ & 0.0014 & $2.89 \%$ & $(0.85)$ \\
\hline DISP & 0.0006 & $4.17 \% * *$ & $(2.23)$ & 0.0016 & $3.49 \% * * *$ & $(6.75)$ & 0.0013 & $3.62 \% * * *$ & $(7.64)$ & 0.0020 & $4.12 \% * * *$ & (7.49) \\
\hline TURN & -0.001 & $-8.33 \%$ & $(-0.98)$ & 0.0022 & $4.79 \% * *$ & $(2.22)$ & 0.0009 & $2.51 \% * *$ & $(2.07)$ & 0.0007 & $1.44 \%$ & $(1.42)$ \\
\hline $\mathrm{COV}$ & 0.0011 & $7.64 \% * *$ & $(2.50)$ & 0.0016 & $3.49 \% * * *$ & (4.79) & 0.0007 & $1.95 \%$ *** & $(4.47)$ & 0.0011 & $2.27 \% * * *$ & $(4.62)$ \\
\hline RGVOL & $-5 \mathrm{E}-04$ & $-3.47 \%$ & $(-1.63)$ & -0.0004 & $-0.87 \%$ & $(-1.87)$ & -0.0002 & $-0.56 \%$ & $(-1.42)$ & -0.0003 & $-0.62 \%$ & $(-1.95)$ \\
\hline COGS & 0.0002 & $1.39 \%$ & $(0.95)$ & 0.0006 & $1.31 \% * * *$ & $(3.29)$ & 0.0003 & $0.84 \%$ *** & $(3.31)$ & 0.0004 & $0.82 \%$ *** & $(2.79)$ \\
\hline IVOL & 0.0012 & $8.33 \%$ & $(0.60)$ & 0.0003 & $0.65 \%$ & $(0.24)$ & 0.0006 & $1.67 \%$ & $(0.63)$ & -0.0017 & $-3.51 \%$ & $(-1.32)$ \\
\hline $\mathrm{r} 12,7$ & -0.001 & $-7.64 \%$ & $(-1.83)$ & -0.0007 & $-1.53 \%$ & $(-1.05)$ & 0.0088 & $24.51 \% * * *$ & (6.24) & 0.0107 & $22.06 \% * * *$ & (5.33) \\
\hline Industry $\mathrm{r} 6,1$ & 0.0006 & $4.17 \%$ & (1.11) & 0.0023 & $5.01 \% * * *$ & (3.34) & 0.0013 & $3.62 \% * * *$ & (3.01) & 0.0025 & $5.15 \%$ **** & (4.67) \\
\hline SK & -0.0002 & $-1.39 \%$ & $(-0.49)$ & 0.0009 & $1.96 \% * * *$ & (3.10) & 0.0005 & $1.39 \%$ *** & $(3.28)$ & 0.0009 & $1.86 \%$ *** & (3.88) \\
\hline Resid & 0.0082 & $56.94 \% * * *$ & $(4.47)$ & 0.0235 & $51.20 \%$ *** & $(14.39)$ & 0.0130 & $36.21 \%$ **** & $(11.42)$ & 0.0194 & $40.00 \%$ **** & (12.29) \\
\hline
\end{tabular}


Table 10. Portfolio: univariate analysis

This table reports slopes of decomposed components and fractions of each candidate at portfolio-level. Stocks are ranked into 200 portfolios based on past 6-month returns in each month and the portfolio-level returns, r6,1 and candidates are constructed by calculating value-weighted average of the firm-level data. In stage 1 , the regression model is $r_{i t}=\alpha_{t}+\beta_{t} r 6,1_{i t-1}+\varepsilon_{i t}$. In stage 2 , a candidate variable is added to the regression model: $r_{i, t}=\widetilde{\alpha}_{t}+\widetilde{\beta_{t}^{R}} r 6,1_{i, t-1}+\widetilde{\beta_{t}^{C}}$ candidate ${ }_{i, t-1}+\widetilde{\varepsilon}_{i, t}$. In stage 3 , we run regression of past 6-month return on candidate variable: $\mathrm{r} 6,1_{\mathrm{i}, \mathrm{t}-1}=\mu_{\mathrm{t}-1}+\delta_{\mathrm{t}-1}$ Candidate $_{\mathrm{i}, \mathrm{t}-1}+\varphi_{\mathrm{i}, \mathrm{t}-1}$, then past 6-month return is decomposed to two orthogonal components:

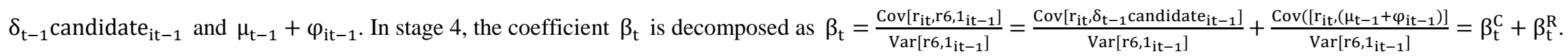

The time-series average of $\beta_{t}^{C}$ divided by the time-series average of $\beta_{t}$ then measures the fraction of candidate contribution and the time-series average of $\beta_{t}^{R}$ divided by the time-series average of $\beta_{\mathrm{t}}$ measures the fraction of residual contribution. The standard errors of the fractions are based on multivariate delta method. r6,1 is past 6-month return skipping the most recent one month. 52W (52-week-high) is the stock price divided by the highest price in the past 52 weeks in each month. r12,7 is the cumulative return from month t-12 to month t-7 in each month. SUE is the most recent standardized unexpected earnings surprise in each month. CAR is cumulative abnormal return from one day before and one day after earnings announcement date and abnormal return is stock return minus market return. SUR is the most recent standardized unexpected revenue surprise in each month. CGO is capital gains overhang following Grinblatt and Han (2005). TVOL (total volatility) is standard deviation of returns in each month (minimum 15 days are required). TURN (turnover) is the average of daily turnover in the past 120 days. Daily turnover is number of traded shares divided by number of outstanding shares. DISP (dispersion) is standard deviation of analyst earnings forecasts scaled by stock price. COV (analyst coverage) is number of analysts. RGVOL (revenue growth volatility) is the volatility of firm revenue growth in the past 10 quarters (minimum 5 quarters are required). Firm revenue growth is revenue in current quarter divided by revenue in lagged 4 quarter and minus 1. COGS (cost of goods sold) is quarterly cost of goods divided by quarterly total assets. IVOL (idiosyncratic volatility) is the standard deviation of residuals from regression on daily return on daily market return in each month (minimum 15 days are required). Industry r6,1 is the past 6-month return in an industry (based on 2-digit SIC code) in each month. Skew is the skewness of raw daily returns in a month. $*, * *$, and $* * *$ indicate significance level at the $10 \%, 5 \%$ and $1 \%$ respectively.

\begin{tabular}{|c|c|c|c|c|c|c|c|c|c|c|c|c|}
\hline \multirow[t]{2}{*}{ Stage } & \multirow[t]{2}{*}{ Description } & \multirow[t]{2}{*}{ Variable } & \multirow{2}{*}{\multicolumn{2}{|c|}{$\begin{array}{c}\text { Panel A: Anchoring } \\
52 \mathrm{~W}\end{array}$}} & \multicolumn{6}{|c|}{ Panel B: Fundamental } & \multirow{2}{*}{\multicolumn{2}{|c|}{$\begin{array}{c}\text { Panel C: PT/MA } \\
\text { CGO }\end{array}$}} \\
\hline & & & & & $\mathrm{SL}$ & & $\overline{\mathrm{C} A}$ & & $\mathrm{St}$ & & & \\
\hline \multirow[t]{2}{*}{1} & Return on $\mathrm{r} 6,1$ & Intercept & $-0.0019 * * *$ & $(-3.32)$ & $-0.0016^{* *}$ & $(-2.23)$ & $-0.0016 * *$ & $(-2.13)$ & $-0.0017 * *$ & $(-2.28)$ & -0.0018 *** & $(-2.79)$ \\
\hline & & $\mathrm{r} 6,1$ & $0.0075 * * *$ & (3.64) & 0.0031 & $(1.30)$ & 0.0037 & $(1.51)$ & 0.0032 & $(1.31)$ & $0.0049 * *$ & $(2.16)$ \\
\hline \multirow[t]{3}{*}{2} & Add candidate & Intercept & $-0.0048 *$ & $(-1.85)$ & $-0.0019^{* *}$ & $(-2.56)$ & $-0.0016^{* *}$ & $(-2.15)$ & $-0.0022^{* * * *}$ & $(-2.78)$ & $-0.0019^{* * * *}$ & $(-2.71)$ \\
\hline & & $\mathrm{r} 6,1$ & $0.0076^{* * *}$ & $(4.00)$ & 0.0018 & $(0.76)$ & 0.0027 & (1.11) & 0.0029 & $(1.25)$ & $0.0043^{* *}$ & $(2.12)$ \\
\hline & & Candidate & 0.0032 & $(0.90)$ & $0.0013^{* * *}$ & (4.17) & $0.0332 * * *$ & $(4.40)$ & 0.0003 & $(1.20)$ & 0.0008 & $(0.80)$ \\
\hline \multirow[t]{3}{*}{3} & r6,1 on & Intercept & $-0.8097 * * *$ & $(-51.42)$ & $0.0996^{* * *}$ & $(10.78)$ & $0.0993^{* * *}$ & $(11.63)$ & $0.0563 * * *$ & $(5.76)$ & $0.1201 * * *$ & $(18.23$ \\
\hline & candidate & Candidate & $1.1506^{* * *}$ & $(59.90)$ & $0.1018^{* * *}$ & (37.15) & $2.1554 * * *$ & $(31.63)$ & $0.0392 * * *$ & $(14.99)$ & $0.3605 * * *$ & $(35.04$ \\
\hline & & Avg adj. $R^{2}$ & 0.302 & & 0.079 & & 0.081 & & 0.042 & & 0.236 & \\
\hline \multirow[t]{6}{*}{4} & Decompose & Candidate compo. & 0.0021 & & 0.0014 & & 0.0010 & & 0.0005 & & 0.0013 & \\
\hline & r6,1 coeff. & Candidate frac. & $28.00 \%$ ** & $(2.21)$ & $45.16 \% *$ & $(1.80)$ & $27.03 \% * *$ & $(2.00)$ & $15.62 \%$ & $(1.60)$ & $26.53 \% *$ & $(1.89)$ \\
\hline & In Stage 1 & Residual compo. & 0.0054 & & 0.0017 & & 0.0027 & & 0.0027 & & 0.0036 & \\
\hline & & Residual frac. & $72.00 \%$ *** & (5.57) & $54.84 \% * *$ & $(2.19)$ & $72.97 \% * * *$ & (5.14) & $84.38 \%$ *** & $(9.25)$ & $73.47 \%$ *** & $(5.21)$ \\
\hline & Start date & & 196308 & & 197402 & & 197402 & & 197402 & & 196308 & \\
\hline & End date & & 201612 & & 201612 & & 201612 & & 201612 & & 201612 & \\
\hline
\end{tabular}


Continued

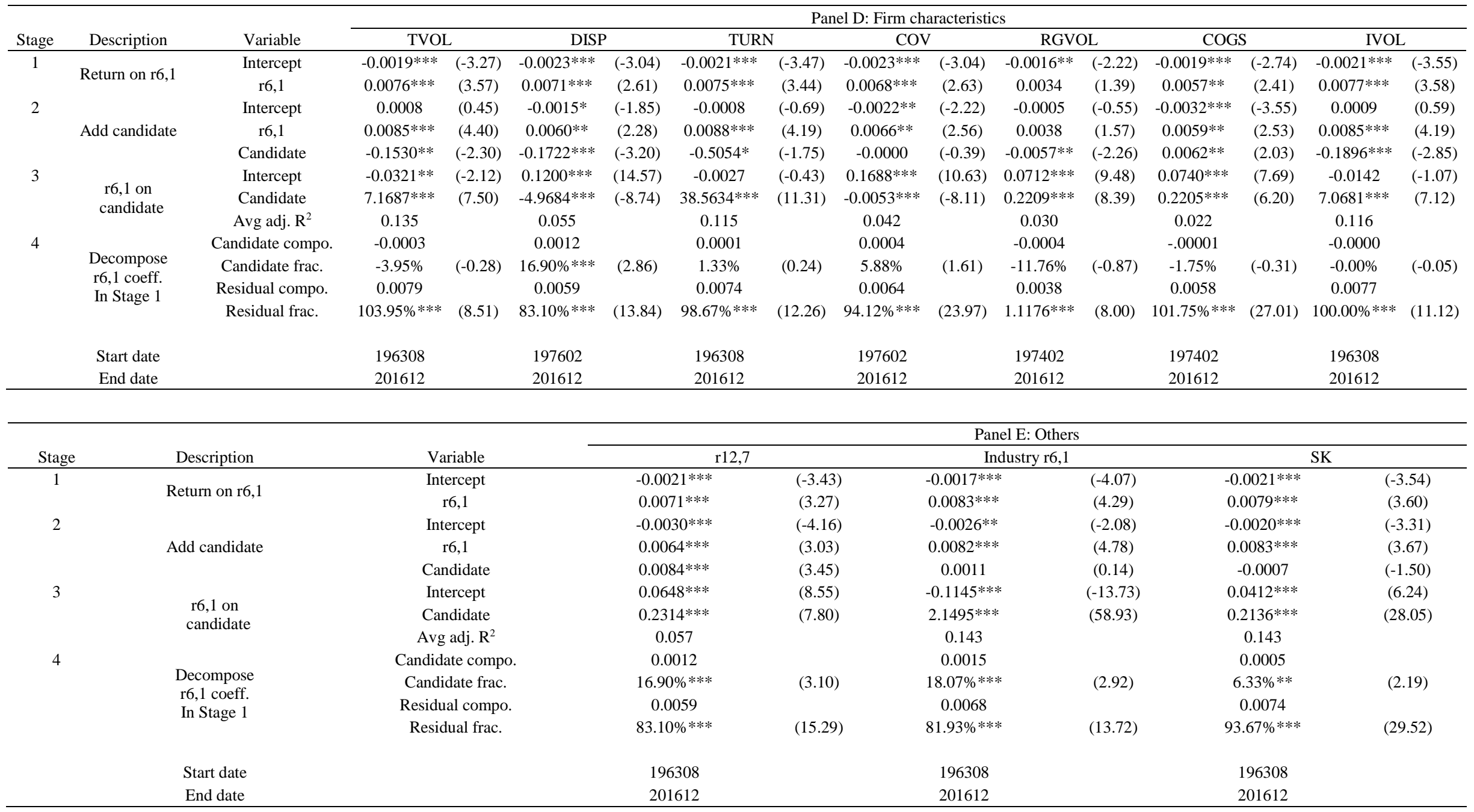


Table 11. Portfolio: multivariate analysis

This table reports slopes of decomposed components and fractions of each candidate at portfolio-level. Stock are ranked into 200 portfolios based on past 6 -month returns in each month and the portfolio-level returns, $\mathrm{r} 6,1$ and candidates are constructed by calculating value-weighted ayerage of the firm-level data. In stage 1 , the regression model is $r_{i t}=\alpha_{t}+\beta_{t} r 6,1_{i t-1}+\varepsilon_{i t .}$. In stage 2 , a candidate variable is added to the regression model: $r_{i, t}=\widetilde{\alpha}_{t}+\beta_{t}^{R} r 6,1_{i, t-1}+\sum_{k=1}^{n} \beta_{k t}^{C}$ candidate $k_{k i, t-1}+\tilde{\varepsilon}_{i, t}$. In stage 3 , we run regression of past 6-month return on candidate variable: $\mathrm{r} 6,1_{\mathrm{it}-1}=\mu_{\mathrm{t}-1}+\sum_{\mathrm{k}=1}^{\mathrm{n}} \delta_{\mathrm{kt}-1}$ candidate $_{\mathrm{kit}-1}+\varphi_{\mathrm{it}-1}$, then past 6-month return is decomposed into orthogonal

components: $\delta_{1 \mathrm{t}-1}$ candidate $_{1 \mathrm{it}-1}, \delta_{2 \mathrm{t}-1}$ candidate $_{2 \mathrm{it}-1}, \ldots, \delta_{\mathrm{nt}-1}$ candidate $_{\mathrm{nit}-1}$ and $\mu_{\mathrm{t}-1}+\varphi_{\mathrm{it}-1}$. In stage 4 , the coefficient $\beta_{\mathrm{t}}$ is decomposed as $\beta_{\mathrm{t}}=\frac{\left.\text { Cov[r } \mathrm{r}_{\mathrm{t} t} \mathrm{r} 6,1_{\mathrm{it}-1}\right]}{\operatorname{Var}\left[\mathrm{r} 6,1_{\mathrm{it}-1}\right]}=$

$\sum_{\mathrm{k}=1}^{\mathrm{n}} \frac{\operatorname{Cov}\left[\mathrm{r}_{\mathrm{it}}, \delta_{\mathrm{kt}-1} \mathrm{candidate}_{\mathrm{kit}-1}\right]}{\operatorname{Var}\left[\mathrm{r} 6,1_{\mathrm{it}-1}\right]}+\frac{\operatorname{Cov}\left(\left[\mathrm{r}_{\mathrm{it}},\left(\mu_{\mathrm{t}-1}+\varphi_{\mathrm{it}-1}\right)\right]\right.}{\operatorname{Var}\left[\mathrm{r} 6,1_{\mathrm{it}-1}\right]}=\sum_{\mathrm{k}=1}^{\mathrm{n}} \beta_{\mathrm{kt}}^{\mathrm{C}}+\beta_{\mathrm{t}}^{\mathrm{R}}$. The standard errors of the fractions are based on multivariate delta method. r6,1 is past 6-month return

skipping the most recent one month. 52W (52-week-high) is the stock price divided by the highest price in the past 52 weeks in each month. $\mathrm{r} 12,7$ is the cumulative return from month t-12 to month t-7 in each month. SUE is the most recent standardized unexpected earnings surprise in each month. CAR is cumulative abnormal return from one day before and one day after earnings announcement date and abnormal return is stock return minus market return. SUR is the most recent standardized unexpected revenue surprise in each month. CGO is capital gains overhang following Grinblatt and Han (2005). TVOL (total volatility) is standard deviation of returns in each month (minimum 15 days are required). TURN (turnover) is the average of daily turnover in the past 120 days. Daily turnover is number of traded shares divided by number of outstanding shares. DISP (dispersion) is standard deviation of analyst earnings forecasts scaled by stock price. COV (analyst coverage) is number of analysts. RGVOL (revenue growth volatility) is the volatility of firm revenue growth in the past 10 quarters (minimum 5 quarters are required). Firm revenue growth is revenue in current quarter divided by revenue in lagged 4 quarter and minus 1. COGS (cost of goods sold) is quarterly cost of goods divided by quarterly total assets. IVOL (idiosyncratic volatility) is the standard deviation of residuals from regression on daily return on daily market return in each month (minimum 15 days are required). Industry r6,1 is the past 6-month return in an industry (based on 2-digit SIC code) in each month. Skew is the skewness of raw daily returns in a month. $*, * *$, and $* * *$ indicate significance level at the $10 \%, 5 \%$ and $1 \%$ respectively.

\begin{tabular}{|c|c|c|c|c|c|c|c|c|c|c|c|c|}
\hline \multicolumn{4}{|c|}{ Stages 1 and 2} & \multicolumn{4}{|c|}{ Stage 3} & \multicolumn{5}{|c|}{ Stage 4} \\
\hline & & coeff & $\mathrm{t}$ & & & coeff & $\mathrm{t}$ & & & coeff & frac & $\mathrm{t}$ \\
\hline \multirow{10}{*}{$\begin{array}{c}\text { Return on } \\
\text { r6,1 }\end{array}$} & Intercept & $-0.0014 * *$ & $(-2.14)$ & & Intercept & $-0.7524 * * *$ & $(-28.60)$ & & $52 \mathrm{~W}$ & -0.0002 & $-6.06 \%$ & $(-0.15)$ \\
\hline & $\mathrm{r} 6,1$ & 0.0033 & (1.23) & & $52 \mathrm{~W}$ & $0.7651^{* * * *}$ & $(29.01)$ & & SUE & -0.0001 & $-3.03 \%$ & $(-0.54)$ \\
\hline & Intercept & $0.0088^{* *}$ & $(2.52)$ & & SUE & $-0.0045 * * *$ & $(-4.40)$ & & CAR & 0.0003 & $9.09 \%$ & $(1.30)$ \\
\hline & r6,1 & 0.0039 & $(1.57)$ & & CAR & $0.3821 * * *$ & (15.58) & & SUR & 0.0003 & $9.09 \%$ & (1.33) \\
\hline & $52 \mathrm{~W}$ & $-0.0078 * *$ & $(-2.29)$ & & SUR & $0.0128^{* * * *}$ & (19.46) & & CGO & 0.0009 & $27.27 \%$ & (1.57) \\
\hline & SUE & $0.0012 * * *$ & (4.30) & & CGO & $0.1028 * * *$ & (19.77) & & TVOL & -0.0017 & $-51.52 \%$ & $(-0.90)$ \\
\hline & CAR & $0.0187 * * *$ & (2.67) & & TVOL & $9.8418^{* * * *}$ & (11.41) & & DISP & 0.0006 & $18.18 \%$ & $(1.32)$ \\
\hline & SUR & -0.0002 & $(-0.85)$ & & DISP & -0.6531 **** & $(-4.27)$ & & TURN & -0.0001 & $-3.03 \%$ & $(-0.14)$ \\
\hline & CGO & -0.0012 & $(-1.13)$ & $\mathrm{r} 6,1$ on & TURN & $14.4514^{* * * *}$ & (12.60) & Decompose & $\mathrm{COV}$ & 0.0004 & $12.12 \%$ & (1.17) \\
\hline & TVOL & -0.1735 & $(-0.94)$ & candidates & $\mathrm{COV}$ & $-0.0016^{* * * *}$ & $(-8.88)$ & r6,1 coeff. & RGVOL & -0.0002 & $-6.06 \%$ & $(-0.87)$ \\
\hline \multirow{9}{*}{$\begin{array}{c}\text { Add } \\
\text { candidates }\end{array}$} & DISP & $-0.1127 * * *$ & $(-2.74)$ & & RGVOL & $0.0451 * * *$ & $(6.77)$ & & COGS & 0.0000 & $0.00 \%$ & $(0.06)$ \\
\hline & TURN & 0.0327 & $(0.15)$ & & COGS & $0.0364 * * *$ & (4.48) & & IVOL & 0.0007 & $21.21 \%$ & $(0.71)$ \\
\hline & $\mathrm{COV}$ & $-0.0001 *$ & $(-1.73)$ & & IVOL & $-5.4504 * * *$ & $(-7.20)$ & & $\mathrm{r} 12,7$ & -0.0003 & $-9.09 \%$ & $(-0.79)$ \\
\hline & RGVOL & 0.0012 & $(0.59)$ & & $\mathrm{r} 12,7$ & $-0.1481 * * *$ & $(-13.07)$ & & Industry r6,1 & 0.0005 & $15.15 \%$ & (1.11) \\
\hline & COGS & -0.0009 & $(-0.35)$ & & Industry r6,1 & $0.5344 * * *$ & (28.63) & & SK & 0.0001 & $3.03 \%$ & $(0.49)$ \\
\hline & IVOL & -0.0259 & $(-0.14)$ & & SK & $0.0537 * * *$ & (26.13) & & Resid & 0.0021 & $63.64 \% *$ & (1.70) \\
\hline & $\mathrm{r} 12,7$ & $0.0059 * * *$ & $(2.59)$ & & & & & & & & & \\
\hline & Industry r6,1 & 0.0003 & $(0.05)$ & & Avg. adj. $\mathrm{R}^{2}$ & 0.576 & & & & & & \\
\hline & SK & -0.0007 & $(-1.55)$ & & & & & & & & & \\
\hline
\end{tabular}

